$\frac{12 / 9-918501}{10^{-9}}$

OAK RIDGE

NATIONAL

LABORATORY

MARTIN MARUETRA

\author{
ASSESSMENT OF THE \\ 1988 SAGUENAY EARTHQUAKE - \\ IMPLCATIONS ON ATTENUATION FUNCTIONS \\ FOR SEISMIC HAZARD ANALYSIS \\ REVISED DRAFT REPORT
}

Gabriel R. Toro

Robin K. McGuire 
This report has been reproduced directly from the best available copy.

Available to DOE and DOE contractors from the Office of Scientific and Technical Information, P.O. Box 62, Oak Ridge, TN 37831; prices available from (615) 576-8401, FTS 626-8401.

Available to the public from the National Technical Information Service, U.S. Department of Commerce, 5285 Port Royal Rd., Springfield, VA 22161.

This report was prepared as an account of work sponsored by an agency of the United States Government. Neither the United States Government nor any agency thereof, nor any of their employees, makes any warranty, express or implied, or assumes any legal liability or responsibility for the accuracy, completeness, or usefulness of any information, apparatus, product, or process disclosed, or represents that its use would not infringe privately owned rights. Reference herein to any specific commercial product, process, or service by trade name, trademark, manufaciurer, or otherwise, does not necessarily constifute or imply its endorsement, recommendation, or favoring by the United States Government or any agency thereof. The views and opinions of authors expressed herein do not necessarily state or reflect those of the United States Government or any agency thereof. 


\section{ASSESSMENT OF THE \\ 1988 SAGUENAY EARTHQUAKE - \\ IMPLICATIONS ON ATTENUATION FUNCTIONS FOR SEISMIC HAZARD ANALYSIS}

\section{REVISED DRAFT REPORT}

Gabriel R. Toro

Robin K. McGuire

Risk Engineering, Inc.

Golden, Colorado

Date Published: September 1991

\section{Prepared by}

PICKARD, LOWE AND GARRICK, INC.

4590 MacArthur Boulevard, Suite 400

Newport Beach, California 92660-2027

Subcontract 96X-SA443V

Funded by

Office of Energy Research

ERKCR01

Prepared for

Rescarch Reactors Division

OAK RIDGE NATIONAL LABORATORY

Oak Ridge, Tennessce 37831

managed by

MARTIN MARIETTA ENERGY SYSTEMS, INC.

for the

U.S. DEPARTMENT OF ENERGY

under contract DE-AC05-84OR21400 
CONTENTS

$\underline{\text { Section }} \quad \underline{\text { Page }}$

1 INTRODUCTION 1-1

1.1 REFERENCES 1-1

2 EPRI AND LLNL ATTENUATION FUNCTIONS 2-1

2.1 REFERENCES 2-3

3 EMPIRICAL COMPARISON OF RESPONSE-SPECTRUM AMPLITUDES AND PREDICTIVE EQUATIONS

3.1 Processing of the Data 3-1

3.2 Comparisons to the EPRI and LLNL Attenuation Functions 3-1

3.3 Comparison to Other Ground Motion Data 3-4

3.4 SUMMARY AND CONCLUSIONS 3-5

3.5 REFERENCES 3-6

4 SURVEY AND EVALUATION OF SEISMOLOGICAL STUDIES OF THE SAGUENAY EARTHQUAKE 4-1

4.1 Source Characteristics $4-1$

4.2 Wave-Propagation Effects $4-2$

4.3 Summary 4-3

4.4 REFERENCES 4-4 
5 EXAMINATION OF THE METHODOLOGY USED BY LLNL GROUND MOTION EXPERT 5

5.1 Validity of the Basic Equations to Conditions in ENA $5-1$

5.2 Validity of Substitution Procedures 5-3

5.2.1 Numerical Example $5-5$

5.3 Summary $5-8$

5.4 REFERENCES $5-9$

6 SUMMARY AND CONCLUSIONS $6-1$ 


\section{LIST OF FIGURES}

Figure

$\underline{\text { Page }}$

2-1 Comparison of predicted peak acceleration by the EPRI and LLNL attenuation equations. Predictions are shown for $m_{b} 5$ and 7 .

2-2 Comparison of response spectra predicted by the EPRI and LLNL attenuation equations. Predictions are shown for an epicentral distance of $25 \mathrm{~km}$ and for $m_{b} 5$ and 7 .

3-1 Locations of strong motion stations that recorded the Saguenay earthquake

3-2 1-Hz spectral velocities from the Saguenay earthquake are compared to predictions by the EPRI attenuation functions.

3-3 1-Hz spectral velocities from the Saguenay earthquake are compared to predictions by the LLNL attenuation functions.

$3-4 \quad 2.5-\mathrm{Hz}$ spectral velocities from the Saguenay earthquake are compared to predictions by the EPRI attenuation functions.

3.5 2.5- $\mathrm{Hz}$ spectral velocities from the Saguenay earthquake are compared to predictions by the LLNL attenuation functions.

3-6 5- $\mathrm{Hz}$ spectral velocities from the Saguenay earthquake are compared to predictions by the EPRI attenuation functions.

3-i $\quad 5-\mathrm{Hz}$ spectral velocities from the Saguenay earthquake are compared to predictions by the LLNL attenuation functions.

3-8 $10-\mathrm{Hz}$ spectral velocities from the Saguenay earthquake are compared to predictions by the EPRI attenuation functions.

3.9 $\quad 10 \cdot \mathrm{Hz}$ spectral velocities from the Saguenay earthquake are compared to predictions by the LLNL attenuation functions.

3-10 25-Hz spectral velocities from the Saguenay earthquake are compared to predictions by the EPRI attenuation functions.

3-11 25- $\mathrm{Hz}$ spectral velocities from the Saguenay earthquate are compared to predictions by the LLNL attenuation functions. 
3-12 Peak ground accelerations from the Saguenay earthquatie are compared to predictions by the EPRI attenuation functions.

3-13 Peak ground accelerations from the Saguenay earthquake are compared to predictions by the LLNL attenuation functions.

3-14 1-Hz spectral velocities from other intraplate earthquakes with magnitudes 5.5 to 6.5 are compared to predictions by the EPRI attenuation functions.

3-15 1-Hz spectral velocities from other intraplate earthquakes with magnitudes 5.5 to 6.5 are compared to predictions by the LLNL attenuation functions.

3-16 2.5- $\mathrm{Hz}$ spectral velocities from other intraplate earthquakes with magnitudes 5.5 to 6.5 are compared to predictions by the EPRI attenuation functions.

3-17 2.5- $\mathrm{Hz}$ spectral velocities from other intraplate earthquakes with magnitudes 5.5 to 6.5 are compared to predictions by the LLNL attenuation functions.

3-18 5- $\mathrm{Hz}$ spectral velocities from other intraplate earthquakes with magnitudes 5.5 to 6.5 are compared to predictions by the EPRI attenuation functions.

3-19 5-Hz spectral velocities from other intraplate earthquakes with magnitudes 5.5 to 6.5 are compared to predictions by the LLNL attenuation functions.

3-20 10- $\mathrm{Hz}$ spectral velocities from other intraplate earthquakes with magnitudes 5.5 to 6.5 are compared to predictions by the EPRI attenuation functions.

3-21 10- $\mathrm{Hz}$ spectral velocities from other intraplate earthquakes with magnitudes 5.5 to 6.5 are compared to predictions by the LLNL attenuation functions.

3-22 $25-\mathrm{Hz}$ spectral velocities from other intraplate earthquakes with magnitudes 5.5 to 6.5 are compared to predictions by the EPRI attenuation functions.

3-23 $25-\mathrm{Hz}$ spectral velocities from other intraplate earthquakes with magnitudes 5.5 to 6.5 are compared to predictions by the LLNL attenuation functions.

3-2.t Peak ground accelerations from other intraplate earthquakes with magnitudes 5.5 to 6.5 are compared to predictions by the EPRI attenuation functions. 
3-25 Peak ground accelerations from other intraplate earthquakes with magnitudes 5.5 to 6.5 are compared to predictions by the LLNL attenuation functions.

4-1 Comparison of source parameters of the Saguenay earthquake with those from other North American earthquakes

4-2 Observed Fourier spectra of horizontal components at station S16 compared to theoretical Brune spectra for stress drops of 50, 100, 200,400 , and 800 bars

4-3 Observed response spectra of horizontal components at station S16 compared to predictions for $m_{b L_{g}} 6.5$

4-4 Schematic representation of the various waves that contribute to ground motions at short and intermediate distances from the Saguenay earthquake

4-5 Recorded and synthetic peak velocity and peak acceleration from the Saguenay earthquake as a function of epicentral distance

4-6 Predicted and observed attenuation of the mean peak horizontal ground acceleration as a function of epicentral distance for the Saguenay earthquake.

4-7 Synthetic peak acceleration as a function of distance from the Saguenay earthquake for three values of focal depth.

4-8 Average peak tangential velocity as a function of hypocentral distance for the central U.S. crustal model of Herrmann

4-9 Average geometric spreading obtained from the results of Barker et al. for horizontal spectral velocity at $5 \mathrm{~Hz}$.

5-1 Schematic representation of the data and methods used by LLNL expert 5 to develop attenuation functions for ENA.

5-2 Comparison of attenuation functions obtained using direct regression and using a two-step substitution procedure, from a single data set from California 


\section{LIST OF TABLES}

Table

$\underline{\text { Page }}$

2-1 ATTENUATION EQUATIONS USED IN EPRI CALCULATIONS

2-2 LLNL PEAK ACCELERATION MODELS

2-3 LLNL SPECTRAL VELOCITY MODELS 2-6

3-1 STRONG GROUND MOTION STATIONS 3-2

3-2 EARTHQUAKES USED IN FIGURES 3-14 THROUGH 3-25 3-5

5-1 RELATIONSHIPS BETWEEN INSTRUMENTAL AMPLITUDES AND SITE INTENSITY (DERIVED FROM CALIFORNIA DATA) 5-2

5-2 ATTENUATION EQUATIONS OBTAINED BY LLNL GROUND MOTION EXPERT 5 
Section 1

\section{INTRODUCTION}

This study investigates the earthquake records from the 1988 Saguenay earthquake and examines the implications of these records with respect to ground-motion models used in seismic-hazard studies in eastern North America (ENA). The Saguenay earthquake was the largest in ENA since the 1963 Baffin Bay, Canada, earthquake, and it generated more strongmotion records than any other earthquake in ENA.

A specific purpose of this work is to establish to what extent the ground motions from this earthquake support or reject the various attenuation functions used in the EPRI and LLNL seismic-hazard calculations.

Section 2 provides a brief description of the EPRI and LLNL attenuation functions for peak acceleration and for spectral velocities. Section 3 compares these attenuation functions to the ground motions from the Saguenay earthquake and from other relevant earthquakes. Section 4 review's available seismological studies about the Saguenay earthquake, in order to understand its seismological characteristics and why some observations may differ from predictions. Section 5 examines the assumptions and methodology used in the development of the attenuation functions selected by LLNL ground-motion expert 5. We pay particular attention to the atten.uation functions selected by LLNL ground-motion expert 5 because their predictions are significantly different from those of other attenuation functions, because they are based on questionable assumptions about the equivalence of MMI intensity in California and in ENA, and because some steps in their derivation are perceived to produce biased results $(\underline{1,2})$. Finally, Section 6 draws conclusions about the validity of the various sets of attenuation functions, in light of the Saguenay data and of other evidence presented here.

\subsection{REFERENCES}

1. C. A. Cornell, H. Banon, and A. F. Shatal. "Seismic Motion and Response Prediction Alternatives". Earthquake Engineering and Structural Dymamics. 7:295-315, 1979.

2. D. Veneziano. "The l'se of Intensity Data in Ground Motion Estimation". In Proceedings: Horkshop on Estimation of Ground Motion in the Eastern linited States. 1957. Rept. NP.5ET5. EPRI. 


\section{Section 2}

\section{EPRI AND LLNL ATTENUATION FUNCTIONS}

This section summarizes the attenuation functions used in the EPRI and LLNL seismic hazard calculations for the central and Eastern United states (CEUS), and provides a brief background on the development of these attenuation functions.

Tables 2-1, 2-2 and 2-3 list the attenuation functions used in the EPRI and LLNL seismic hazard calculations. The EPRI attenuation functions were selected by Risk Engineering, Inc., after extensive discussions with other experts and with advisors to EPRI (1,2); they are intended to represent a broad range of opinions about ground motions in the central and eastern United States. The LLNL attenuation functions were selected by a panel of 5 experts.

Two of the EPRI models ( $75 \%$ weight) and 3 of the LLNL models (the models labeled RV; $44 \%$ weight) use methods based on the stochastic $\omega$-square model originally developed by (3). These models use simple seismological representations of the seismic source and wave propagation to derive estimates of the ground-motion parameters of engineering interest. This class of models has received considerable attention in recent years.

Both EPRI and LLNL use the models developed by Nuttli (25\% and $28 \%$ weight, respectively). These models are similar in essence to the stochastic $\omega$-square model, but are more crude in their derivations and result in higher predictions (especially at low frequencies).

LLNL expert 5 selected attenuation functions (G16-A3 and TL) obtained by combining three relationships, as follows:

$$
\begin{aligned}
A & =f_{1}\left(I_{S}\right) & & \text { (from California) } \\
I_{S} & =f_{2}\left(I_{0}, R\right) & & \text { (from ENA) } \\
m_{b L g} & =f_{3}\left(I_{0}\right) & & \text { (from ENA) }
\end{aligned}
$$

where $A$ is instrumental ground-motion amplitude (e.g. peat acceleration or spectral velocit $y) . I_{S}$ is Modified Mercalli Intensity (MMI) at the site. and $I_{0}$ is MMI intensity near the epicenter. 
This procedure was used extensively in the past for the prediction of ground motions in CEUS, but it is currently perceived to have serious mathematical and physical flaws. The physical and statistical problems associated with this procedure will be discussed in Section 5 . It is worth noting that the other four LLNL experts gave zero weight to this method, even though they were well aware of its existence.

LLNL experts 2 and 4 assigned weight to a regression method that combines intensityattenuation data from CEUS with instrumental data from CEUS and California (4,5). This method is mathematically unbiased but, like the method of expert 5 , it requires the assumption that intensities in CEUS and California correspond to similar ground motions.

Figures 2.1 and 2.2 show the predictions by all EPRI and LLNL models for magnitudes 5 and i. These figures show that, with the exception of the models selected by LLNL expert 5 , there is general agreement between the EPRI and LLNL sets of attenuation functions. Seismichazard calculations performed in (2, Appendix A) for several test sites using the EPRI and LLNL (without expert 5) sets of attenuation functions indicate that the two sets yield similar results, when the same seismic sources and seismicity parameters are used. 


\subsection{REFERENCES}

1. R. K. McGuire, G. R. Toro, and W. J. Silva. Engineering Model of Earthquake Ground Motion for Eastern North America. Technical Report NP-6074, Electric Power Research Institute, 1988.

2. R. K. McGuire, G. R. Toro, J. P. Jacobson, T. F. O'Hara, and W. J. Silva. Probabilistic Seismic Hazard Evaluations in the Central and Eastern United States: Resolution of the Charleston Earthquake Issue. Special Report NP-6395-D, Electric Power Research Institute, April 1989.

3. T. C. Hanks and R. K. McGuire. "The Character of High-Frequency Strong Ground Motion". Bulletin of the Seismological Society of America, 71-6:2071-2095, December 1981 .

4. D. Veneziano and M. Heidari. "Statistical Analysis of Attenuation in the Eastern United States". In iviethods for Earthquake Ground-Motion Prediction for the Eastern L'nited States, 1986. Project RP2556-16.

5. D. Veneziano. Letter dated December 24, 1986 to D. L. Bernreuter. Reproduced in: D. Bernreuter, J. Savy, R. Mensing, J. Chen, and B. Davis. Seismic Hazard Characterization of 69 Nuclear Plant Sites East of the Rocky Muntains: Questionnaires. U. S. Nuclear Regulatory Commission, Technical Report NUREG/CR-5250, UCID21517, Volume 7, 1989. Prepared by the Lawrence Livermore National Laboratory.

6. D. M. Boore and G. M. Atkinson. "Stochastic Prediction of Ground Motion and Spectral Response Parameters at Hard-Rock Sites in Fastern North America". Bulletin of the Seismological Society of America, 77(2):440-467, 1987.

7. O. W. Nuttli. Letter dated September 19, 1986 to J. B. Savy. Reproduced in: D. Bernreuter, J. Savy, R. Mensing, J. Chen, and B. Davis. Seismic Hazard Characterization of 69 Nuclear Plant Sites East of the Rocky Muntains: Questionnaires. U. S. Nuclear Regulatory Commission, Technical Report NUREG/CR-5250, UCID-21517, Volume $T$, 1989. Prepared by the Lawrence Livermore National Laboratory.

8. D. L. Bernreuter, J. B. Savy, R. W. Mensing, and J. C. Chen. Seismic Hazard Characterization of 69 Plant Sites East of the Rocky Mountains: Methodology, Input Data and Comparisons to Previous Results for Ten Test Sites. Technical Report NUREG/CR5250, UCID-21517, U. S. Nuclear Regulatory Commission, 1989. Volume 1, Prepared by Lawrence Livermore National Laboratory.

9. G. R. Toro and R. K. McGuire. "An Investigation into Earthquake Ground Motion Characteristics in Eastern North America". Bulletin of the Seismological Society of America, $77(2): 468-489$, April 1987.

10. M. D. Trifunac. "A Note on the Range of Peak Amplitudes of Recorded Accelerations. Velocities, and Displacements With Respect to the Modified Mercalli Intensity Scale". Earthquake Notes, 47:9-24, 1976.

11. I. N. Gupta and O. W. Nuttli. "Spatial Attenuation of Intensities for Central U.S. Earthquakes". Bulletin of the Seismological Society of America, 743-751, June 1976. Number 66-3.

12. M. Trifunac and V. W. Lee. Frequency-Dependent Attcnuation of Strong Earthquate Ground Motion. Technical Report 86-02, Lniversity of Southern California, Department of Civil Engineering. 1986.

13. N. M. Newmark and 11. J. Hall. Earthquate Spectra and Design. Earthquake Engineering Rescarch Institute, Berkeley. CA. 1952. 
Table 2-1

ATTENUATION EQUATIONS USED IN EPRI CALCULATIONS

(After (2))

$$
\left(\ln [Y]=a+b m_{b}+c \ln [R]+d R\right)
$$

\begin{tabular}{lrrrrrrr} 
MODEL & WEIGHT & & $Y \dagger$ & $a$ & $b$ & $c$ & $d$ \\
\hline $\begin{array}{l}\text { McGuire } \\
\text { et al. (1) }\end{array}$ & 0.5 & $\operatorname{PSV}(1 \mathrm{~Hz})$ & -7.95 & 2.14 & -1.00 & -0.0018 \\
& & $\operatorname{PSV}(2.5 \mathrm{~Hz})$ & -3.82 & 1.49 & -1.00 & -0.0024 \\
& & $\operatorname{PSV}(5 \mathrm{~Hz})$ & -2.11 & 1.20 & -1.00 & -0.0031 \\
& & $\operatorname{PSV}(10 \mathrm{~Hz})$ & -1.55 & 1.05 & -1.00 & -0.0039 \\
& & $\operatorname{PSV}(25 \mathrm{~Hz})$ & -1.63 & 0.98 & -1.00 & -0.0053 \\
& & Accel. & 2.55 & 1.00 & -1.00 & -0.0046
\end{tabular}

Boore and

Atkinson ( $\underline{6})$

Nuttli (I),

Newmark-Hall

Amplification

Factors
0.25 All Frequencies More complicated functional and Acceleration form; see Equations 12 and 13 and Table 3 of (ㅁ).

0.25

$$
\begin{array}{rllll}
\operatorname{PSV}(1 \mathrm{~Hz}) \ddagger & 0.29 & 1.15 & -0.83 & -0.0028 \\
\operatorname{PSV}(2.5 \mathrm{~Hz}) \ddagger & -0.62 & 1.15 & -0.83 & -0.0028 \\
\operatorname{PSV}(5 \mathrm{~Hz}) \ddagger & -1.32 & 1.15 & -0.83 & -0.0028 \\
\operatorname{PSV}(10 \mathrm{~Hz}) \ddagger & -2.13 & 1.15 & -0.83 & -0.002 \mathrm{~S} \\
\operatorname{PSV}(25 \mathrm{~Hz}) \ddagger & -3.53 & 1.15 & -0.83 & -0.0028 \\
\text { Accel. } & 1.38 & 1.15 & -0.83 & -0.0028
\end{array}
$$

$\dagger \quad$ Spectral velocities have units of $\mathrm{cm} / \mathrm{sec}$; acceleration has units of $\mathrm{cm} / \mathrm{sec}^{2} ; R$ has units of $\mathrm{km}$. Variability of $\ln \left[\mathrm{Y}^{\prime}\right]$ around the predicted value is characterized by a normal distribution with $\sigma=0.5$.

$\ddagger \quad$ For given $m_{b}$ and $R, \ln \left[Y^{\prime}\right]$ is the smaller of $a+b m_{b}+c \ln [R]+d R$ and $-8.3+2.3 m_{b}-0.83 \ln [R]-0.0012 R$ 
Table 2-2

\section{LLNL PEAK ACCELERATION MODELS}

(Based on $(\underline{8})$ )

\begin{tabular}{|c|c|c|c|c|c|c|c|}
\hline \multirow[b]{2}{*}{ Designation } & \multirow[b]{2}{*}{ Description } & \multicolumn{6}{|c|}{ Expert's Weights } \\
\hline & & 1 & 2 & 3 & 4 & 5 & Total \\
\hline $\begin{array}{l}\mathrm{RV} 1 \\
\mathrm{RV} 2\end{array}$ & $\begin{array}{l}\text { Boore \& Atkinson }(\underline{6}) \text {, } \\
\text { Toro and McGuire }(\underline{9}) ; \\
\omega^{2} \text { model, } 100 \text { bars. }\end{array}$ & 0.5 & & 0.7 & 0.4 & & 0.32 \\
\hline RV5(x2) & $\begin{array}{l}\omega^{2} \text { model; parameters } \\
\text { specified by expert } 2\end{array}$ & & 0.3 & & & & 0.06 \\
\hline $\operatorname{RV} 5(x 3)$ & $\begin{array}{l}\omega^{2} \text { model; parameters } \\
\text { specified by expert } 3\end{array}$ & & & 0.3 & & & 0.06 \\
\hline G16-A3 & $\begin{array}{l}\text { Trifunac }(\underline{10})+ \\
\text { modif. Gupta-Nuttli }(\underline{11})+ \\
I_{0}=2 m_{b}-3.5\end{array}$ & & & & & 1.0 & 0.20 \\
\hline SE1 & $\begin{array}{l}\text { Nuttli }(I) \text { model; } \\
M_{0} f_{0}^{4}=\text { const }\end{array}$ & 0.25 & 0.4 & & 0.25 & & 0.18 \\
\hline SE- $2 A$ & $\begin{array}{l}\text { Nuttli (I) model; } \\
M_{0} f_{0}^{3}=\text { Const }\end{array}$ & 0.25 & & & 0.25 & & 0.10 \\
\hline Comb-1A & $\begin{array}{l}\text { Veneziano }(\underline{4.5}) \text {, } \\
\text { Uses intensity and } \\
\text { strong motion data }\end{array}$ & & 0.3 & & 0.1 & & 0.08 \\
\hline
\end{tabular}


Table 2-3

LLNL SPECTRAL VELOCITY MODELS

(Based on (ㅇ) )

\begin{tabular}{|c|c|c|c|c|c|c|c|}
\hline \multirow[b]{2}{*}{ Name } & \multirow[b]{2}{*}{ Description } & \multicolumn{6}{|c|}{ Expert's Weights } \\
\hline & & 1 & 2 & 3 & 4 & 5 & Total \\
\hline $\begin{array}{l}\text { RV1, } \\
\text { RV2 }\end{array}$ & $\begin{array}{l}\text { Boore \& Atkinson ( } \underline{6}), \\
\text { Toro and McGuire }(\underline{9}), \\
\omega^{2} \text { model, } 100 \text { bars }\end{array}$ & 0.5 & & 0.7 & 0.4 & & 0.32 \\
\hline $\operatorname{RV} 5(x 2)$ & $\begin{array}{l}\omega^{2} \text { model; parameters } \\
\text { specified by expert } 2\end{array}$ & & 0.3 & & & & 0.06 \\
\hline $\operatorname{RV} 5(x 3)$ & $\begin{array}{l}\omega^{2} \text { model; parameters } \\
\text { specified by expert } 3\end{array}$ & & & 0.3 & & & 0.06 \\
\hline $\mathrm{TL}$ & $\begin{array}{l}\text { Trifunac and Lee }(\underline{12})+ \\
\text { Modif. Gupta-Nuttli }(\underline{11})+ \\
I_{0}=2 m_{b}-3.5\end{array}$ & & & & & 1.0 & 0.20 \\
\hline NH-SE1 & $\begin{array}{l}\text { Newmark-Hall (1.3) spectrum } \\
\text { anchored to Nuttli (1986) } \\
\left(M_{0} f_{0}^{4}=\text { const.) acceleration }\right. \\
\text { and velocity; }\end{array}$ & 0.25 & 0.4 & & 0.25 & & 0.18 \\
\hline NH-SE2 & $\begin{array}{l}\text { Newmark-Hall }(13) \text { spectrum } \\
\text { anchored to Nuttli }(1986) \\
\left(M_{0} f_{0}^{3}=\text { const.) acceleration }\right. \\
\text { and velocity. }\end{array}$ & 0.25 & & & 0.25 & & 0.10 \\
\hline NH-RV 5 & $\begin{array}{l}\text { Newmark-Hall }(\underline{13}) \text { spectrum } \\
\text { anchored to acceleration and } \\
\text { velocity from } \omega^{2} \text { model } \\
\text { (expert } 2 \text { ). }\end{array}$ & & 0.3 & & & 0.1 & 0.08 \\
\hline
\end{tabular}



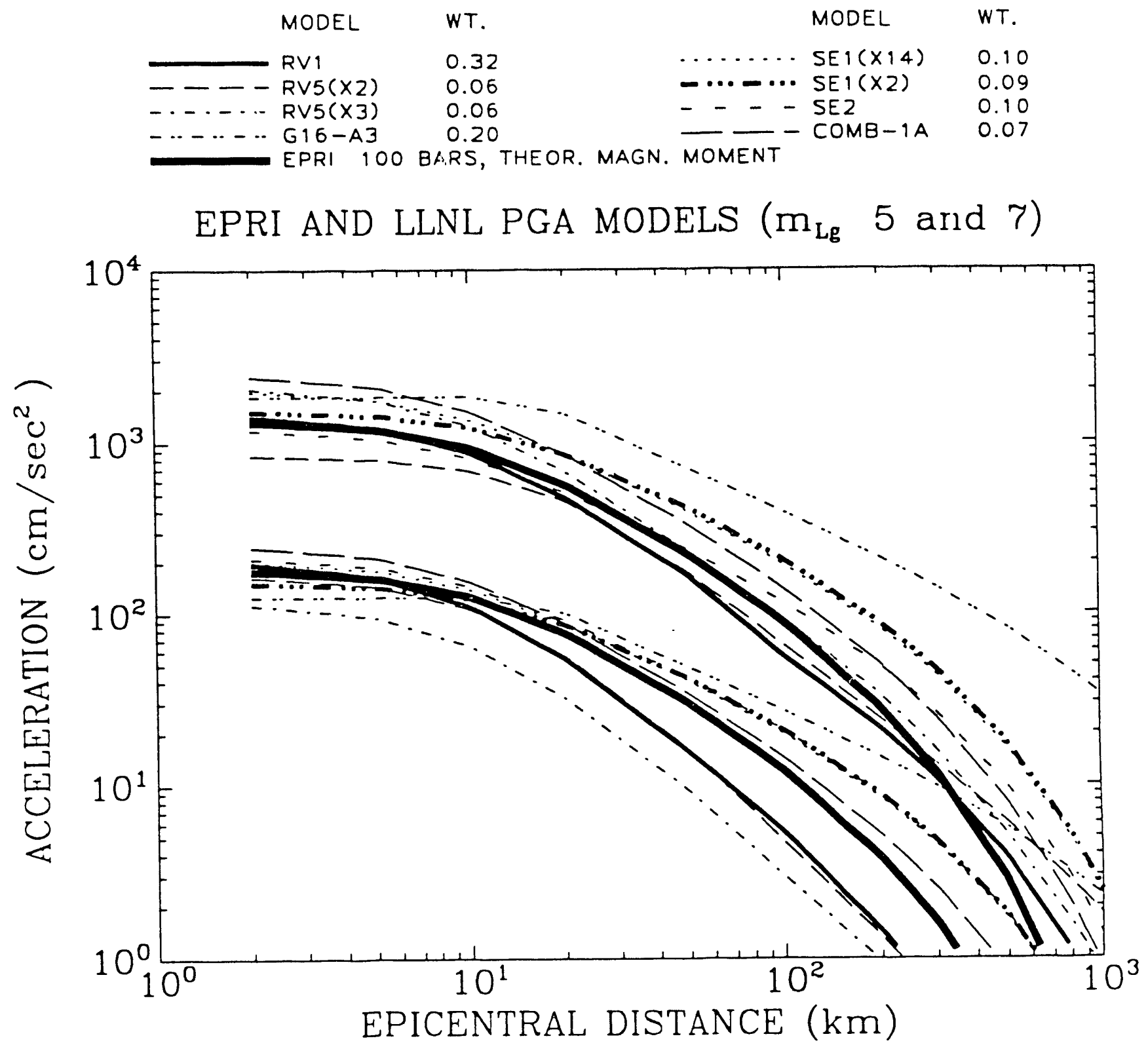

Figure 2-1. Comparison of predicted peak acceleration by the EPRI and LLNL attenuation equations. Predictions are shown for $m_{b} 5$ and $\tau$. Predictions by McGuire et al. (1) are shown as thick lines. Predictions by Boore-Atkinson (RV1) and by Nuttli (SE1) are shown as medium lines; predictions by other LLNL models are shown as thin lines. Source: (2) 


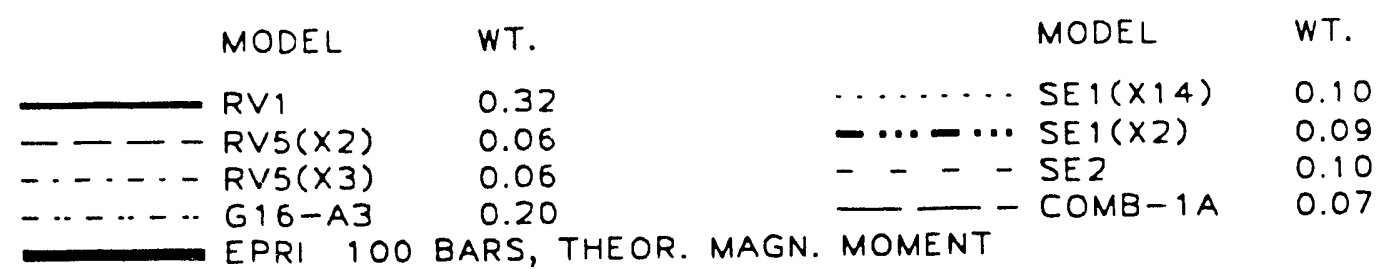

\section{EPRI AND LLNL SPECTRA $\left(m_{b} 5\right.$ and $\left.7, R=25 \mathrm{~km}\right)$}

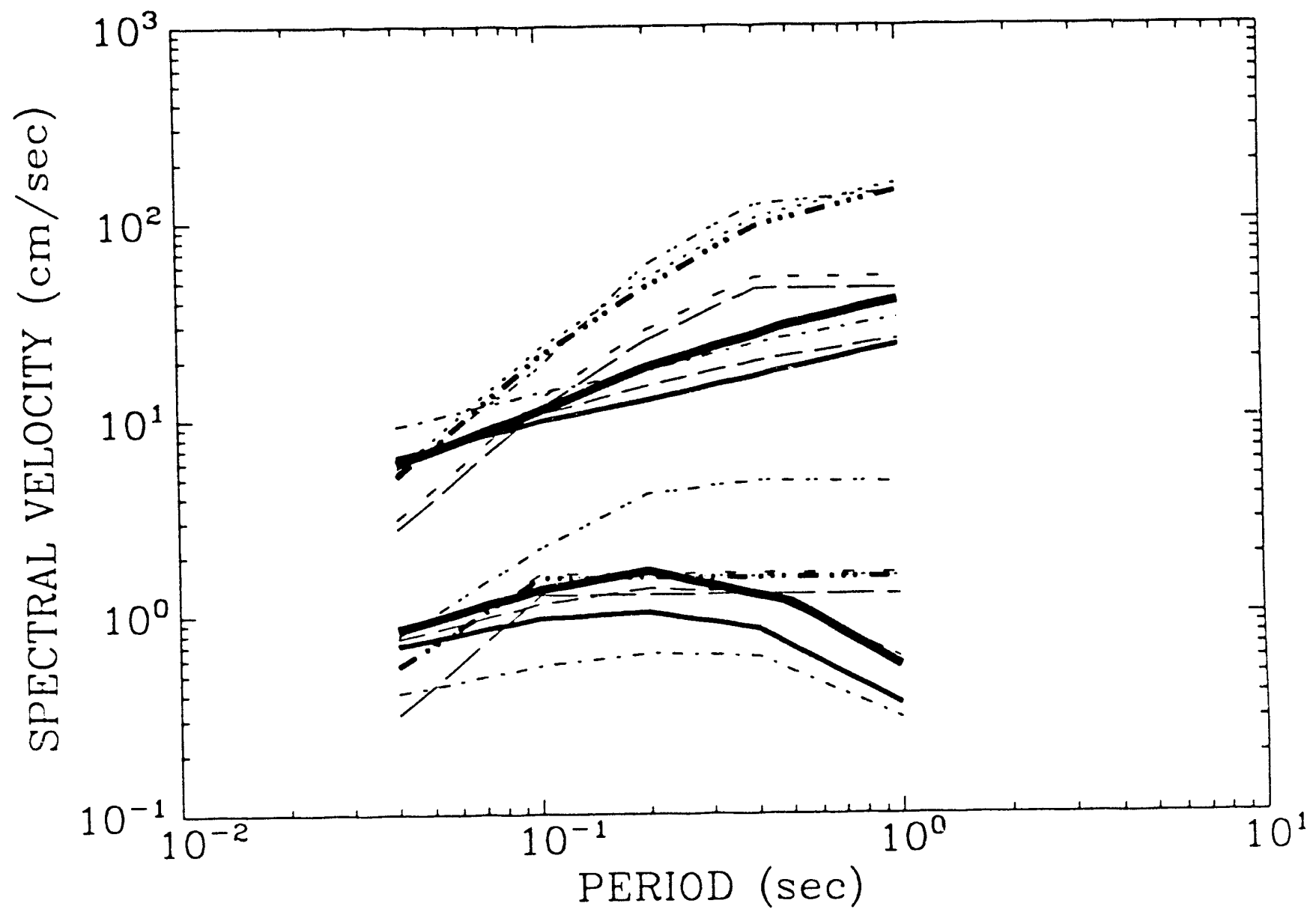

Figure 2-2. Comparison of response spectra predicted by the EPRI and LLNL attenuation equations. Predictions are shown for an epicentral distance of $25 \mathrm{~km}$ and for $r_{16} 5$ and $i$. Predictions by McGuire et al. (1) are shown as thick lines. Predictions by Boore-Atkinson (RV'1) and by Nuttli-Newmark-Hall (SEl) are shown as medium lines: predictions by ofler LLNL models are shown as thin lines. Source: (2) 


\section{Section 3}

\section{EMPIRICAL COMPARISON OF RESPONSE-SPECTRUM AMPLITUDES AND PREDICTIVE EQUATIONS}

In this section, we compare the observed spectral velocities from the Saguenay earthquake (and from other relevant earthquakes) to the predictive equations used in the EPRI and LLNL studies. The objective of this comparison is to evaluate how accurately the EPRI and LLNL attenuation equations predict the Saguenay observations, over the range of distances and frequencies of engineering interest.

\subsection{PROCESSING OF THE DATA}

We obtained instrument-corrected ground-motion records from the Geological Survey of Canada (1) and from the National Center for Earthquake Engineering Research (2). Table 3-1 lists the station names and their distances to the epicenter of the Saguenay earthquake. Figure 3-1 show's the location of the stations. Spectral velocities (for $5 \%$ damping) were calculated for all 3 components of all records, for frequencies of $1,2,5,10$, and $25 \mathrm{~Hz}$. All records from station SM01 were excluded from further consideration because their amplitudes are orders of magnitude lower than other records.

\subsection{COMPARISONS TO THE EPRI AND LLNL ATTENUATION FUNCTIONS}

Figures 3-2 through 3-13 show the observed spectral veiocities from the Saguenay earthquake. Both horizontal components are included; soil sites are not included. The error bars represent the logarithmic mean $\pm \sigma$ range of the observations in the following distance ranges: 40-70 km (2 stations), $70-120 \mathrm{~km}$ (4 stations), and 120-200 km (3 stations). Also shown in these figures are the ground-motions predicted for the Saguenay earthquake $\left(m_{b L_{g}}=6.5\right)$ by the EPRI and LLNL attenuation functions.

He use the $m_{b L_{g}}$ magnitude to characterize the Saguenay earthquake, because this is the instrumental magnitude scale used in the EPRI and LLNL seismicity catalogs. When mb was not available for a certain event. the available size measure was converted to mbLa. Similarly, some LL $\mathrm{XL}$ seismicity experts specified seismicity parameters in terms of epicentral intensity, and those seismicity parameters were converted to $m_{b L g}$. 
Table 3-1

STRONG GROUND MOTION STATIONS

Soil

Code Station Distance $(\mathrm{km})$ Typef

Eastern Canada Strong Motion Stations

SM16 Chicoutimi Nord, Quebec

SM17 St-Andre, Quebec

SM20 Les Eboulements, Quebec

SM07 Baie-St-Paul, Quebec

SM08 La Malbaie, Quebec

SM05 Tadoussac, Quebec

SM01 St-Ferreol, Quebec

S10 Riviere-Ouelle, Quebec

S09 St. Pascal, Quebec

SM02 Quebec, Quebec

S14 Ste Lucie de Beauregard, Quebec

$43.41 \quad 5$

$64.31 \quad 5$

$89.96 \quad 5$

$90.57 \quad 3$

$92.65 \quad 5$

$109.10 \quad 5$

$113.42 \quad 5$

$114.03 \quad 5$

$122.44 \quad 3$

$149.00 \quad 5$

$176.46 \quad 5$

NCEER Strong Motion Array:

DCK'Y Dickey, ME

$198.3 \quad 5$

ISFL Island Falls, ME

$322.5 \quad 5$

MIME Milo, ME

$359.2 \quad 5$

LYON Lyon Mt., NY

MSNA Massena, NY

$431.1 \quad 4$

EMME Machias, ME

NEWC Newcomb, NY'

$445.6 \quad 3$

$470.8 \quad 5$

PAL Palisades, NY

$524.2 \quad 5$

$819.9 \quad 5$

†Soil types are defined as follow's: 3 , deep soil $(>15 \mathrm{~m}) ; 4$, sandstone or soft rock; 5 , hard rock 
For spectral velocities at 1 and $2.5 \mathrm{~Hz}$ (Figures 3-2 through 3-5), the observations at 40$70 \mathrm{~km}$ (leftmost error bar) are significantly lower than all predictions. The observations at $70-120$ and $120-200 \mathrm{~km}$ are higher than the observations at $40-70 \mathrm{~km}$, and they are consistent with the lower set of attenuation functions in both the EPRI and LLNL studies. The predictions by LLNL expert 5 (model TL-RS) and by one of the Nuttli attenuation functions (EPRI's "Nuttli" and LLNL NH-SE1) greatly exceed the average observations over all distance ranges.

For spectral velocities at 5 and $10 \mathrm{~Hz}$ (Figures 3-6 and 3-7), the observations at 40-70 $\mathrm{km}$ agree with the lower sets of attenuation functions. The observations at $70-120 \mathrm{~km}$ and $120-200 \mathrm{~km}$ are higher than those at $40-70 \mathrm{~km}$, and they are consistent with the attenuation functions developed by Nuttli (EPRI's Nuttli and LLNL's NH-SE1 and NFi-SE2). The predictions by LLNL expert 5 are higher than the average observations, over all distance ranges, especially at short distances (where they exceed observations by a factor of 5 ). The predictions by LLNL expert 5 come barely within the $\pm 1 \sigma$ range for one distance range (120-200 km for $5 \mathrm{~Hz}$ PSV and $70-120 \mathrm{~km}$ for $10 \mathrm{~Hz}$ PSV).

For spectral velocities at $25 \mathrm{~Hz}$, observations over the various distance ranges show the familiar $1 / R$ dependence. Observations at $40-70 \mathrm{~km}$ agree with all EPRI attenuation functions and virtually all LLNL attenuation functions. The predictions by LLNL expert 5 are higher than observations for distances greater than $70 \mathrm{~km}$, especially in the $120-200 \mathrm{~km}$ range.

For peak acceleration, observations show a mild decay with distance. Observations fall between EPRI's two higher models, and they agree with the intermediate LLNL models. The predictions by LLNL expert 5 exceed average observations by a factor of 3 , over all distance ranges.

One can summarize the observations from Figures 3-2 through 3-13 as follows:

- In the 40-70 km distance range, the averages of the observed amplitudes agree with (or are lower than) the attenuation functions by Boore and Atkinson (ㅍ) and McGuire et al. (4). These attenuation functions received large weights in both the EPRI and LLNL studies ( $75 \%$ and $38 \%$, respectively). The attenuation functions by LL. $I L$ expert 5 agree with these average observations for $25 \mathrm{~Hz}$ PSV. but overpredicts the average observations by a factor of 2.5 to 30 for the other ground-motion measures. 
- The observed amplitudes at distances 70-200 km, do not follow the $1 / K$ geometric attenuation typically assumed in attenuation functions. ${ }^{1}$ In fact, the average amplitudes tend to increase slightly with increasing distance, for frequencies of 1 to $5 \mathrm{~Hz}$. This trend gradually disappears at higher frequencies, reaching the $1 / R$ trend for 25 $\mathrm{Hz}$ PSV. Consequently, the models that agree with observations at $40-70 \mathrm{~km}$ underpredict the observations at $70-120 \mathrm{~km}$ and at $120-200 \mathrm{~km}$. Models that over-predict the observations at short distances show better agreement with observations in the $70-200 \mathrm{~km}$ distance range. LLNL expert 5 is the extreme example; his predictions come barely within the $1 \sigma$ error bars at 5 and $10 \mathrm{~Hz}$ in the distance ranges that deviate the most from the $1 / R$ trend and grossly over-predicts observations at shorter distances.

\subsection{COMPARISON TO OTHER GROUND MOTION DATA}

It is also useful to compare the predictions by the EPRI and LLNL attenuation functions to ground motions from other intraplate earthquakes with magnitudes $m_{b L g} 5.5$ to 6.5 (see Table 3-2). We include three earthquakes from outside ENA in this data set because their source charicteristics are believed to be similar to those of ENA earthquakes. We include the Gazli, USSR, earthquake of $1976(\underline{5.6})$. This was a shallow crustal event, and it occurred far from tectonic-plate margins, which suggests that this earthquake might be analogous to earthquakes in ENA. There is some uncertainty as to the magnitude of this event, and the possibility that the records are affected by unusual soil conditions ( $\underline{6})$. We also include the Nahanni, Northwest Territories, Canada, earthquake of 1985 and one of its aftershocks. These earthquakes occurred in a region of low seismicity and tectonic characteristics similar to those in $\operatorname{ENA}(\underline{I})$.

In figures 3-14 through 3-25, we have scaled all recorded amplitudes to $m_{b L_{g}} 6$ (using the ground-motion model in (4) ] and compare them to the predictions of the EPRI and LLNL models for $m_{b L g} 6$. The data within $100 \mathrm{~km}$ in this data sets come from accelerograph records from Gazli and Nahanni ( 1 and 3 stations, respectively). These data show considerable scatter, especially at distances shorter than $10 \mathrm{~km}$. The data at longer distances comes from the Eastern Canada Telemetered Network (\$).

Focusing on the dat a within $100 \mathrm{~km}$, we observe that all attenuation functions are consistent whit ofservations. The attenuation functions proposed by LLNL expert j are somewhat

\footnotetext{
${ }^{1}$ Section 3 will explain this trend as caused by the combined effect of crustal structure and inpocerital depth
} 
Table 3-2

EARTHQUAKES USED IN FIGURES 3-14 THROUGH 3-25

(Source: (4))

\begin{tabular}{cclll} 
Symbol & Date & \multicolumn{1}{c}{ Location } & $m_{L g}$ & Record Types \\
\hline D & 051776 & Gazli, USSR & 6.3 & Accelerograph \\
E & 011182 & New Brunswick & 5.5 & ECTN \\
J & 100783 & Goodnow,NY & 5.6 & ECTN \\
S & 122385 & Nahanni, NWT & 6.5 & Accelerograph \\
U & 122585 & Nahanni, NWT & 5.7 & Accelerograph
\end{tabular}

higher than average observations at frequencies of 1 and $2 \mathrm{~Hz}$ and for peak acceleration, but they are consistent with observations from Gazli.

At distances of $100 \mathrm{~km}$ or longer, the attenuation functions proposed by LLNL expert 5 grossly over-predict amplitudes, for all ground-motion measures (except 25- $\mathrm{Hz}$, for which there are no data in this distance range. The distance dependence in the predictions by LLNL expert 5 show a slope that decreases with increasing distance. This trend is not supported by the data.

\subsection{SUMMARY AND CONCLUSIONS}

We can conclude the following from the Saguenay ground motions, regarding the EPRI and LLNL attenuation functions:

- The attenuation functions by LLNL expert 5 are generally inconsistent with the sserved ground motions from the Saguenay earthquake, except for a few isolated aistance ranges. In particular, these attenuation functions greatly over-predict the observations in the 40-70 km distance range (except for $25 \mathrm{~Hz}$ PSV').

- No individual attenuation function, from either the EPRI or LLNL sets, fits the Saguenay observations over the entire 40-200 km distance range. Both the EPRI sct and the LLNL set without expert 5 , when considered as a whole, are consistent with all observed ground motions from the Saguenay earthquate. 
Comparisons to the short-distance data from other intraplate earthquates is not conclusive because these data show large scatter and come from only a few stations. The predictions by LLNL expert 5 for frequencies of 1 and $2 \mathrm{~Hz}$ and for peak acceleration are somewhat higher than the observations. The data at longer distances indicates that LLNL expert 5 over-predicts the observations. Also, LLNL expert 5 predicts a trend towards decreasing geometric attenuation with increasing frequency; this trend is not consistent with the data.

\subsection{REFERENCES}

1. P. S. Munro and D. Weichert. The Saguenay Earthquake of November 25, 1988 Processed Strong Motions Records. Open-File Report 1996, Geological Survey of Canada, 1989.

2. P. Friberg, R. Busby, D. Lentrichia, D. Johnson, K. Jacob, and D. Simpson. The $M=6$ Chicoutimi Earthquake of November 25, 1988, in the Province of Quebec, Canada: Preliminary NCEER Strong Motion Data Report. Technical Report, National Center for Earthquake Engineering Research, 1988.

3. D. M. Boore and G. M. Atkinson. "Stochastic Prediction of Ground Motion and Spectral Response Parameters at Hard-Rock Sites in Eastern North America". Bulletin of the Seismological Society of America, $77(2): 440-467,1987$.

4. R. K. McGuire, G. R. Toro, and W'. J. Silva. Engineering Model of Earthquake Ground Motion for Eastern North America. Technical Report NP-6074, Electric Power Research Institute, 1988.

5. W. J. Person. "Seismological Notes, May-June 1976". Bulletin of the Seismological Society of America, $68(1), 1978$.

6. S. Hartzell. "Faulting Process of the May 17, 1976 Gazli, USSR Earthquake". Bulletin of the Seismological Society of America, 70(5), 1980.

7. R. J. Wetmiller, R. B. Horner, H. S. Hasegawa, R. G. North, M. Lamontagne, D. H. Weichert, and S. G. Evans. "An Analy'sis of the 1985 Nahanni Earthquakes". Bulletin of the Seismological Society of America, $78(2), 1987$.

8. G. M. Atkinson. Ground Motions from Moderate Earthquakes Recorded by the Eastern Canada Telemetered Network. Open File Report 85-5, Earth Physics Branch. 1985.

9. P. Somerville, J. McLaren, C. Saikia, and D. Helmberger. "The 25 November, 19 Ss Saguenay, Quebec, Earthquake Source Parameters and the Attenuation of Strong Ground Motion". Bulletin of the Seismological Society of America, 80:1118-1143. 1990. 


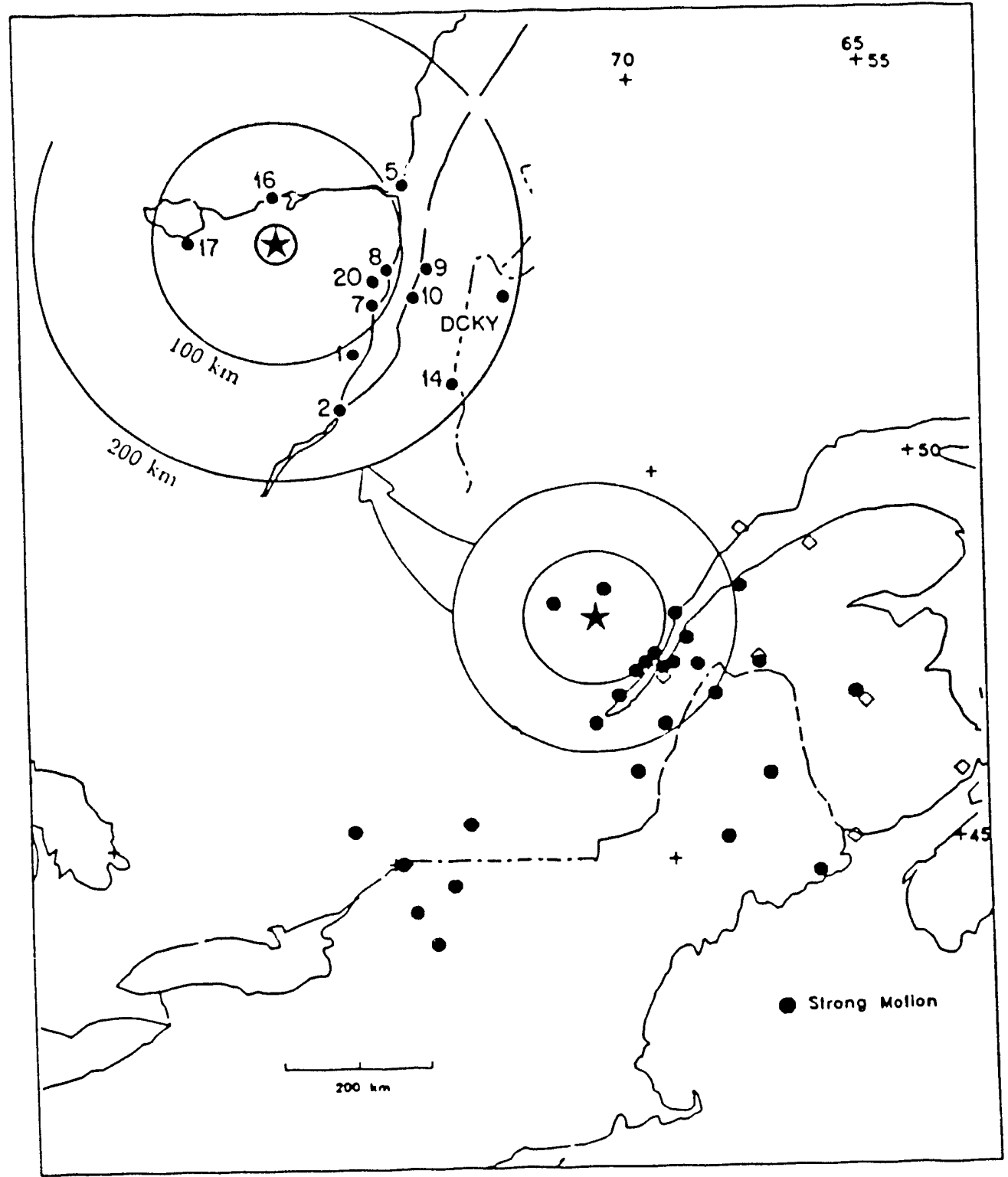

Figure 3-1. Locations of strong motion stations that recorded the Saguenay earthquake. Modified from ( 9 ). 


\section{SAGUENAY EARTHQUAKE $\mathrm{m}_{\mathrm{Lg}} 6.5 \mathrm{PSV}(1 \mathrm{~Hz})$ \\ Comparison to EPRI models}

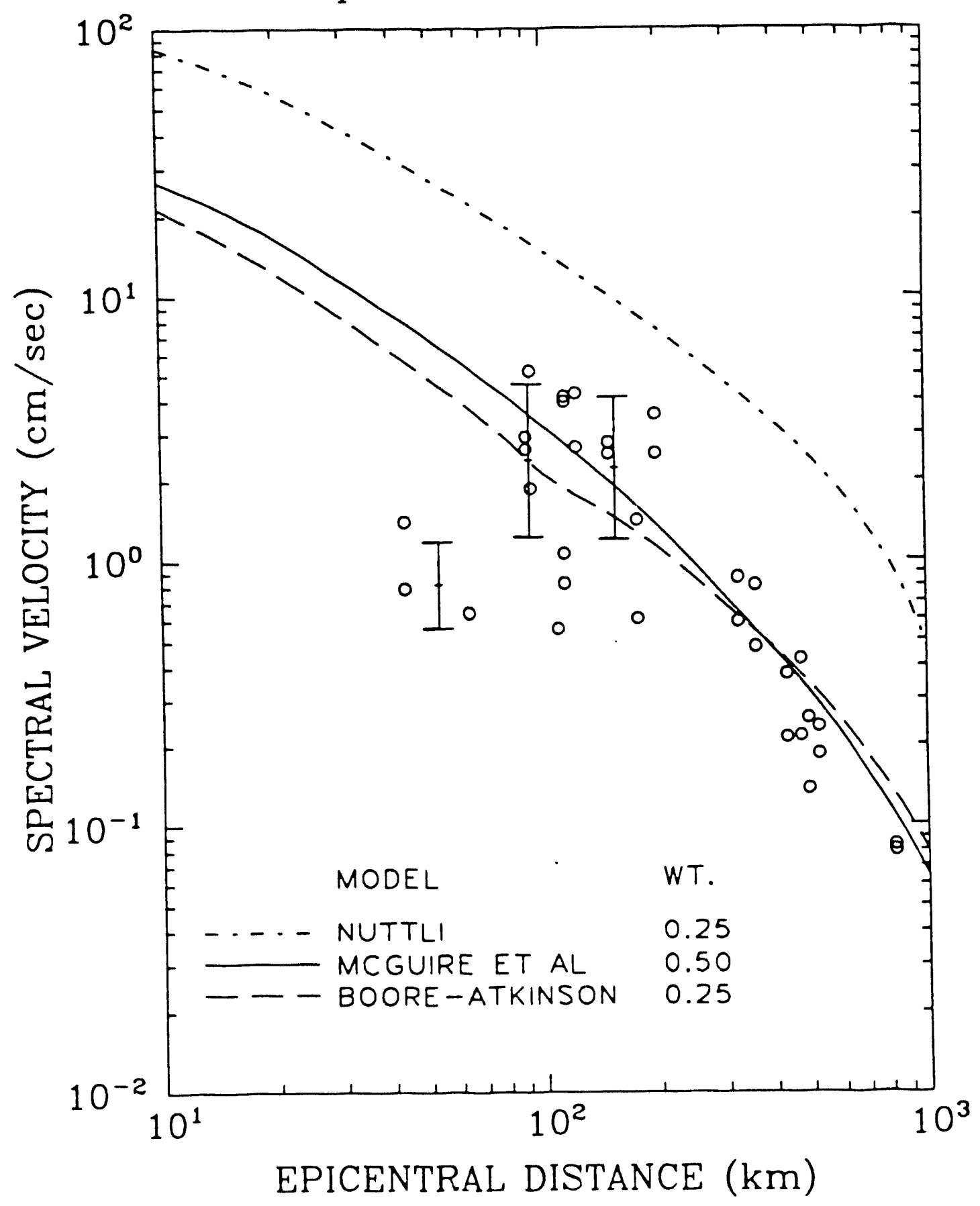

Figure 3-2. $1-\mathrm{Hz}$ spectral velocities from the Saguenay earthquake (circles) are compared to predictions by the EPRI attenuation functions. The error bars represent the logarithmic mean $\pm \sigma$ of amplitudes in the following distance ranges: $40-70 \mathrm{~km}, 70-120$ $\mathrm{km}$. and $120.200 \mathrm{~km}$. 


\section{SAGUENAY EARTHQUAKE $\mathrm{m}_{\mathrm{Lg}} 6.5 \mathrm{PSV}(1 \mathrm{~Hz})$}

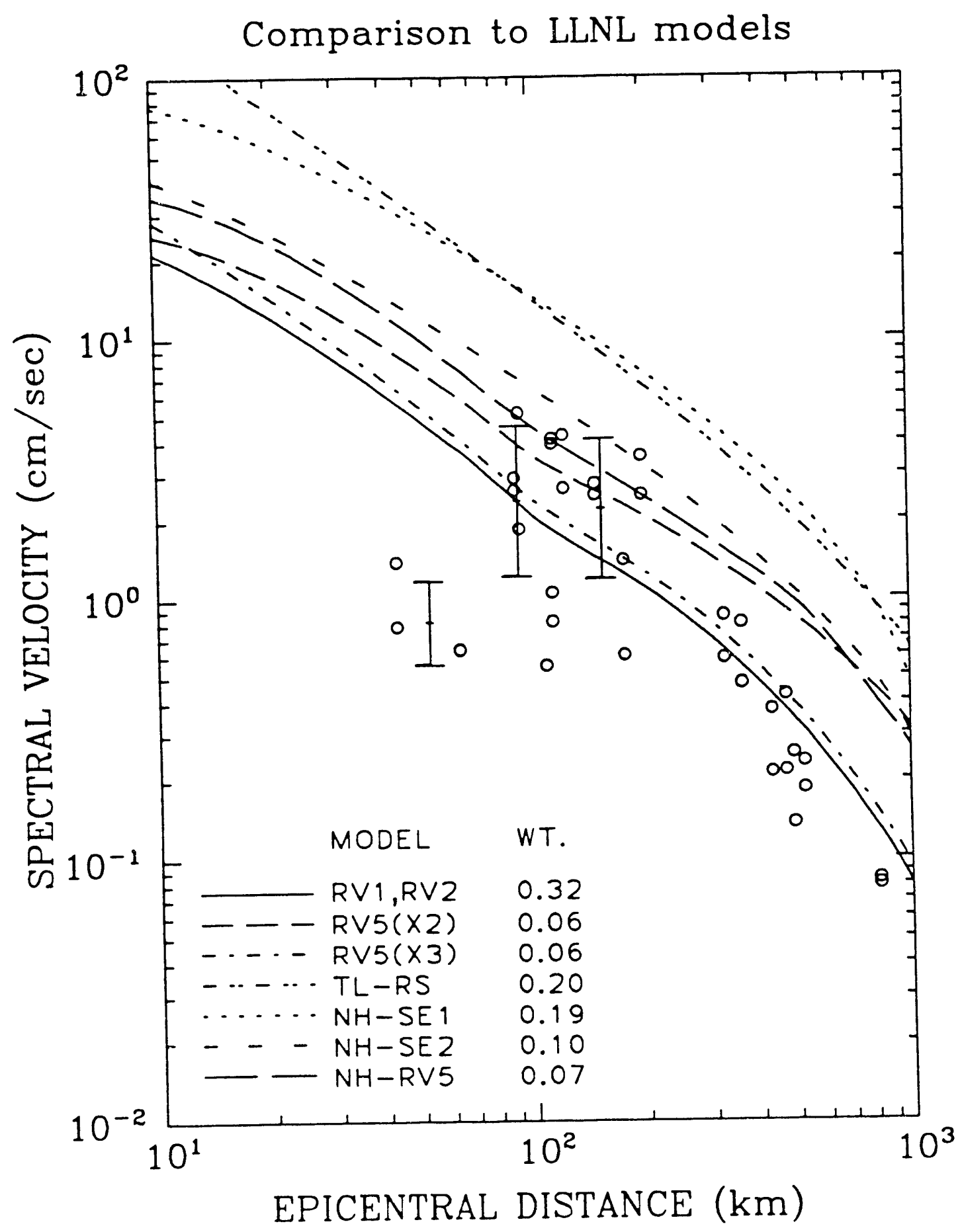

Figure 3-3. 1-Hz spectral velocities from the Saguenay earthquake (circles) are compared to predictions by the LLNL attenuation functions. The error bars represent the logarithmic mean $\pm \sigma$ of amplitudes in the following distance ranges: $40-70 \mathrm{~km}, 70-120$ $\mathrm{km}$, and $120 \cdot 200 \mathrm{~km}$. 


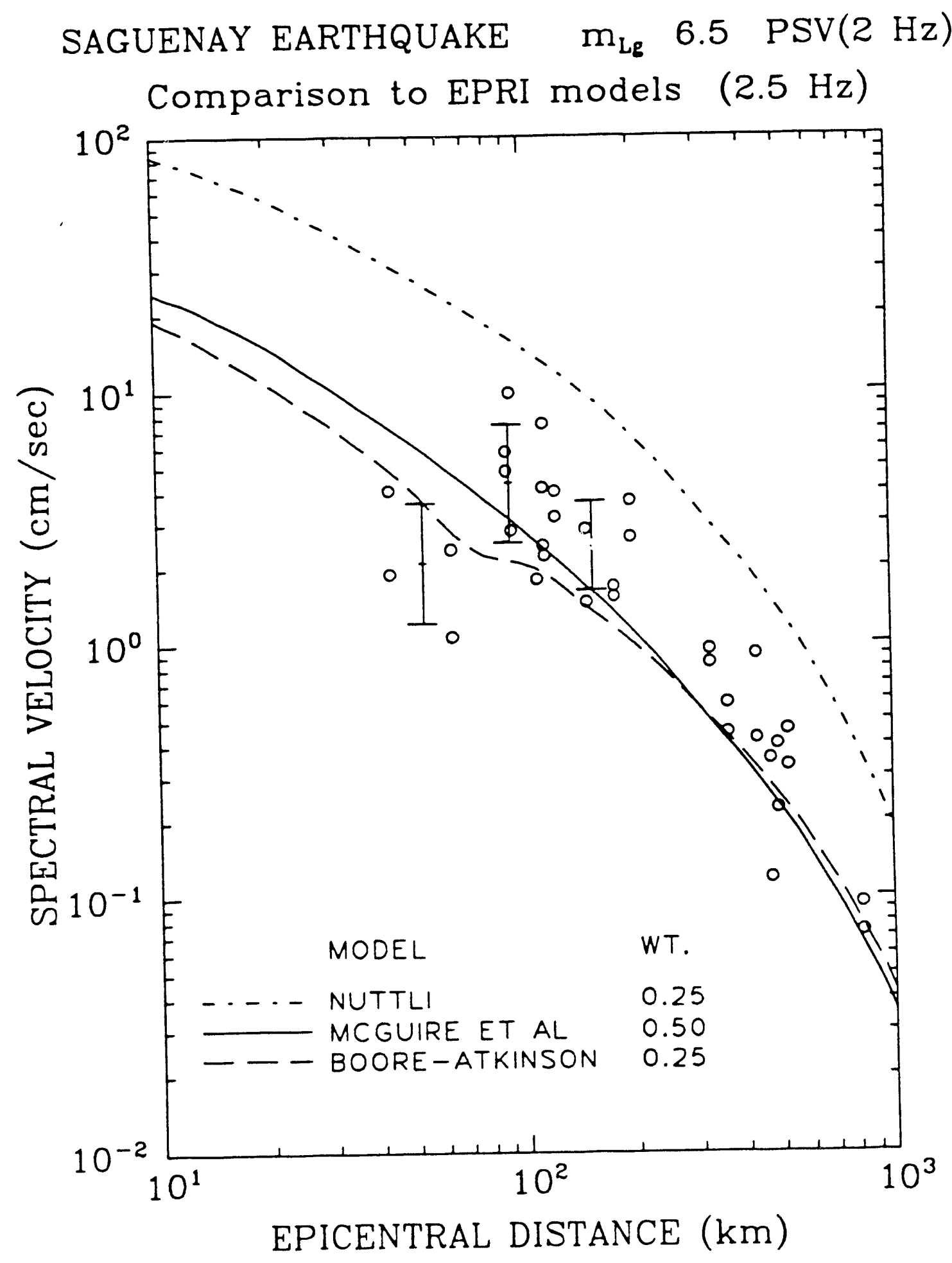

Figure 3-4. 2.5- $\mathrm{Hz}$ spectral velocities from the Saguenay earthquate (circles) are compared to predictions by the EPRI attenuation functions. The error bars represent the logarithmic mean $\pm \sigma$ of amplitudes in the following distance ranges: $40-70 \mathrm{~km}, 70-120$ $\mathrm{km}$. and $120.200 \mathrm{~km}$. 


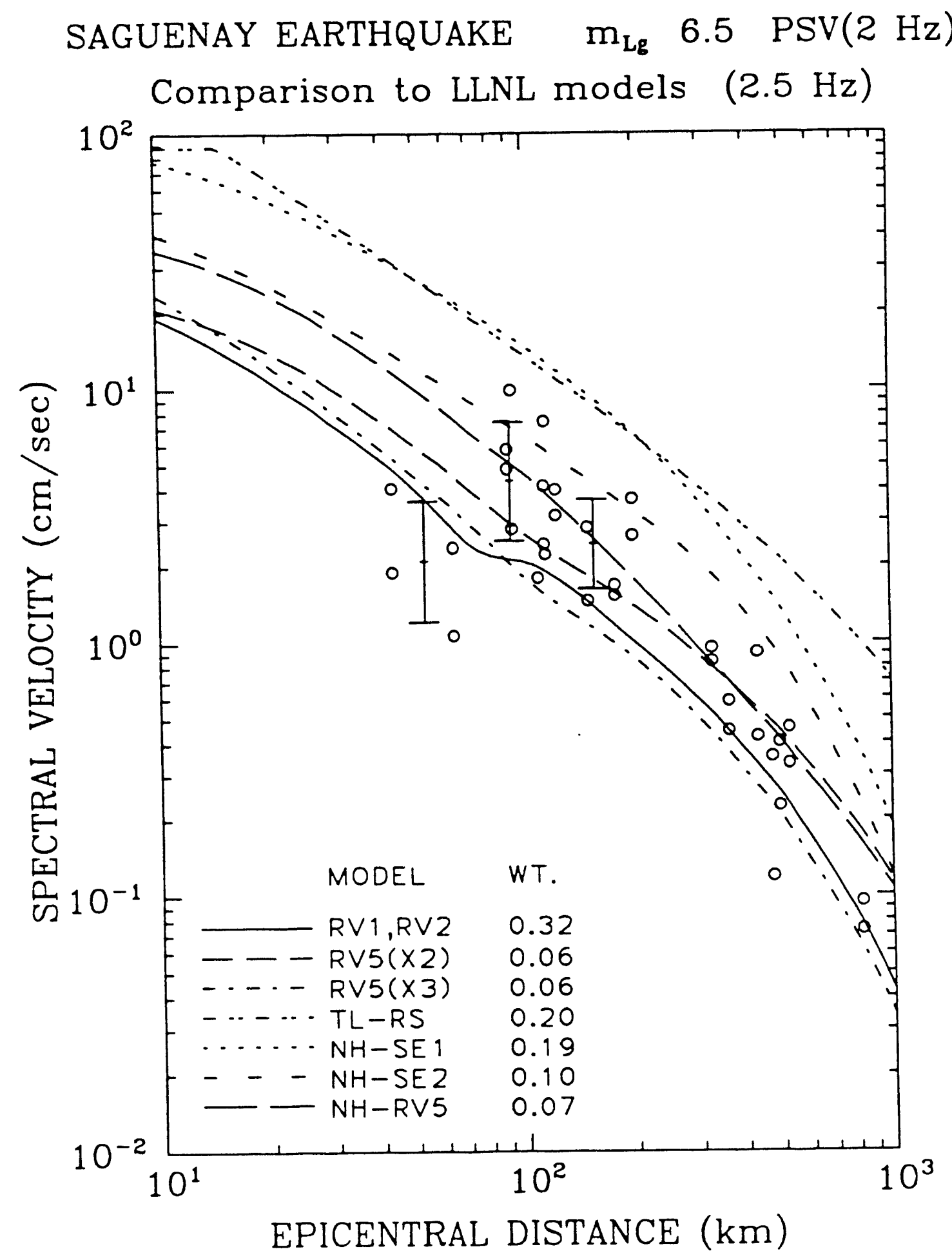

Figure 3-5. 2.5- $\mathrm{Hz}$ spectral velocities from the Saguenay earthquate (circles) are compared to predictions by the LLNL attenuation functions. The error bars represent the logarithmic mean $\pm \sigma$ of amplitudes in the following distance ranges: $40-70 \mathrm{~km}, 70-120)$ $\mathrm{km}$, and $120-200 \mathrm{~km}$. 


\section{SAGUENAY EARTHQUAKE $\mathrm{m}_{\mathrm{Lg}} 6.5 \mathrm{PSV}(5 \mathrm{~Hz})$ \\ Comparison to EPRI models}

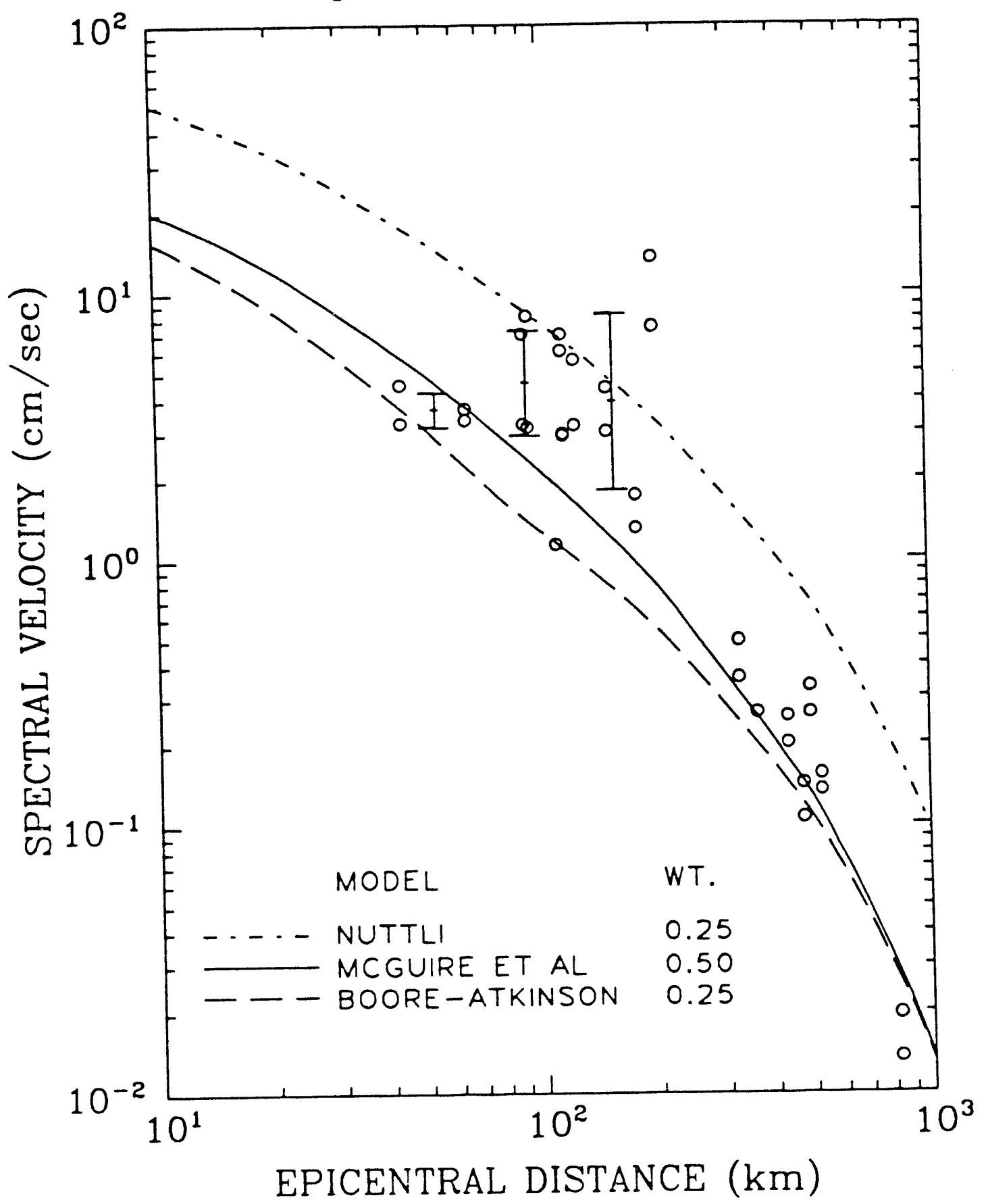

Figure 3-6. 5- $\mathrm{Hz}$ spectral velocities from the Saguenay earthquake (circles) are compared to predictions by the EPRI attenuation functions. The error bars represent the logarithmic mean $\pm \sigma$ of amplitudes in the following distance ranges: $40-70 \mathrm{~km}, 70-120$ $\mathrm{km}$. and $120-200 \mathrm{~km}$. 


\section{SAGUENAY EARTHQUAKE $\mathrm{m}_{\mathrm{Lg}} 6.5 \mathrm{PSV}(5 \mathrm{~Hz})$ \\ Comparison to LLNL models}

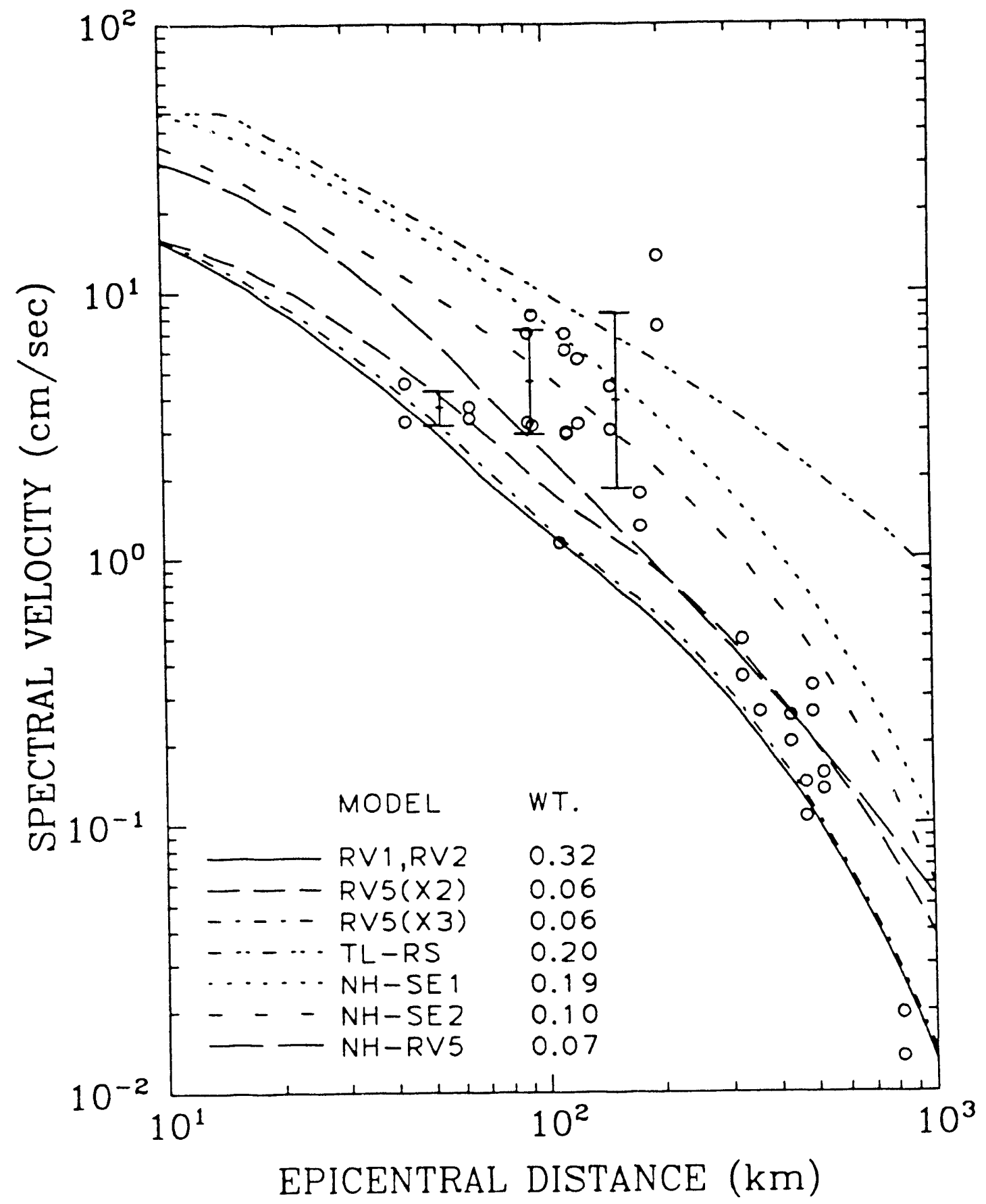

Figure 3-i. $5-\mathrm{Hz}$ spectral velocities from the Saguenay earthquate (circles) are compared to fredictions by the LLNL at tenuation functions. The error bars represent the logarithmic mean $\pm \sigma$ of amplitudes in the following distance ranges: $40-70 \mathrm{~km}, 70-12()$ $\mathrm{km}$. and $120.200 \mathrm{~km}$. 


\section{SAGUENAY EARTHQUAKE $\mathrm{m}_{\text {Lg }} 6.5$ PSV $(10 \mathrm{~Hz})$ \\ Comparison to EPRI models}

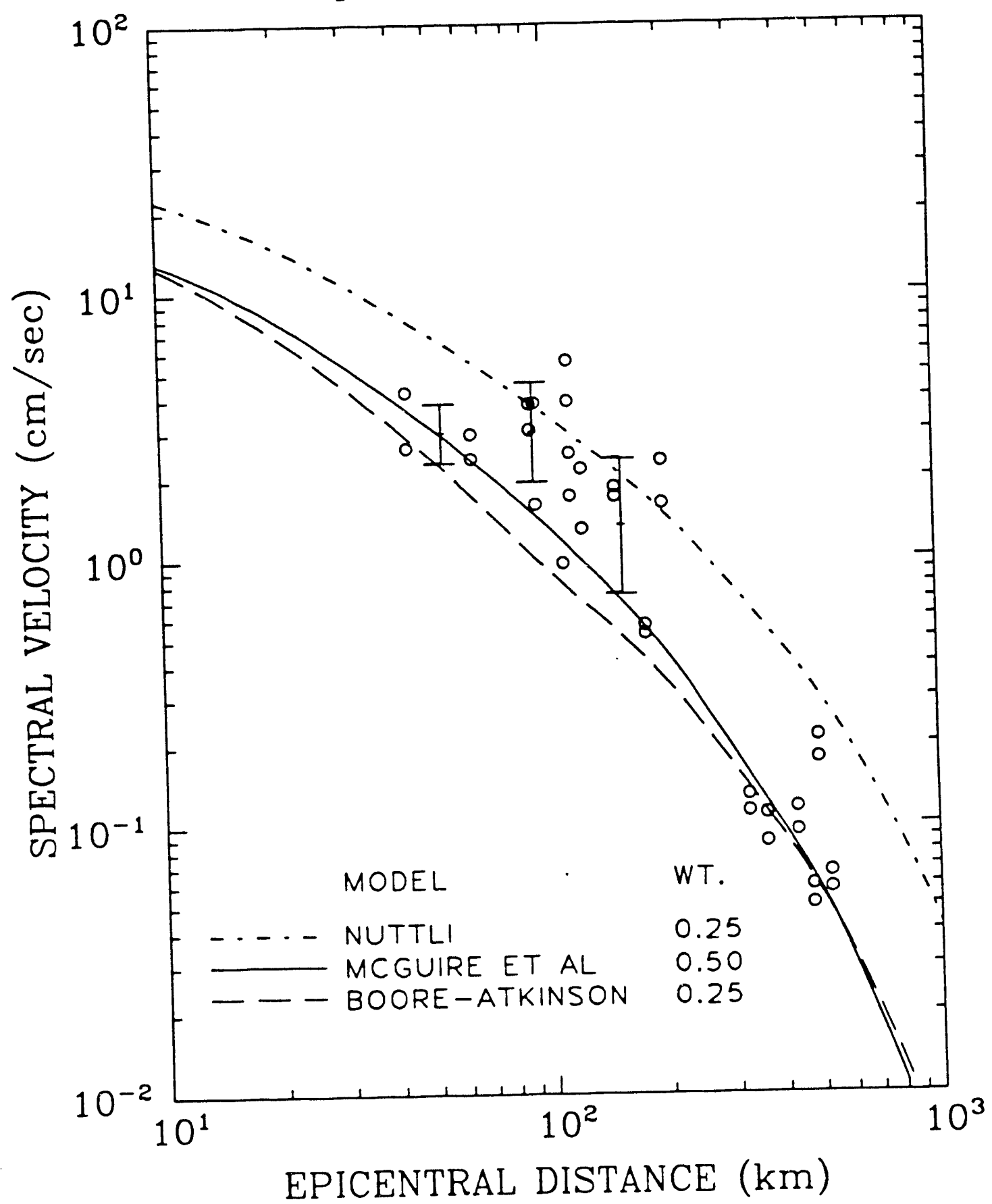

Figure 3-8. 10- $\mathrm{Hz}$ spectral velocities from the Saguenay earthquake (circles) are compared to predictions by the EPRI attenuation functions. The error bars represcnt the logarithmic mean $\pm \sigma$ of amplitudes in the following distance ranges: $40-70 \mathrm{~km}, 70-1: 20$ $\mathrm{km}$, and $120-200 \mathrm{~km}$. 


\section{SAGUENAY EARTHQUAKE $\quad \mathrm{m}_{\mathrm{Lg}} \quad 6.5 \quad \mathrm{PSV}(10 \mathrm{~Hz})$ \\ Comparison to LLNL models}

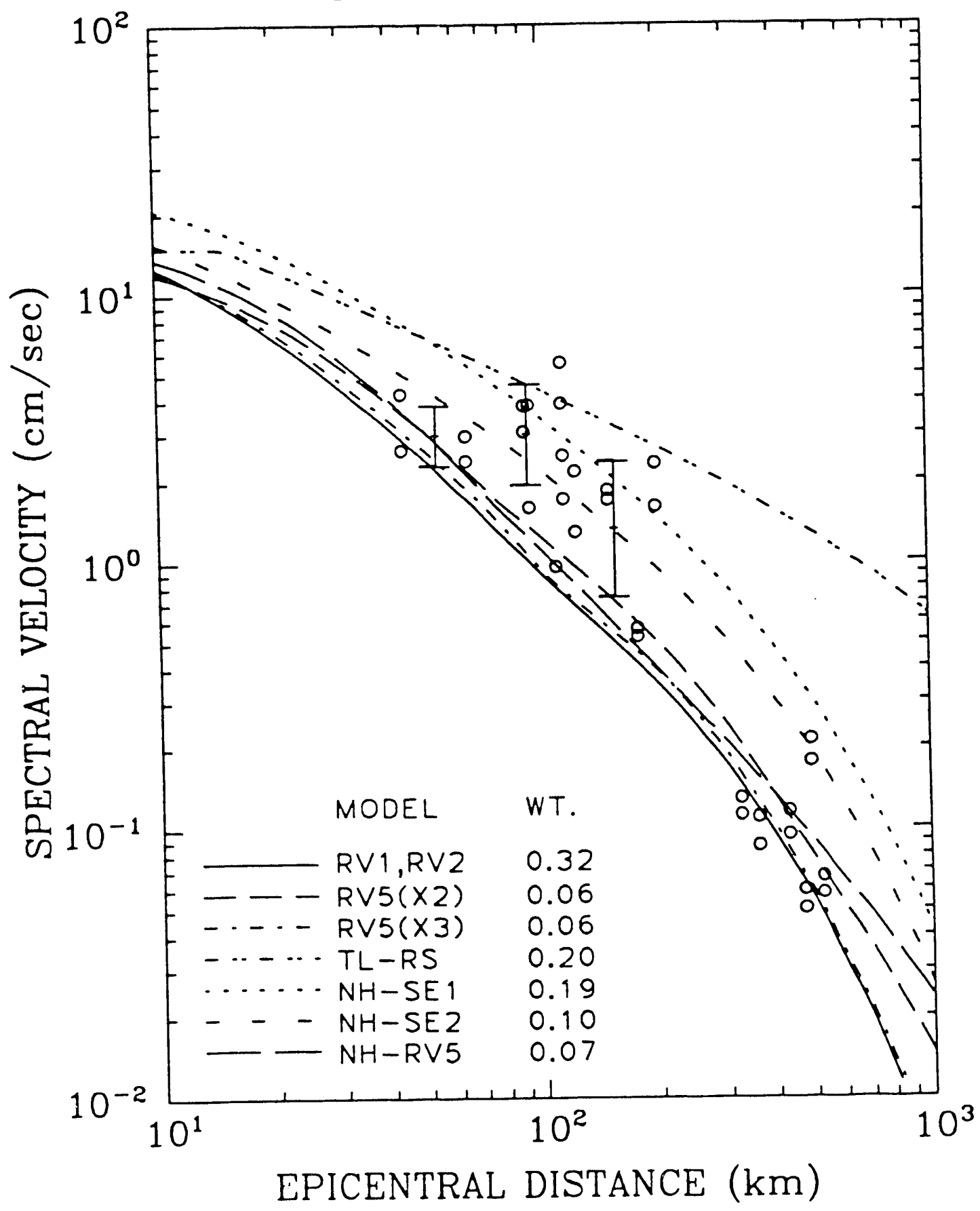

Figure 3-9. $10-\mathrm{Hz}$ spectral velocities from the Saguenay earthquake (circles) are compared to predictions by the LLNL attenuation functions. The error bars represent the logarithmic mean $\pm \sigma$ of amplitudes in the following distance ranges: $40-70 \mathrm{~km} .70-120$ $\mathrm{km}$, and $120-200 \mathrm{~km}$. 


\section{SAGUENAY EARTHQUAKE $\quad \mathrm{m}_{\mathrm{Lg}} \quad 6.5 \quad \mathrm{PSV}(25 \mathrm{~Hz})$}

\section{Comparison to EPRI models}

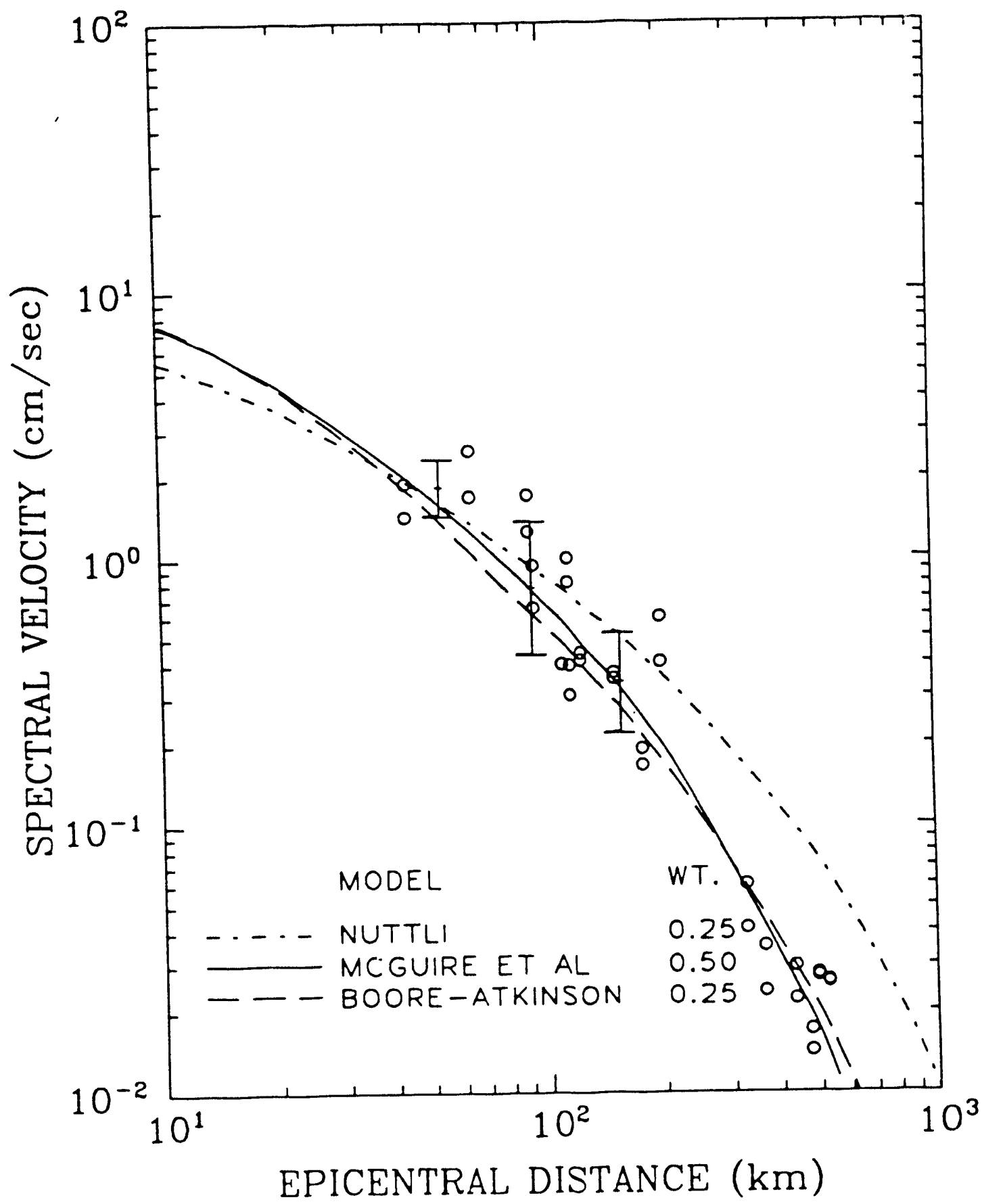

Figure 3-10. 25- $\mathrm{Hz}$ spectral velocities from the Saguenay earthquake (circles) are compared to predictions by the EPRI attenuation functions. The error bars represcul the logarithmic mean $\pm \sigma$ of amplitudes in the following distance ranges: $40-i 0 \mathrm{~km}$. $70-120 \mathrm{~km}$, and $120.200 \mathrm{~km}$. 


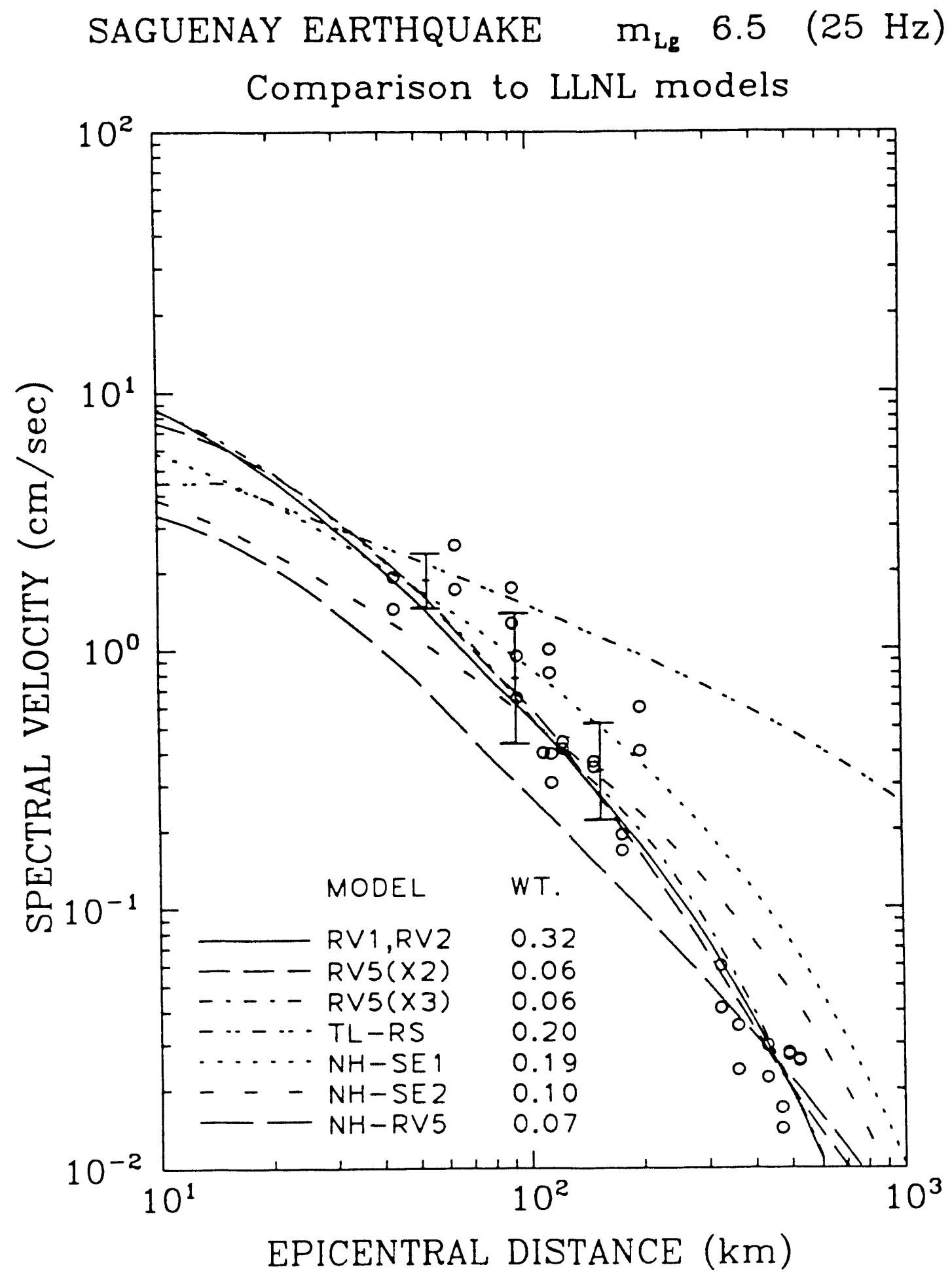

Figure 3-11. 25- $\mathrm{Hz}$ spectral velocities from the Saguenay earthquake (circles) are compared to predictions by the LL ${ }^{\circ} \mathrm{L}$ attenuation functions. The error bars represent the logarithmic mean $\pm \sigma$ of amplitudes in the following distance ranges: $40-70 \mathrm{~km}$. $70-120 \mathrm{~km}$. and $120-200 \mathrm{~km}$. 


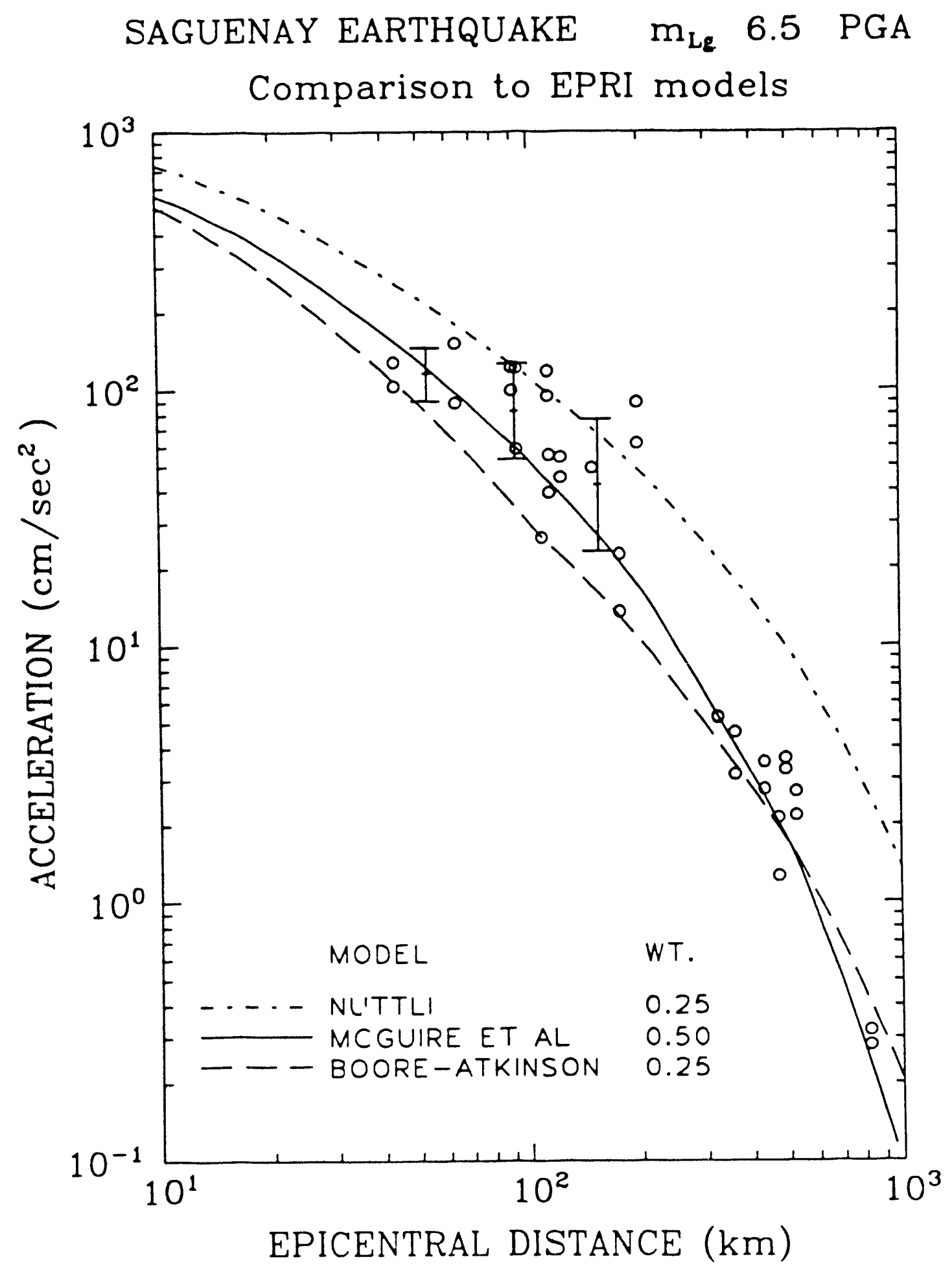

Figure 3-12. Peak ground accelerations from the Saguenay earthquatic (circles) arc compared to predictions by the EPRI attenuation functions. The error bars represent the logarithmic mean $\pm \sigma$ of amplitudes in the following distance ranges: $10-70$ kin. $70-120 \mathrm{~km}$, and $120.200 \mathrm{~km}$. 


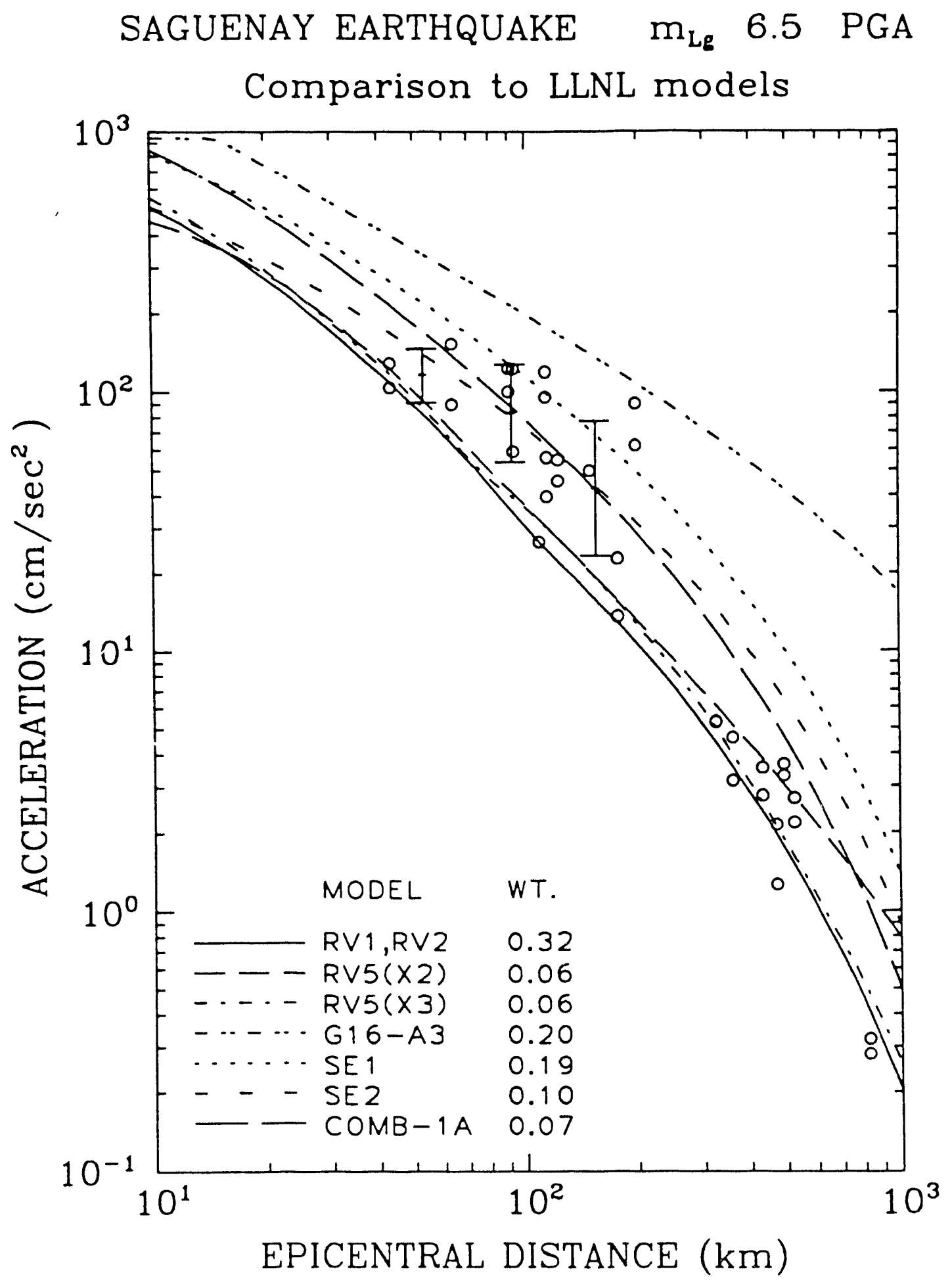

Figure 3-13. Peak ground accelerations from the Saguenay earthquake (circles) are compared to predictions by the LLNL attenuation functions. The error bars represent the logarithmic mean $\pm \sigma$ of amplitudes in the following distance ranges: $40-70 \mathrm{~km}$. $70-120 \mathrm{~km}$. and $120-200 \mathrm{~km}$. 
ENA AND INTRAPLATE DATA $\mathrm{m}_{\mathrm{Lg}}$ 5.6-6.5 PSV $(1 \mathrm{~Hz})$

Comparison to EPRI models

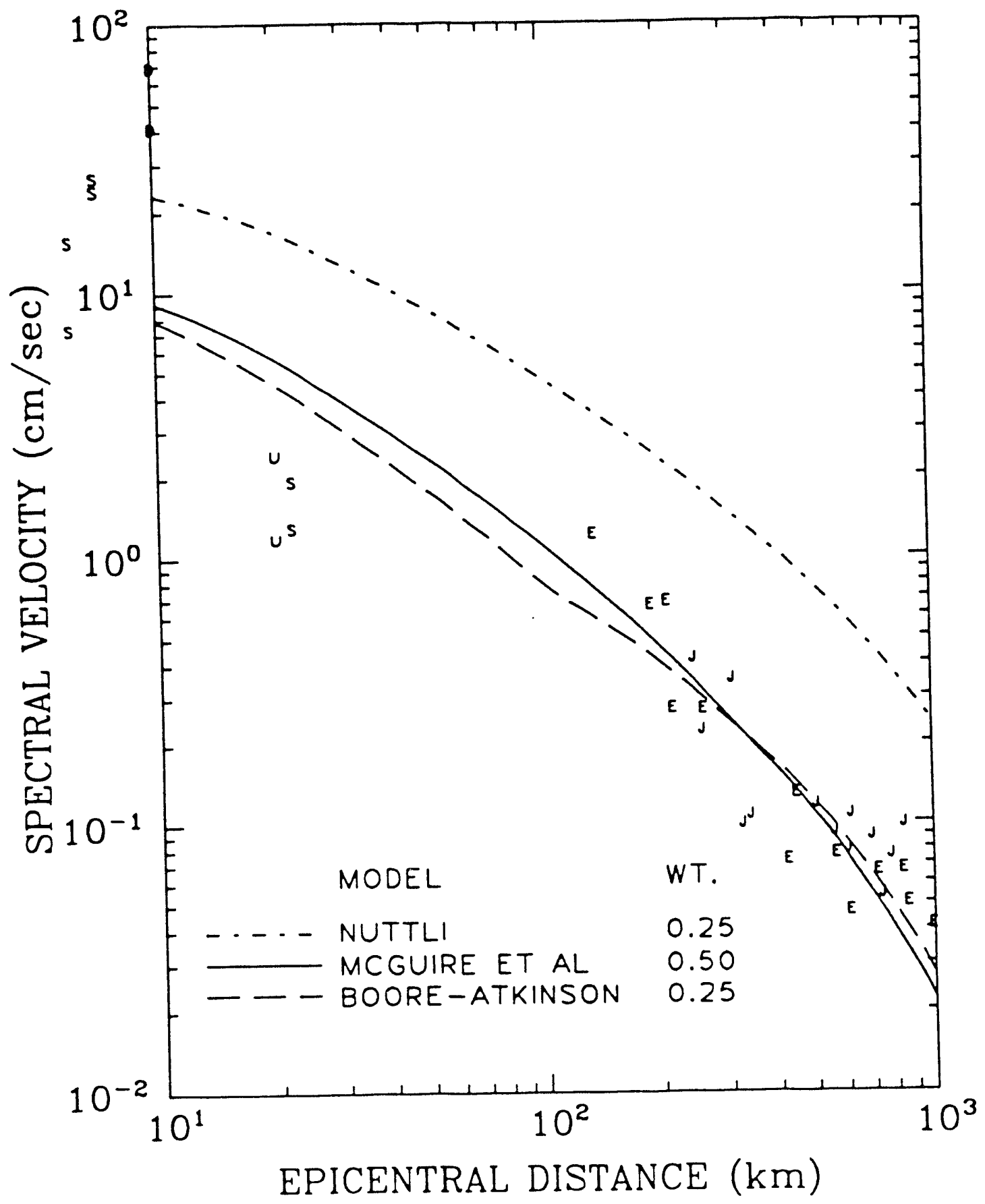

Figure 3-14. 1-Hz spectral velocities from other intraplate earthquakes with magnitudes 5.5 to 6.5 are compared to predictions by the EPRI attenuation functions. All data are scaled to $m_{6 L_{9}} 6$ using the model in (4). See table 3.2 for symbols. 


\section{ENA AND INTRAPLATE DATA $\mathrm{m}_{\mathrm{Lg}}$ 5.6-6.5 PSV $(1 \mathrm{~Hz})$ Comparison to LLNL models}

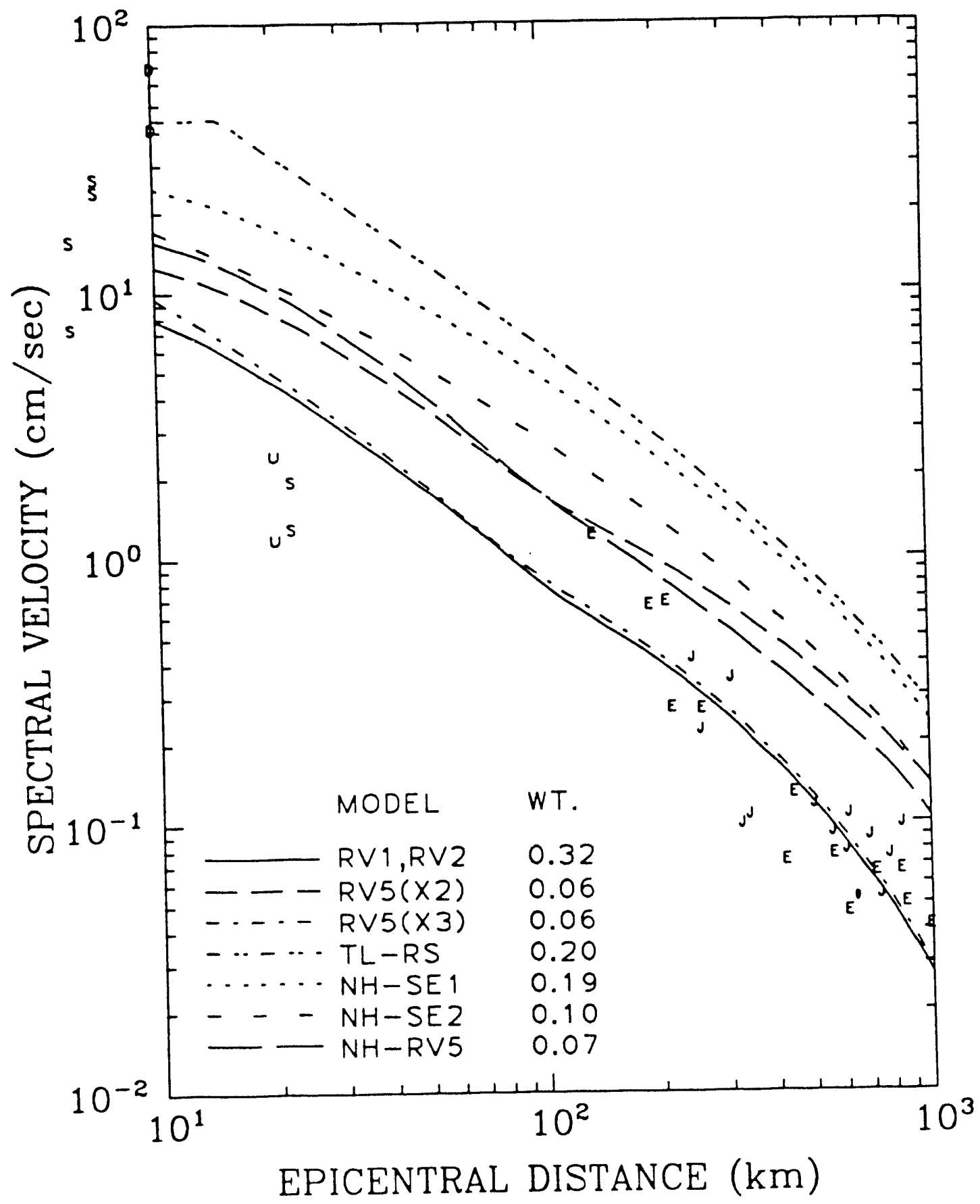

Figure 3-15. 1-Hz spectral velocities from other intraplate earthquakes with magnitudes 5.5 to 6.5 are compared to predictions by the LLNL attenuation functions. All data are scaled to $m_{b L g} 6$ using the model in ( 1 ). See table $3-2$ for s 5 mbols. 


\section{ENA AND INTRAPLATE DATA $\mathrm{m}_{\mathrm{Lg}} \quad 5.6-6.5 \mathrm{PSV}(2 \mathrm{~Hz})$ Comparison to EPRI models $(2.5 \mathrm{~Hz})$}

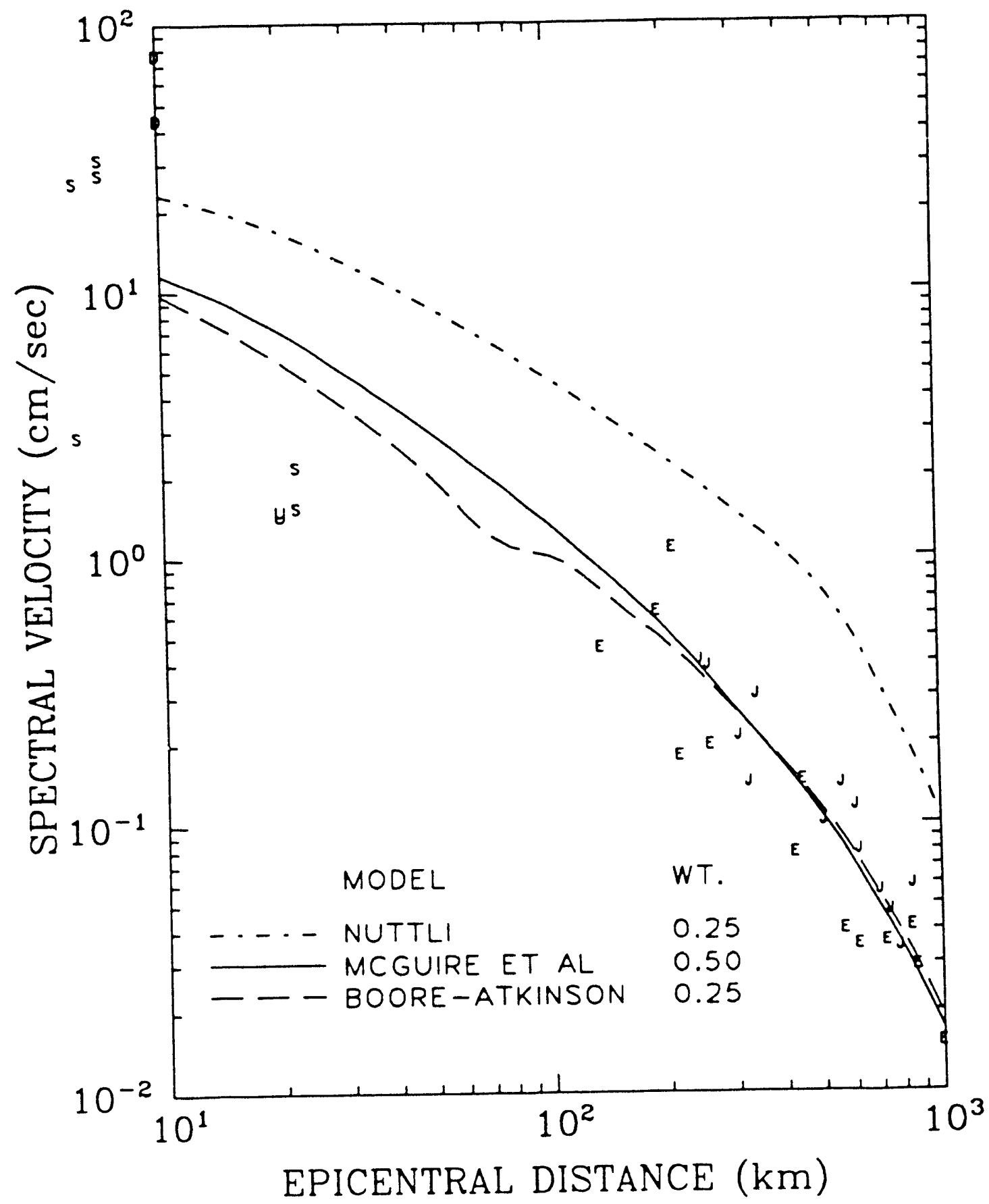

Figure 3-16. 2.5-11z spectral velocities from other intraplate earthquates with magnitudes 5.5 to 0.5 are compared to predictions by the EPRI attenuation functions. All data are scaled to $m_{b L_{3}} G$ using the model in (1). See table $3-2$ for symbols. 


\section{ENA AND INTRAPLATE DATA $\mathrm{m}_{\mathrm{Lg}} \quad 5.6-6.5 \mathrm{PSV}(2 \mathrm{~Hz})$ \\ Comparison to LLNL models $(2.5 \mathrm{~Hz})$}

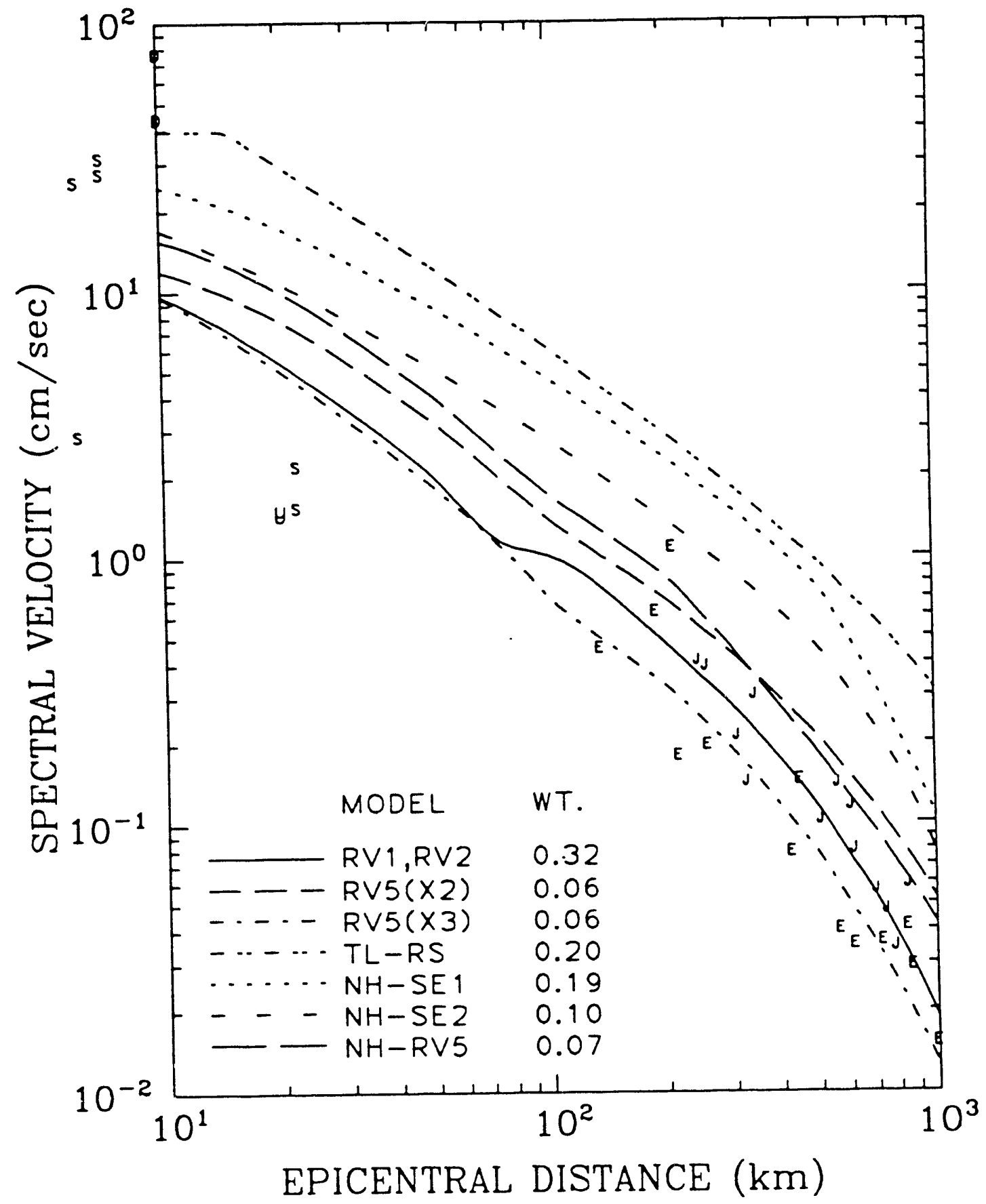

Figure 3-17. 2.5- Hz spectral velocities from other intraplate earthquakes with magnitudes 5.5 to 6.5 are compared to predictions by the LLNL attenuation functions. All data are scaled to $m_{b L_{g}} 6$ using the model in (1). See table 3-2 for symbols. 


\section{ENA AND INTRAPLATE DATA $\mathrm{m}_{\mathrm{Lg}}$ 5.6-6.5 PSV(5 Hz) \\ Comparison to EPRI models}

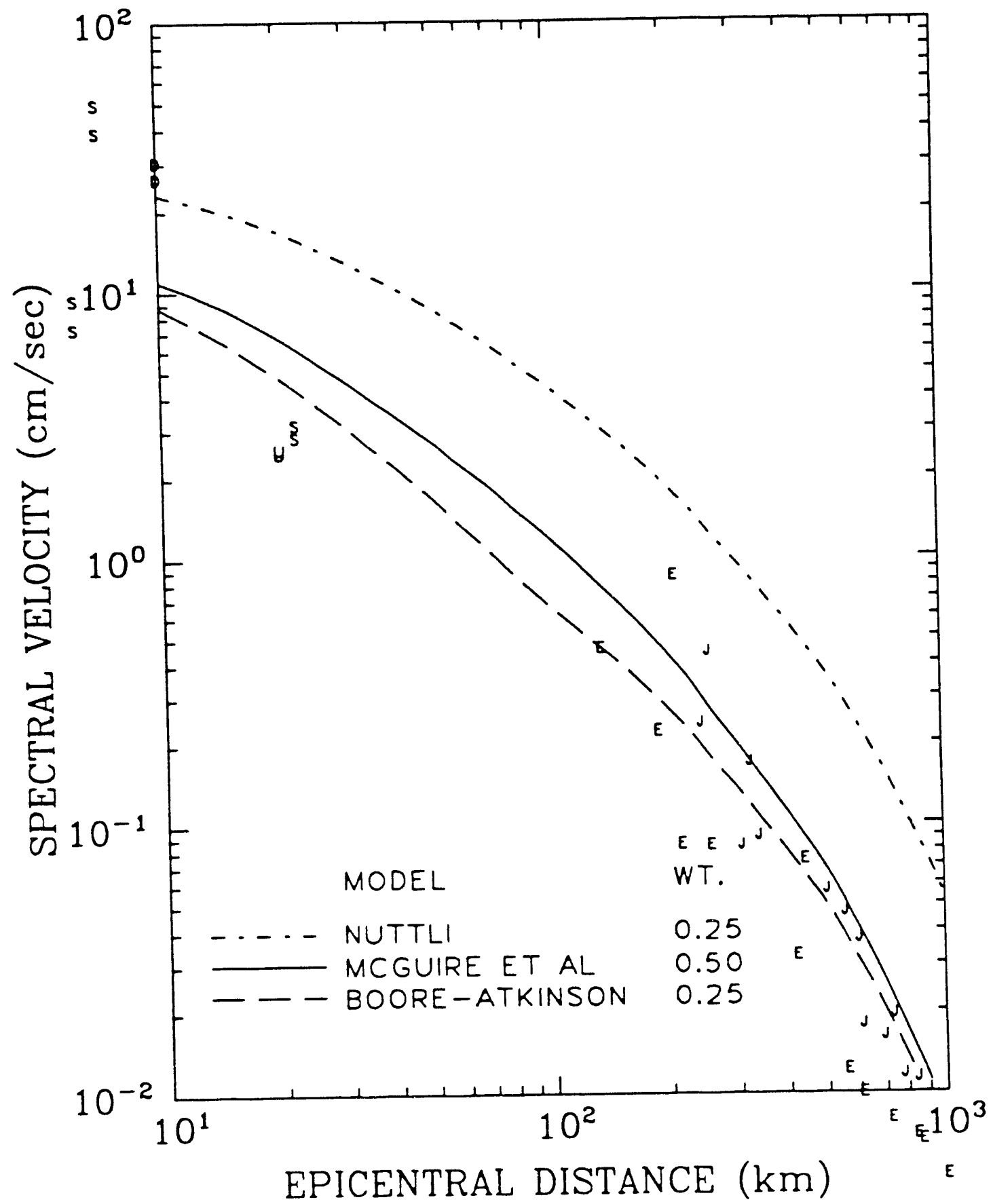

Figure 3-18. 5-Hz spectral velocities from other intraplate earthquakes with magnitudes 5.5 to 6.5 are compared to predictions by the EPRI attenuation functions. All data are scaled to $m_{t L_{3}} 6$ using the model in (1) . See table 3.2 for symbols. 
ENA AND INTRAPLATE DATA $\mathrm{m}_{\mathrm{Lg}}$ 5.6-6.5 PSV $(5 \mathrm{~Hz})$

Comparison to LLNL models

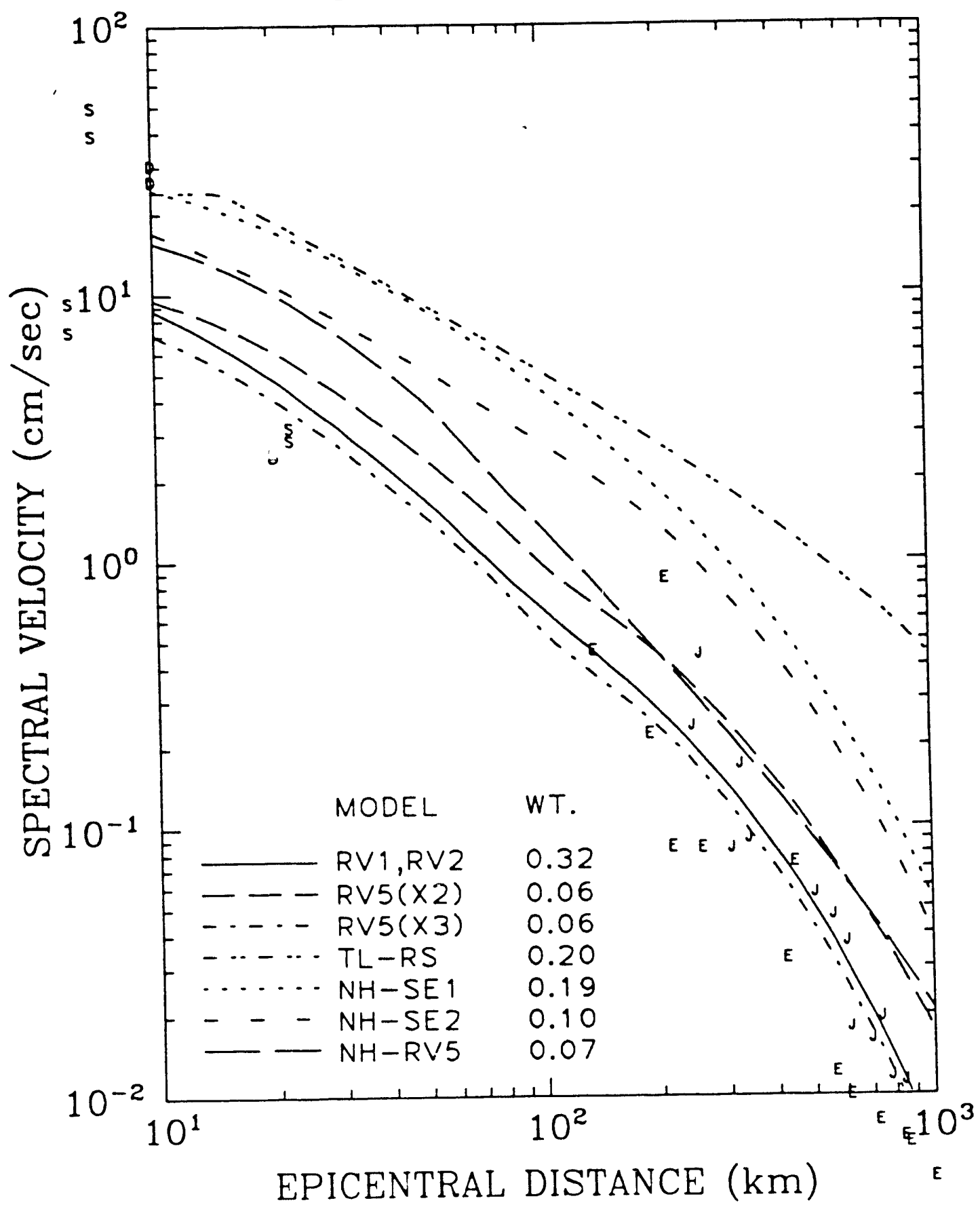

Figure 3-19. 5- Hz spectral velocities from other intraplate earthquakes with magnitudes 5.5 to 6.5 are compared to predictions by the LLNL attenuation functions. All data are scaled to $m_{b L_{g}} 6$ using the model in (4). See table $3-2$ for symbols. 


\section{ENA AND INTRAPLATE DATA $\mathrm{m}_{\mathrm{Lg}} \quad 5.6-6.5 \quad \mathrm{PSV}(10 \mathrm{~Hz})$ \\ Comparison to EPRI models}

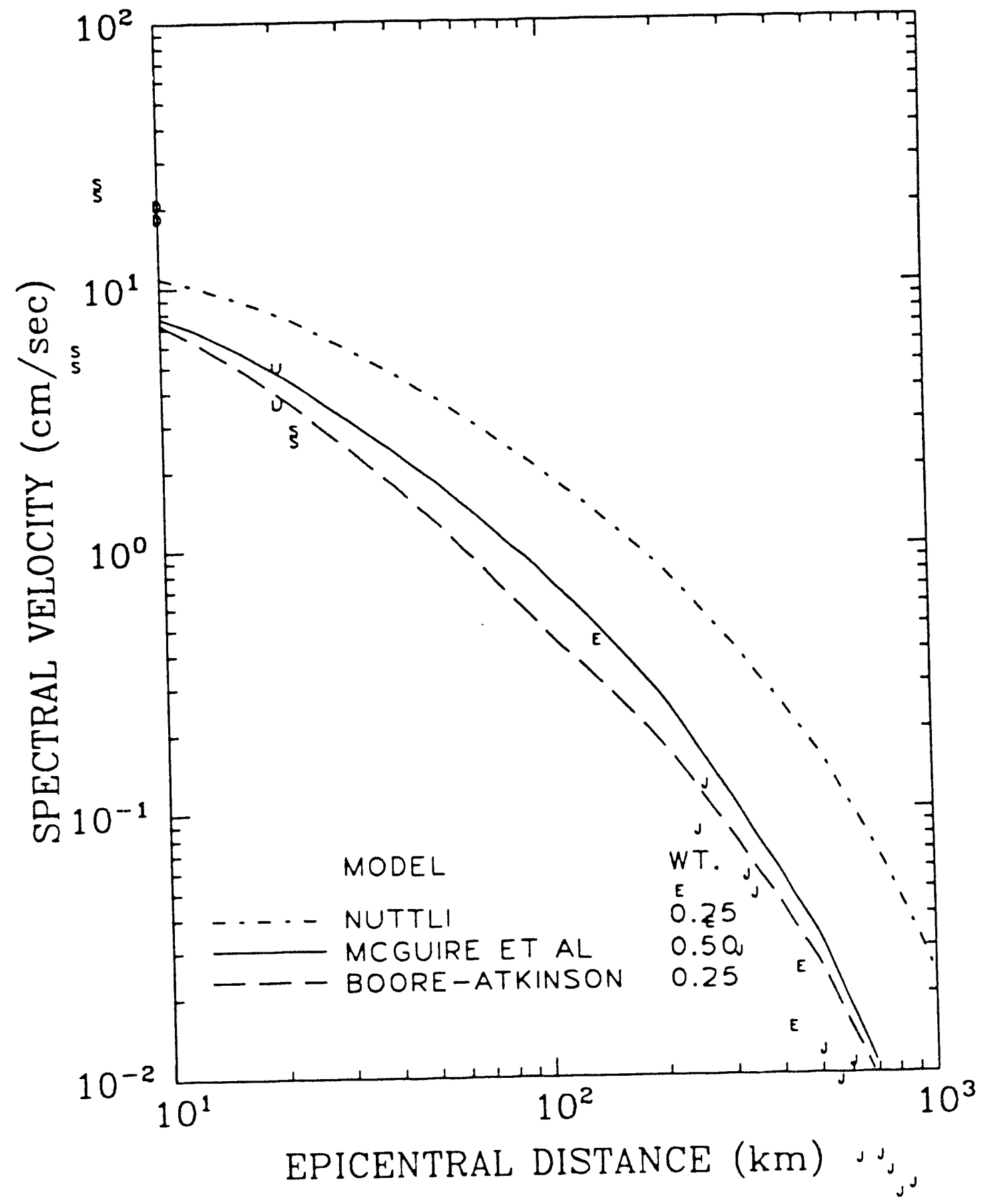

Figure 3-20. 10- $\mathrm{Hz}$ spectral velocities from other intraplate earthquakes with magnitudes 5.5 to 6.5 are compared to predictions by the EPRI attenuation functions. All data are scaled to $m_{t L, g} 6$ using the model in ( 1 ). See table 3.2 for symbols. 


\section{ENA AND INTRAPLATE DATA $\mathrm{m}_{\mathrm{Lg}} \quad 5.6-6.5 \quad \mathrm{PSV}(10 \mathrm{~Hz})$ \\ Comparison to LLNL models}

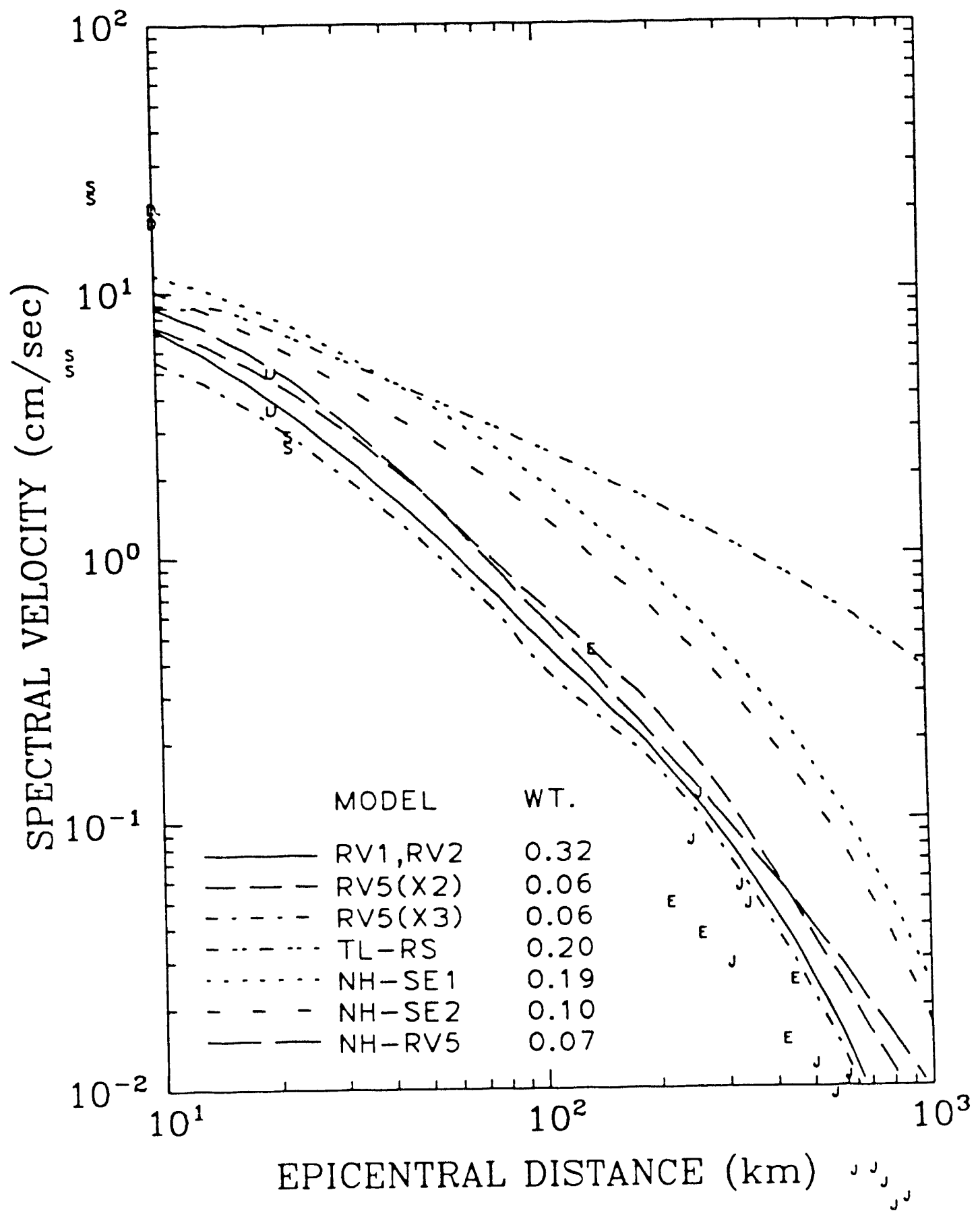

Figure 3-21. 10-11z spectral velocities from other intraplate earthquakes with magnitudes 5.5 to 6.5 are compared to predictions by the LLNL attenuation functions. All data are scaled to $m_{b L g} 6$ using the model in (1). See table $3 \cdot 2$ for symbols. 
ENA AND INTRAPLATE DATA $\mathrm{m}_{\mathrm{L}_{\mathbf{g}}} \quad 5.6-6.5 \quad \mathrm{PSV}(25 \mathrm{~Hz})$ Comparison to EPRI models

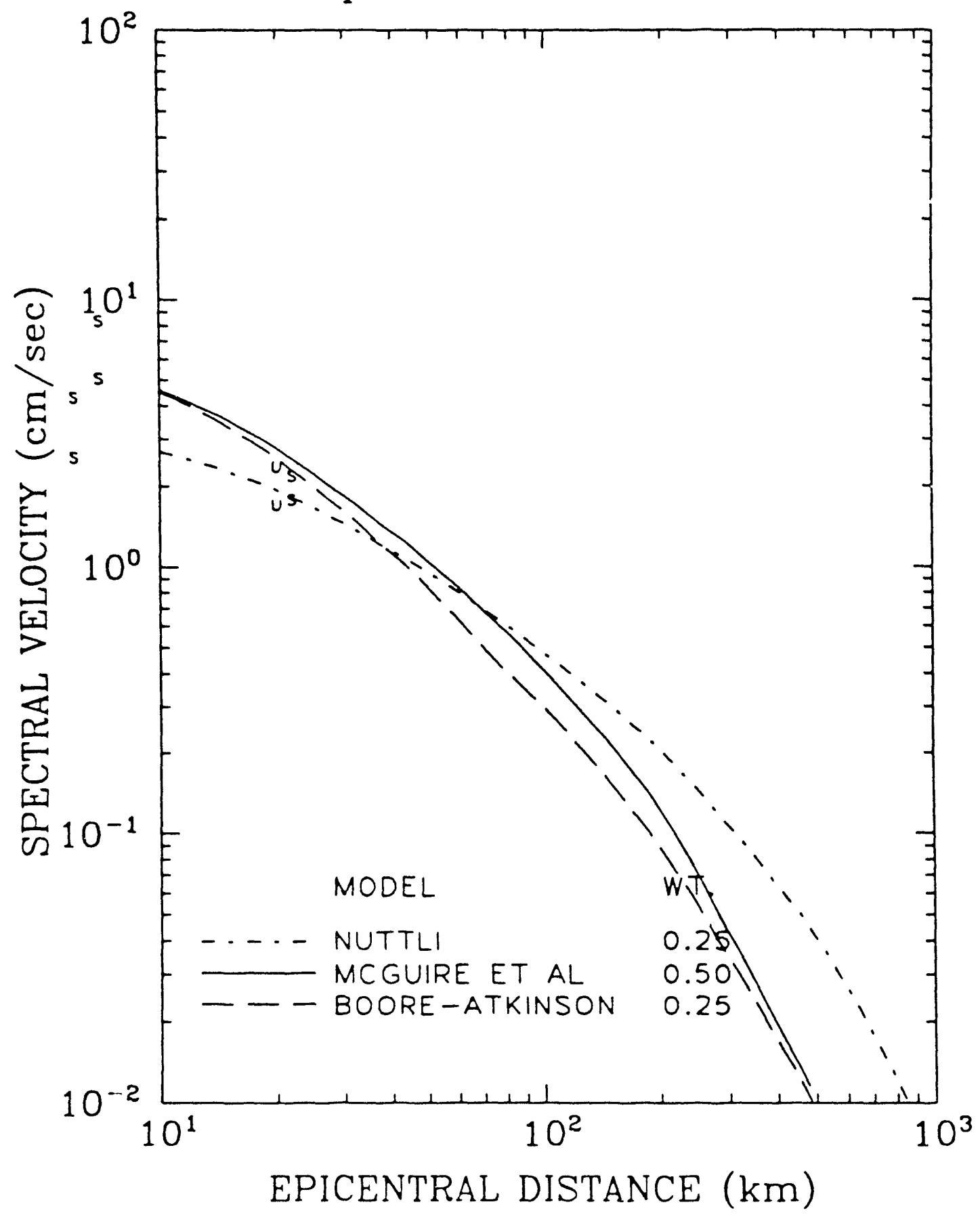

Figure 3.22. $2.5 \mathrm{~Hz}$ spectral velocities from other intraplate earthquakes with magnitudes 5.5 to 6.5 are compared to predictions by the EPRI attenuation functions. All data are scaled to $m_{t L_{g}} 6$ using the model in (4). Sec table $3-2$ for symbols. 


\section{ENA AND INTRAPLATE DATA $\mathrm{m}_{\mathrm{Lg}} 5.6-6.5(25 \mathrm{~Hz})$ \\ Comparison to LLNL models}

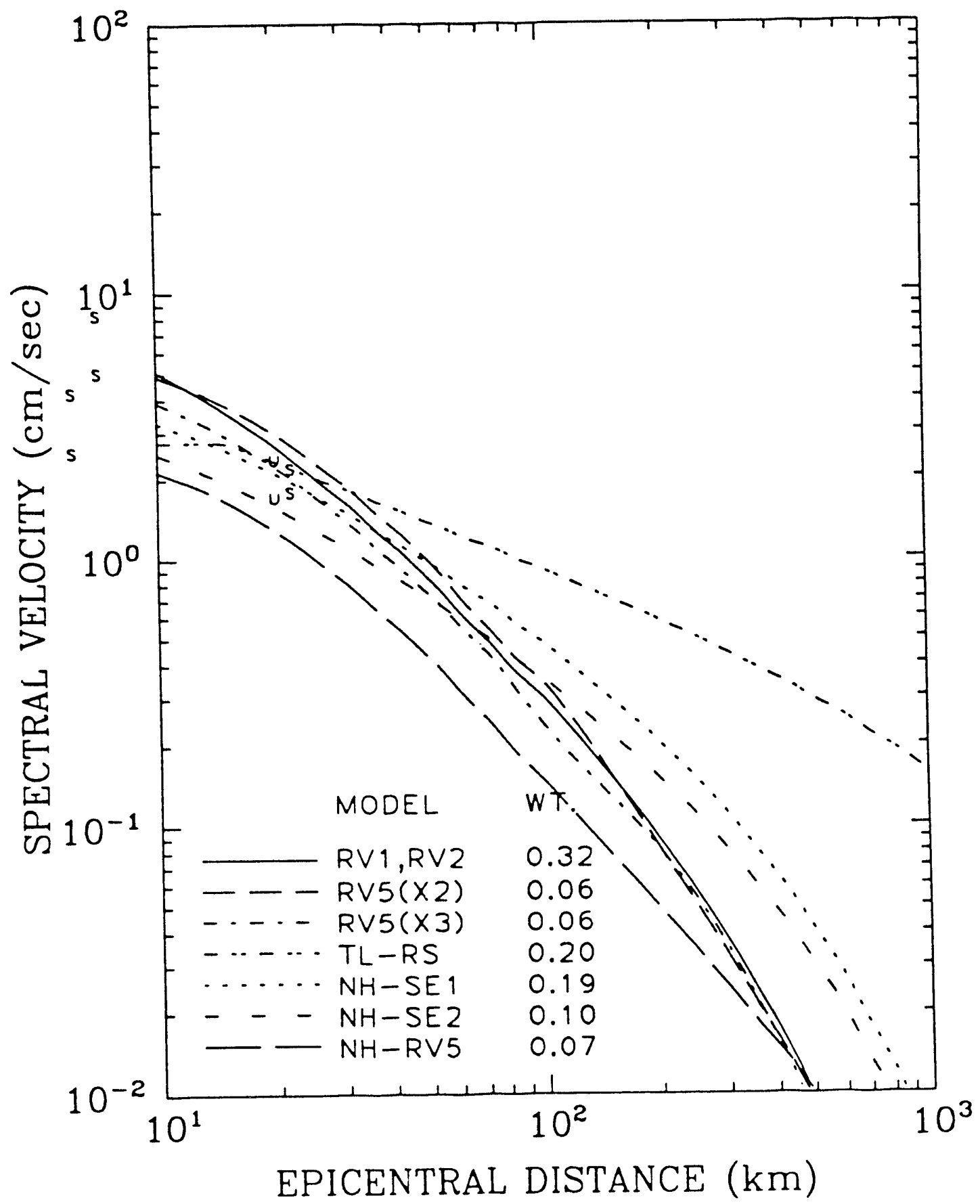

Figure 3-23. 25- $\mathrm{Hz}$ spectral velocities from other intraplate earthquakes with magnitudes 5.5 to 6.5 are compared to predictions by the LLNL attenuation functions. All data are scaled to $m_{b L_{g}} 6$ using the model in (1). See table 3-2 for symbols. 
ENA AND INTRAPLATE DATA $\mathrm{m}_{\mathrm{Lg}}$ 5.6-6.5 PGA

Comparison to EPRI models

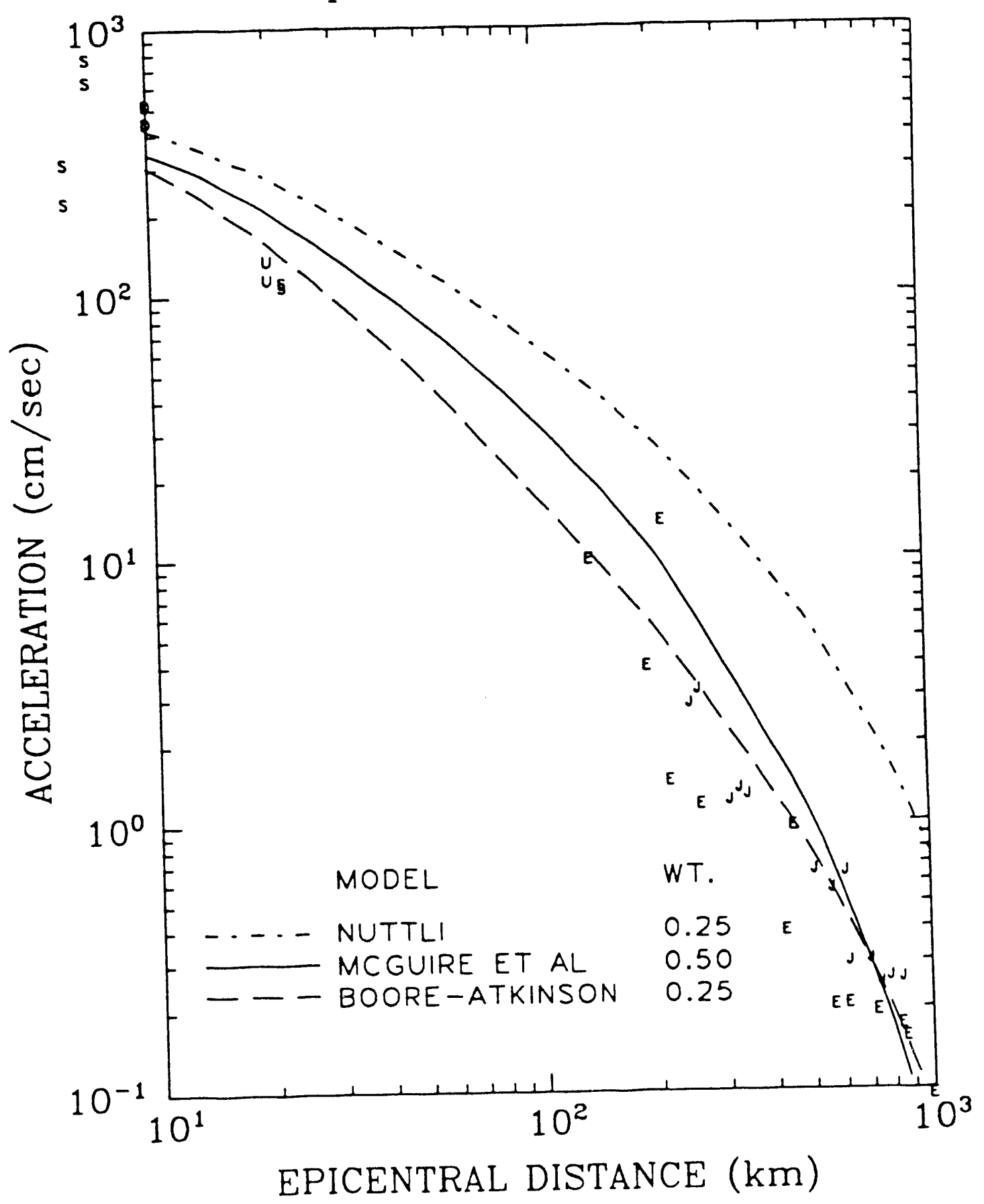

Figure 3-24. Peak ground accelerations fr $m$ other intraplate earthquakes with magnitudes 5.5 to 6.5 are compared to predictions by the EPRI attenuation functions. All data are scaled to $m_{b L_{9}} 6$ using the model in (4). See table 3.2 for symbols. 


\section{ENA AND INTRAPLATE DATA $\mathrm{m}_{\mathrm{Lg}}$ 5.6-6.5 PGA Comparison to LLNL models}

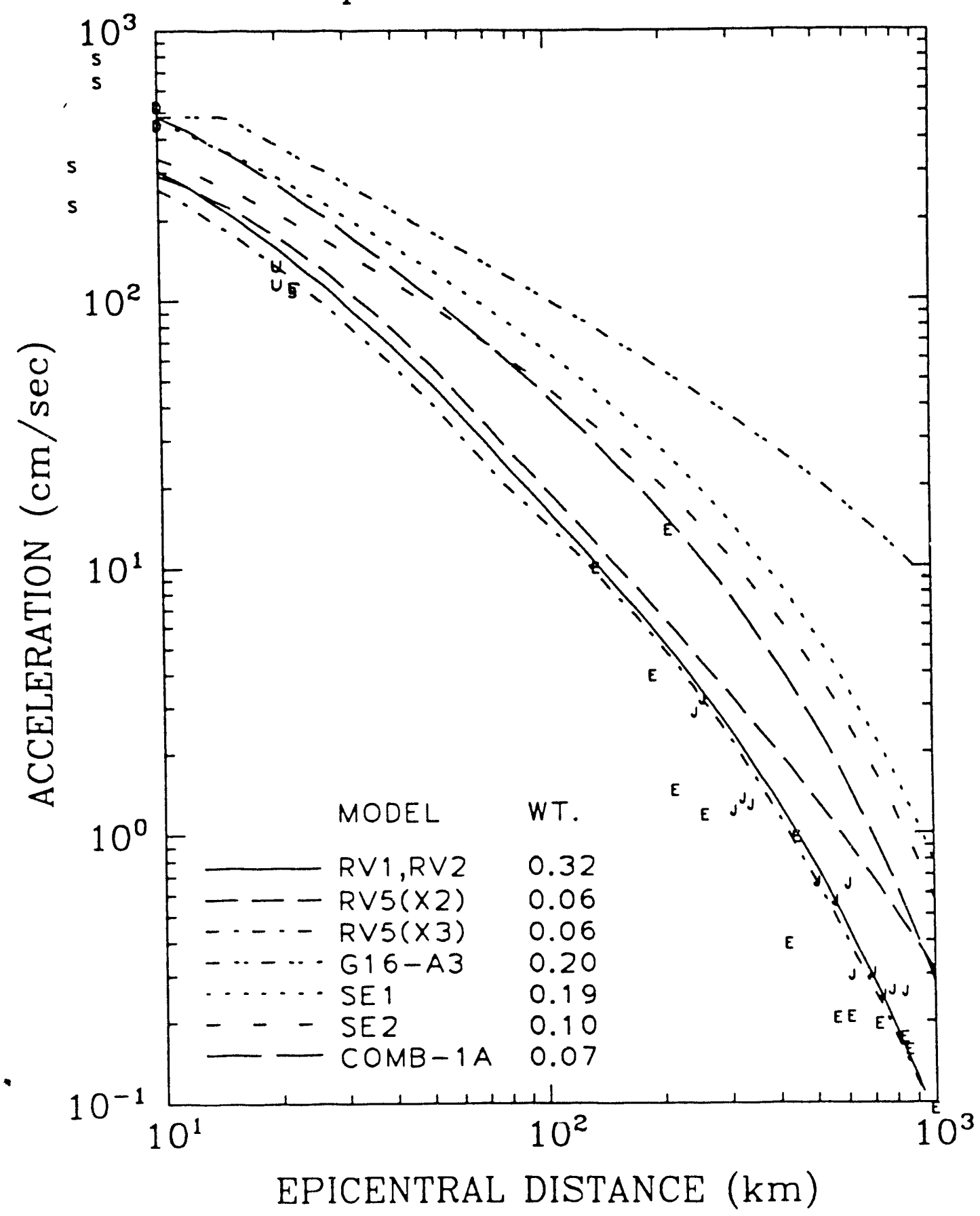

Figure 3-25. Peak ground accelerations from other intraplate earthquaties with magnitudes 5.5 to 6.5 are compared to predictions by the LLNL attenuation functions. All data are scaled to $m_{t L, g} 6$ using the model in (). See table $3-2$ for symbols. 


\section{Section 4}

\section{SURVEY AND EVALUATION OF SEISMOLOGICAL STUDIES OF THE SAGUENAY EARTHQUAKE}

This section reviews studies about the Saguenay earthquake in order to determine the current understanding about this event and its implications on ground motions from potential future earthquakes in eastern North America (ENA). Specifically we want to understand to what extent this earthquake is typical of earthquakes in ENA, regarding its source characteristics and path effects.

\subsection{SOURCE CHARACTERISTICS}

From the engineering point of view, the purpose of studying the source characteristics of the Saguenay earthquake is to characterize the intensity of energy release at different frequencies, and the time window during which this release takes place. The source characteristics are often described by the Brune model, which has two parameters: the seismic moment and the stress drop. The seismic moment is a measure of earthquake size and is proportional to the energy release at very los frequencies. The stress drop controls the ratio of high-frequency to low-frequency energy. A standard assumption for ENA is that the stress drop is independent of seismic moment and equal (on average) to 100 bars $\left(10^{8} \mathrm{dynes} / \mathrm{cm}^{2}\right)$. Because damage to structures is caused by high-frequency energy (i.e., 1 to $20 \mathrm{~Hz}$ ), stress drop is a parameter of large engineering significance.

Somerville et al. (1) used seismograph records at regional and teleseismic distances to infer a seismic moment of $5 \times 10^{24}( \pm 25 \%)$ dyne-cm and a source duration of $1.9( \pm 30 \%) \mathrm{sec}$ for the Saguenay earthquake. They also obtained a centroid depth of $26 \mathrm{~km}$. These seismic moment and source duration correspond to a stress drop of 160 bars (with an uncertainty of a factor of 2.3). This estimate is compatible with the average stress drop of 120 bars obtaincd from 13 moderate and large ENA earthquakes using the same method (2). Figure $4-1$ shows the scismic moments and source durations of the Saguenay earthquake and the other earthquakes studied by (2). The above results suggest that the Saguenay earthquatie source. as seen through scismographs at regional and teleseismic distances (i.e., at frequencies of 1 Hz or lower) did not have an unusually high stress drop. The depth of $26 \mathrm{~km}$ is unusual. however, as the typical depth of larger earhquakes in EXA is $51015 \mathrm{~km}$ (1). The onl! 
earthquake having a comparable depth was the 1968 Illinois earthquake, which had a depth of $25 \mathrm{~km}$.

Atkinson and Boore (3) Boatwright and Choy (4) have studied the source characteristics of the Saguenay earthquake in the frequency domain. Atkinson and Boore use the accelerograph data used in Section 3, while Boatwright and Choy use p-wave records at teleseismic distances. Both studies find that the Saguenay earthquake had an unusual source spectrum, which differs substantially from the typical Brune spectrum. Figure 4-2 shows the Fourier spectra of the two horizontal components at station S16 (i.e., the station closest to the epicenter), and compares them to the theoretical spectra calculated using the Brune model and various values of the stress drop. This figure shows that no value of stress drop fits the observed spectrum, and that a very high value is required in order to fit the spectrum at frequencies higher than $5 \mathrm{~Hz}$. Boaturight and Choy (4) have observed similar specral shapes. This same effect is observed in Figures 3-2 through 3-13, by concentrating on the data at shorter distances. According to (5), this is a source effect and not caused by wave propagation because the foreshocks and aftershocks do not show it.

Similar observations have been made by Boatwright and Choy (4) from teleseismic records from other large earthquakes in ENA. They have proposed a more complex model of the seismic source, which provides a better fit to these observations.

The $\omega$-square based attenuation functions used in the EPRI and LLNL studies $(\underline{6,7,8})$ quantify earthquake size through $m_{b L_{g}}$ and back-figure an "effective" seismic moment from $m_{b L_{3}}$ and a stress drop of 100 bars (as opposed to directly using the seismic moment). This approach ${ }^{1}$ is less sensitive to the shape of the the source spectrum at low frequencies. Figure 4-3 shows the horizontal response spectra from station S16, and compares them to the predictions for $m_{b L_{g}} 6.5$ by the attenuation functions in ( $\underline{z}$, see Section 2 ). At low frequencies. predictions are significantly higher than observations. At high frequencies, predictions arc consistent with observations, given the variability of ground motions.

\subsection{WAVE-PROPAGATION EFFECTS}

Investigators have modeled the propagation of seismic waves from the Saguenay earthquatic (9.1.10) from the source to the various stations, including waves that are reflected and refracted at the various layer interfaces in the earth's crust. The unusual depth of this earthquate puts the earthquake source near two major layer interfaces: i.e. the Conrad and

\footnotetext{
${ }^{1}$ This approach is consistent with the EPRI seismicily catalog. Which uses mtl.3 as the measum of earthouatie size.
} 
Moho discontinuities. Figure 4-3 shows the various waves that contribute significantly to ground motions within $200 \mathrm{~km}$ of the epicenter. At short distances (approximately 0 to 60 $\mathrm{km}$ ), the direct shear wave is dominant. At distances of approximately $60 \mathrm{~km}$, the shcar waves reflected from the Conrad and the Moho become important as their incidence angles become shallow and most or all of their energy is reflected. In addition, the travel paths of these waves are only slightly longer than that of the direct wave. Ground motions at these distances are due to the superposition of direct and reflected waves.

Due to the large focal depth of the Saguenay earthquake, and to its proximity to the Conrad and Moho discontinuities, reflections from these discontinuities are unusually strong and become dominant at relatively short distances (1).

By taking these phenomena into account, the above investigators are able to explain the variation of amplitudes with distance in the Saguenay earthquake. They predict no decay in amplitude between 40 and $120 \mathrm{~km}$, as observed (see Figures 4-6 and 4-7). These investigators do not predict the high amplitudes recorded at station DCKY. Also, (1) predicts higher than observed ground motions at station SM16 (i.e., at the closest distance), but the reason for this overprediction is well understood ${ }^{2}$.

For earthquakes with typical source depths, the effects of crustal structure are still present $(11,12,13)$, but they are somewhat less pronounced and become dominant at longer distances (e.g., $80 \mathrm{~km}$ ). As a result, amplitudes within $100 \mathrm{~km}$ of the epicenter deviate only slightly from the typical $1 / R$ dependence. Figure $4-\tau$ shows the effect of source depth on the predictions by Somerville et al. (1). Deviations from the $1 / R$ trend become even smaller if one averages over uncertain depths and source mechanisms. (see Figures 4- 8 and 4-9).

\subsection{SUMMARY}

The study by Somerville et al. (1) suggests that the Saguenay earthquake had a stress drop slightly higher than average for eastern North America, but well within the typical event-

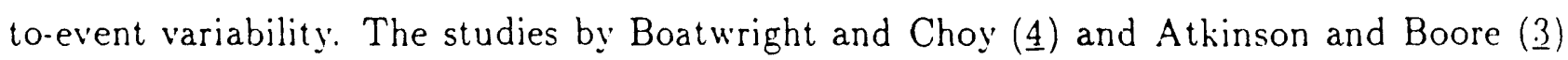
suggest that spectrum from this earthquate deviates from the assumptions of the standard source model. These these deviations have a moderate effect on predictions. as long as earthquake size is quantified by $m_{6 L_{3}}$.

\footnotetext{
2The orientation of this station relative to the earthquake source coincides with one of the peats of the SV-wave radiation pattern (1). Wave scattering caused by small-scale heterogeneity of the earth's crust tends to smooth out these peats. especially at high frequencies. This scattering is not included in the model of ( 1$)$.
} 
The significant deviation from a $1 / \mathrm{R}$ decay with distance within $100 \mathrm{~km}$ is caused by the large focal depth $(26 \mathrm{~km})$, which is unusual for moderate to large earthquakes in eastern North America. The effect of this depth is to cause post-critical reflections and correspondingly high amplitudes at distances around $100 \mathrm{~km}$. As a result, the data show no apparent attenuation for the distance range $40-120 \mathrm{~km}$. Thus, the distance dependence of the Saguenay data is explained in terms of a well-understood physical phenomenon.

\subsection{REFERENCES}

1. P. Somerville, J. McLaren, C. Saikia, and D. Helmberger. "The 25 November, $198 s$ Saguenay, Quebec, Earthquake Source Parameters and the Attenuation of Strong Ground Motion". Bulletin of the Seismological Society of America, 80:1118-1143, 1990.

2. P. G. Somerville, J. P. McLaren, L. V. LeFevre, R. W. Burger, and D. V. Helmberger. "Comparison of Source Scaling Relations of Eastern and Western North American Earthquakes". Bulletin of the Seismological Society of America, $77(2): 322-346,1987$.

3. G. M. Atkinson and D. M. Boore. Evaluation of Ground Motion Data from the $19 S S$ Saguenay Quebec Earthquake. 1991. manuscript in preparation.

4. J. Boatwright and G. Choy. Acceleration Source Spectra for Large Earthquakes in Northeastern North America. 1991. manuscript in preparation.

5. G. M. Atkinson. "A Comparison of Eastern North American Ground Motion Observations with Theoretical Predictions". Seismological Research Letters, 61(3-4):171180, December 1990.

6. D. M. Boore and G. M. Atkinson. "Stochastic Prediction of Ground Motion and Spectral Response Parameters at Hard-Rock Sites in Eastern North America". Bulletin of the Seismological Society of America, $77(2): 440-467,1987$.

7. R. K. McGuire, G. R. Toro, and W. J. Silva. Engineering Model of Earthquate Ground Motion for Eastern North America. Technical Report NP-60it, Electric Power Research Institute, 1988.

S. G. R. Toro and R. K. McGuire. "An Investigation into Earthquake Ground Motion Characteristics in Eastern North America". Bulletin of the Seismological Society of America, Ti(2):468-489, April 198T.

9. J. Gariel and K. Jacob. "The Saguenay Earthquake of November 25, 19Ss: The Effect of the Hypocentral Depth on the Peak Acceleration: A Modeling Approach". In K. Jacob, editor, The Saguenay Earthquake of November 25, 1988, Quebec. Canada: A Strong Motion Data, Ground Failure Observations, and Prcliminary Interpretations, National Center for Earthquake Engineering Research, 1989.

10. G. Ou and R. Hermann. "A Statistical Model for Ground Motion Produced by. Earthquakes at Local and Regional Distances". Bulletin of the Seismological Socicty of America, 80:1397-1417, 1990.

11. R. II. Burger, P. G. Somerville, J. S. Bartier. R. B. Hermann and D. V'. Helmberger. "The Effect of Crustal Structure on Strong Ground Motion Attenuation Relations in Eastern North America". Bulletin of the Seismolegical Society of America, iT(2):42(14.39. $195 \mathrm{~T}$. 
12. J. S. Barker, P. G. Somerville, and J. P. MacLaren. "Wave Propagation Modeling of Ground Motion Attenuation in the Norhteast United States and Adjacent Canada". In Proceedings: Workshop on Estimation of Ground Motion in the Eastern United States, 1988. EPRI Report NP-5875.

13. J. S. Barker, P. G. Somerville, and J. P. MacLaren. Wave Propagation Modeling of Ground Motion Attenuation in Eastern North America. Technical Report NP-55TT, Electric Power Research Institute, 1988.

14. R. B. Herrmann. "An Extension of Random Vibration Theory Estimates of Strong Ground Motion to Large Distances". Bulletin of the Seismological Society of America, 75:1447-1453, 1985. 


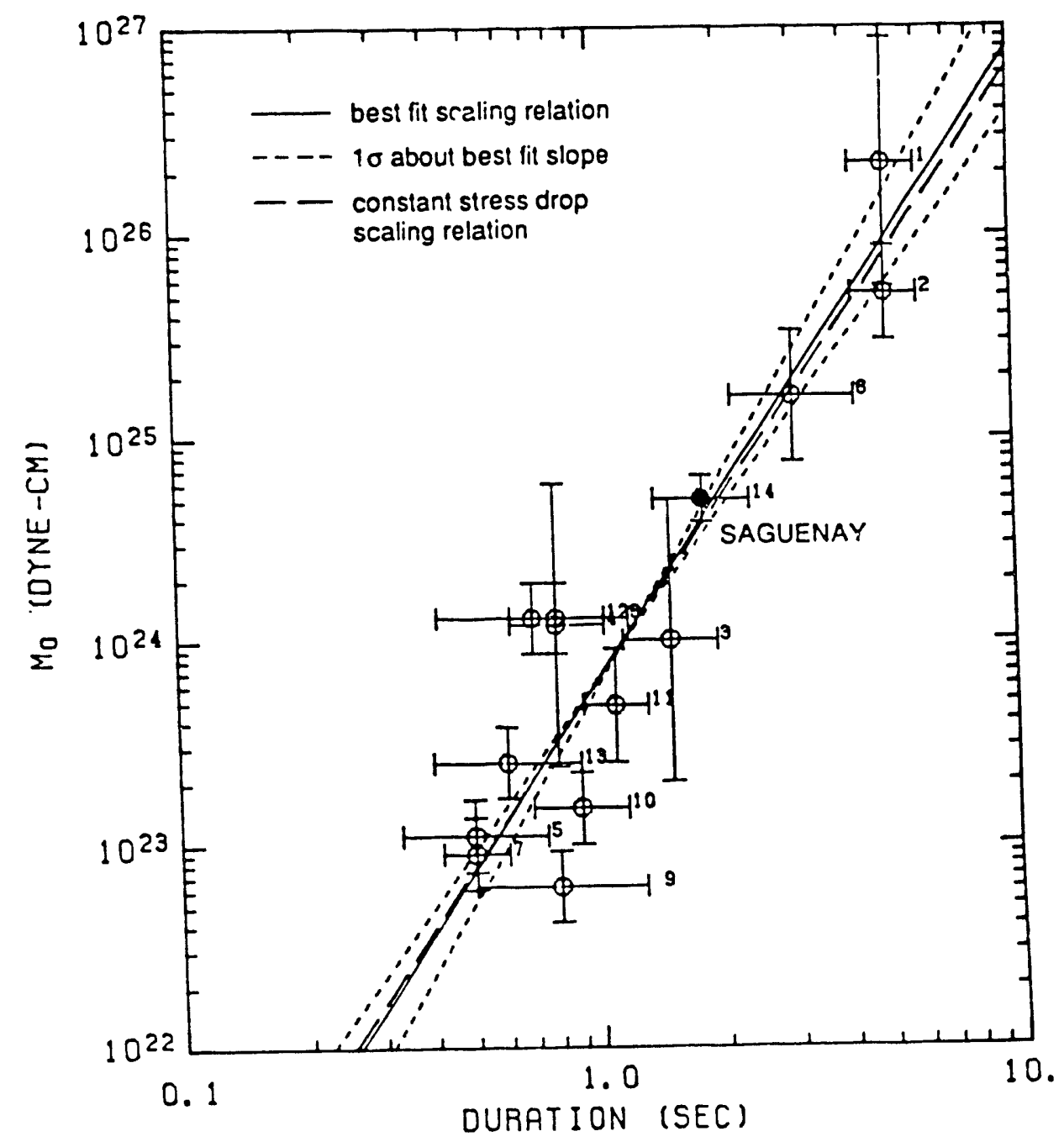

Figure 4-1. Comparison of source parameters of the Saguenay' earthquake with those from other North American earthquakes. Source: (1). 


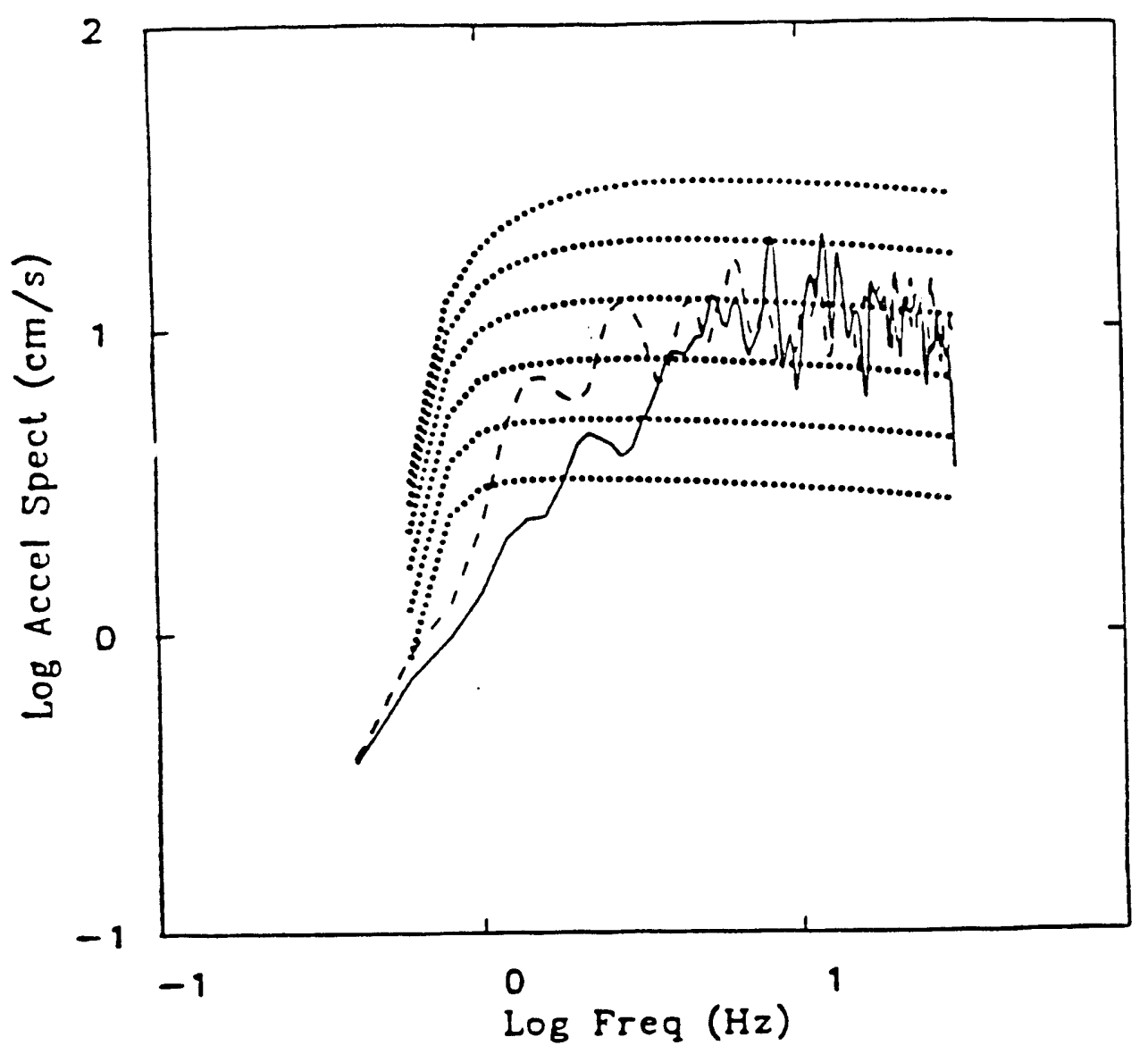

Figure 4-2. Observed spectra of horizontal components at station S16 compared to theoretical Brune spectra for stress drops of 50, 100, 200, 400 , and 800 bars. The abrupt change in slope in the theoretical spectra near $0.5 \mathrm{~Hz}$ represents the same high-pass filter that was applied to the records. Source: ( $\underline{3})$. 


\section{SAGUENAY STATION 16 RESPONSE SPECTRA}

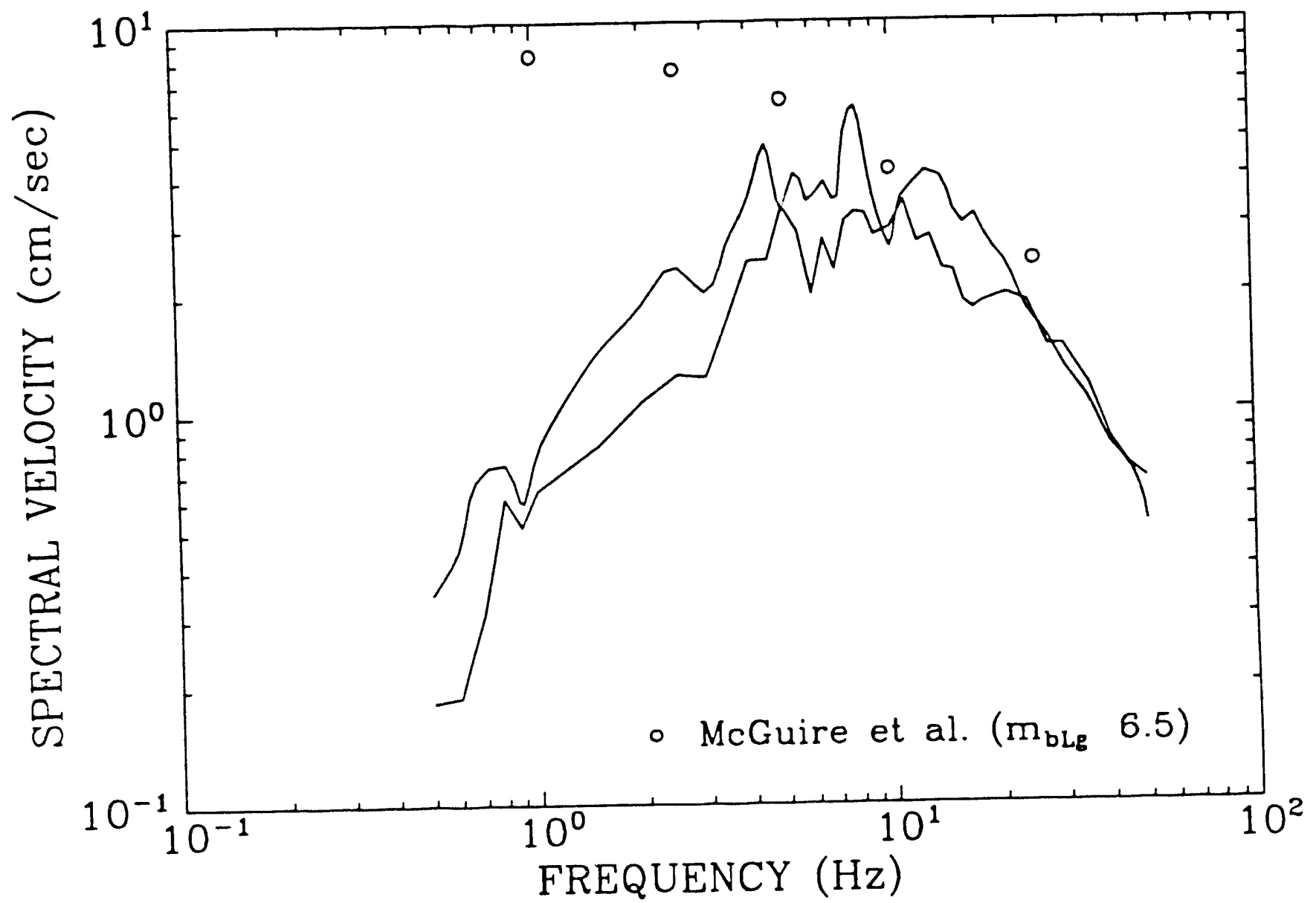

Figure 4-3. Observed response spectra of horizontal components at station S16 compared to predictions by the attenuation functions of $(\underline{I})$ for $m_{b L_{g}} 6.5$. 


\section{a) Distance: 0 to $60 \mathrm{~km}$}

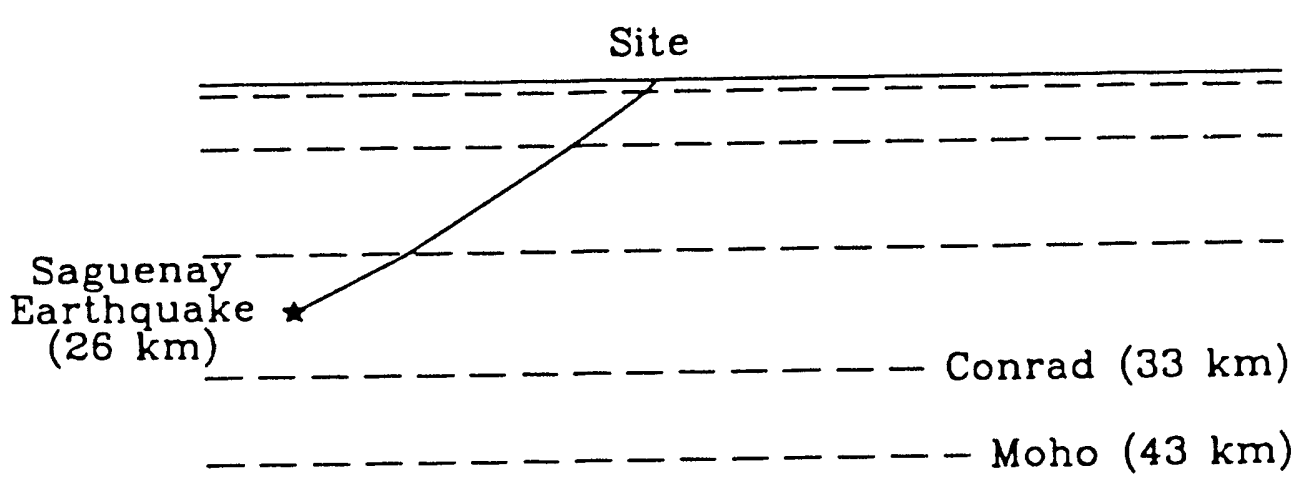

b) Distance: 60 to $200 \mathrm{~km}$

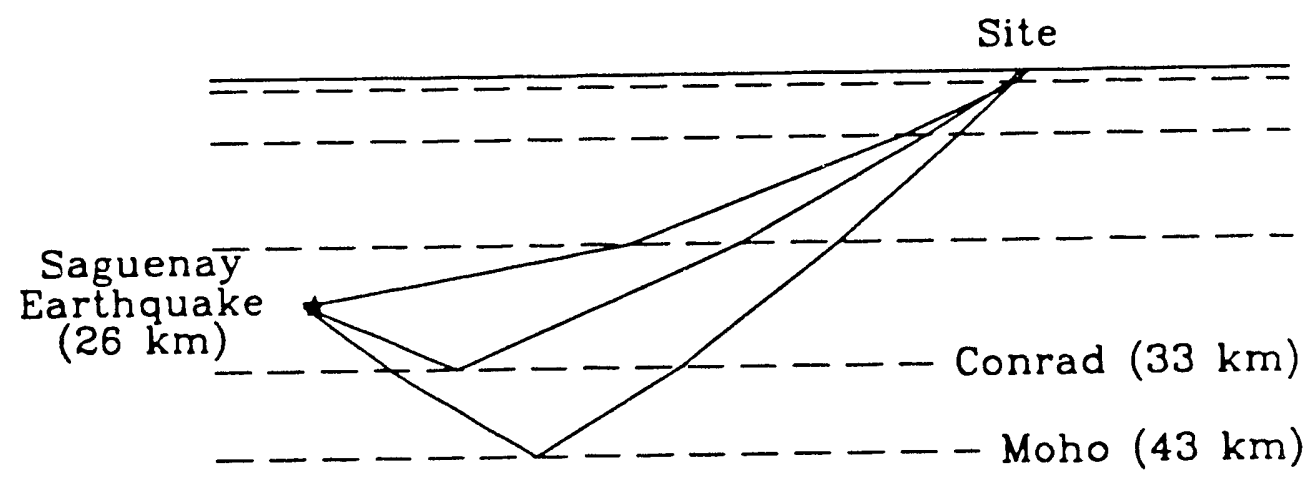

Figure 4-4. Schematic representation of the various waves that contribute to ground motions at shorth and intermediate distances from the Saguenay carthquake. a) At short distances, the direct shear wave is dominant (reflected waves may be present, but their amplitudes are low). b) At intermediate distances, reflected shear waves are significant. The figure shows the direct wave, the Conrad reflection. and the Moho reflection. 


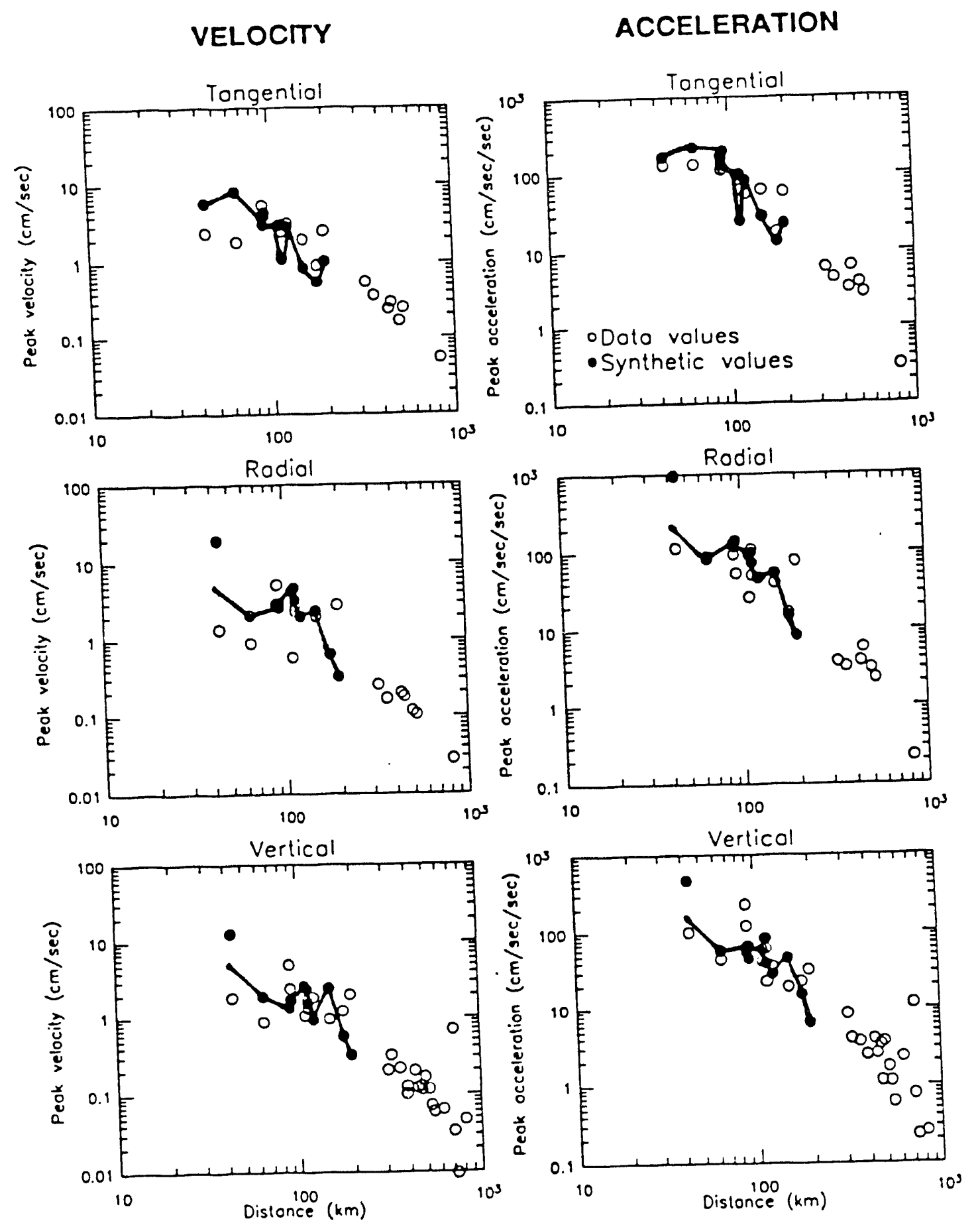

Figure 4-5. Recorded (circles) and synthetic ( 1 , dots and lines) peak velocity and peak acceleration from the Saguenay earthquake as a function of epicentral distance. The lines do not go through the dots at the shorter distance (station S16), because the synthetic ground motions at this station (in the vertical and radial directions) are unrealistically high due to radiation pattern. Modified from (1). 


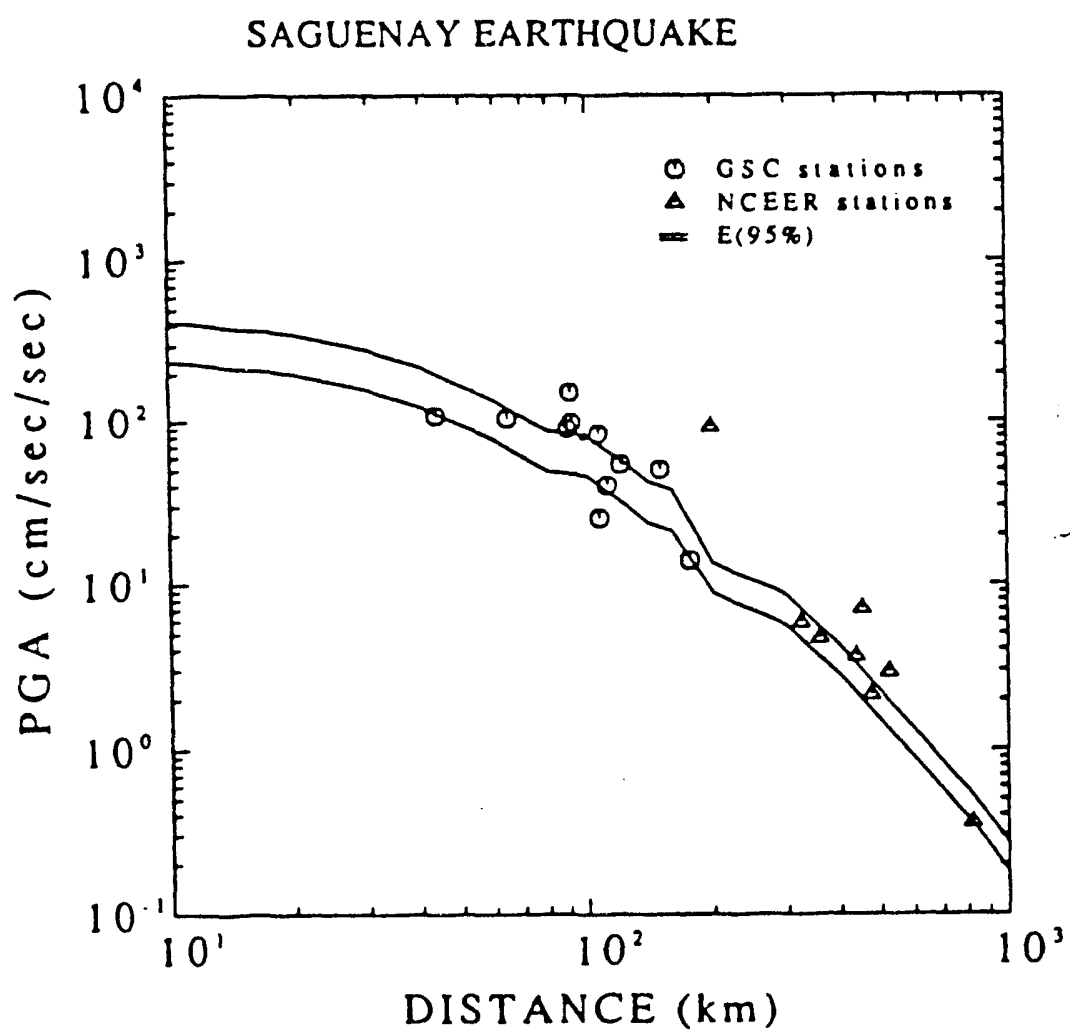

Figure 4-6. Predicted (10, lines) and observed (symbols) attenuation of the mean peak horizontal ground acceleration as a function of epicentral distance for the Saguenay earthquake. Source: (10). Note: the two lines represent $95 \%$ confidence bounds, considering only the variability introduced by random phasing. 


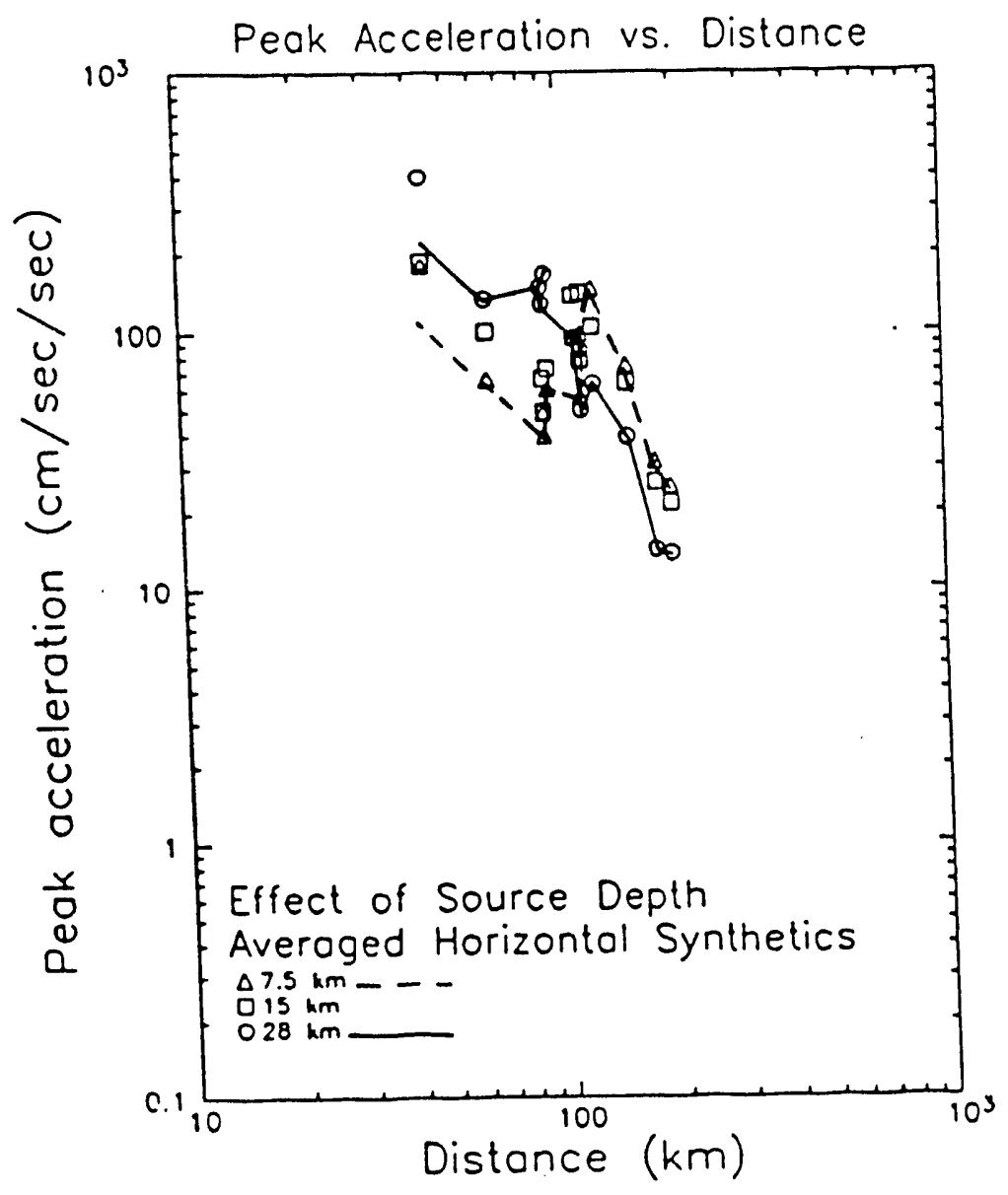

Figure 4- 7 . Synthetic peak acceleration as a function of distance from the Saguenay earthquake for three values of focal depth. The lines do not go through the dots at the shorter distance (station S16), because the synthetic ground motions at this station (in the vertical and radial directions) are unrealistically high due to radiation pattern. Modified from (1). 


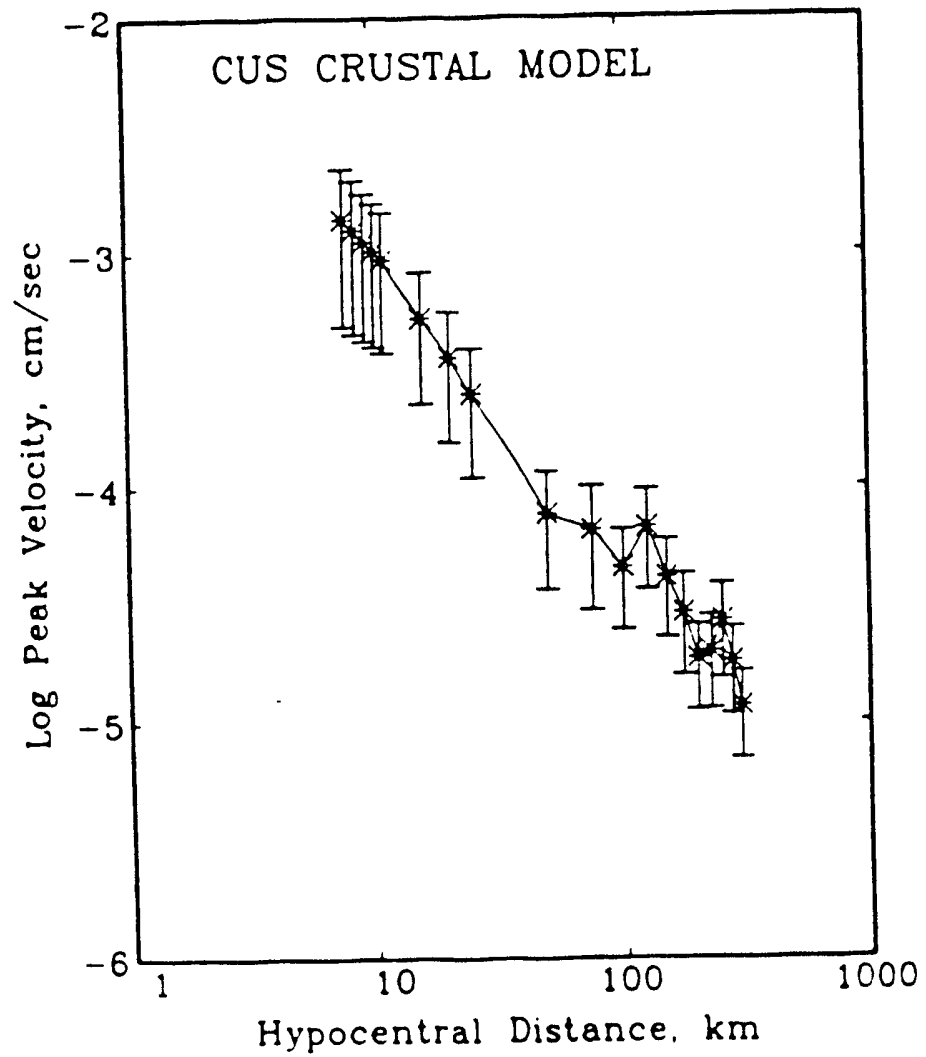

Figure 4-8. Average peak tangential velocity as a function of hypocentral distance for the central U.S. crustal model of Herrmann (14). The average and standard deviations from calculations for 4,536 focal mechanisms are shown. Similar effects are seen on the vertical, radial, and total horizontal components. Source: (11). 


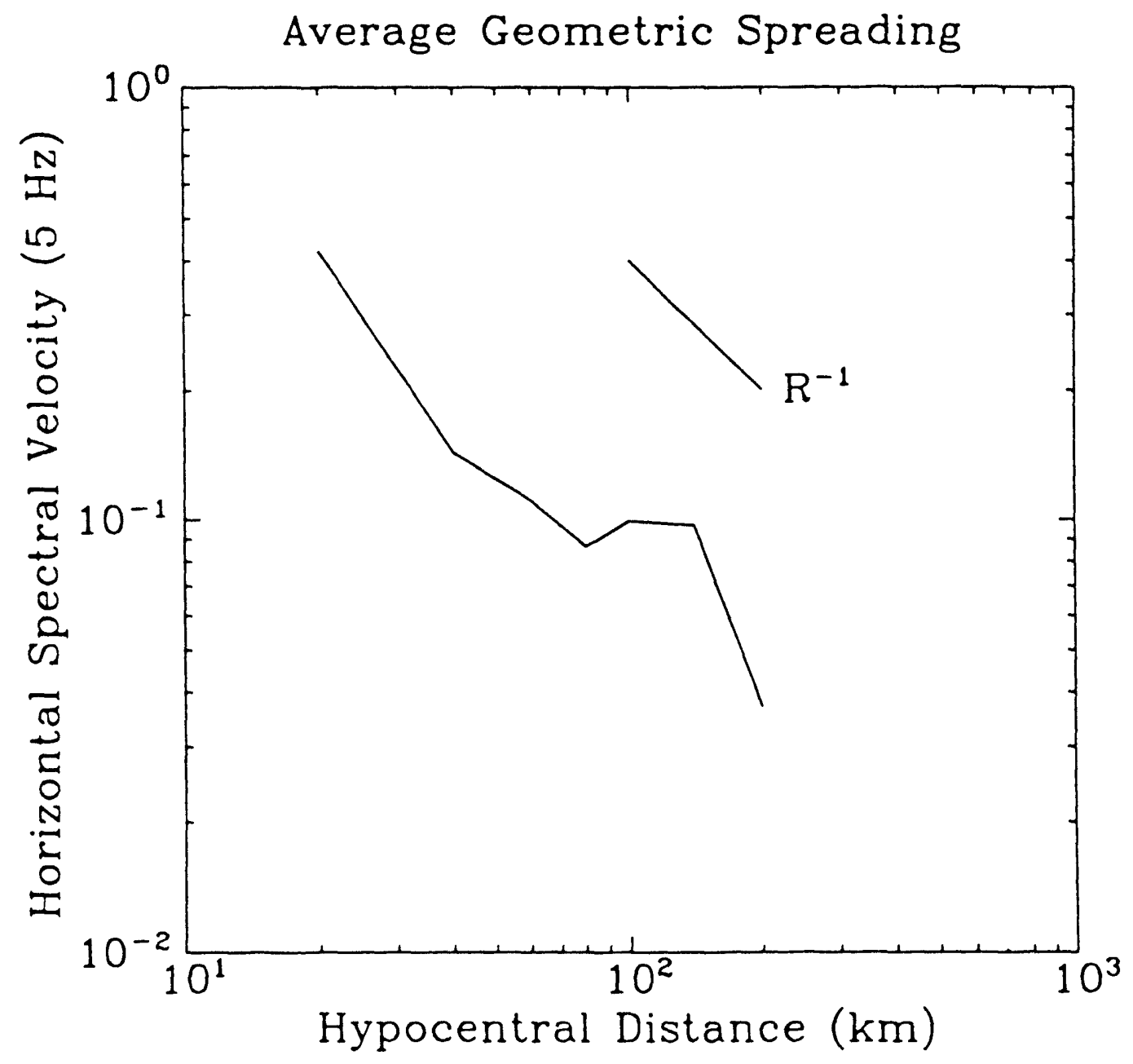

Figure 4-9. Average geometric spreading obtained from the results of Barker et al. (12) for horizontal spectral velocity at $5 \mathrm{~Hz}$. Synthetic seismograms were generated for various ENA crustal profiles, source depths and mechanisms, and earthquake magnitudes. Source: (I). 
Section 5

\section{EXAMINATION OF THE METHODOLOGY USED BY LLNL GROUND MOTION EXPERT 5}

LLNL ground motion expert 5 selected attenuation functions obtained by combining intensity vs. amplitude regressions from California and intensity attenuation relationships from ENA. The following three relationships are used:

$$
\begin{array}{rlrl}
\ln A & =a+b I_{S} \quad(\text { from California) } & & (5-1) \\
I_{S} & =I_{0}+3.2-1.17 \ln R-0.0011 R ; \quad R>15 \mathrm{~km} \quad \text { (from ENA) } & (5-2) \\
I_{0} & =-3.5+2 m_{b} \quad \text { (from ENA) } & & (5-3)
\end{array}
$$

where $A$ represents peak acceleration or spectral velocity, $I_{S}$ represents MMI intensity at the site, and $I_{0}$ represents epicentral intensity (a measure of earthquake size based on the intensity in the epicentral area). For equation 5-1, LLNL expert 5 selected the relationships in $(1$, for PGA) and $(\underline{2}$, for spectral velocity); these relationships are given in Table 51. Equations 5-2 and 5-3 were developed using data from ENA (3.4, respectively). To obtain an attenuation equation for $A$ in terms of $m_{6}$ and $R$, equation 5-3 is substituted into equation 5-2, and the resulting equation is then substituted into equation $5-1$. The resulting attenuation functions are given in Table 5-2 Figure 5-1 contains a graphical representation of the varjous relationships, their origins, and the substitution process.

Although this method permits the construction of attenuation equations for ENA (where accelerometer data were virtually non-existent until a few years ago)-and was used extensively in the past-the method is generally perceived to have two serious sources of error and bias. The first perceived source of error is the very validity of Equations 5-1 and 5-2 for conditions in ENA. The second perceived source of bias is the direct substitution of equations obtained by regression. The remainder of this section examines these two issues.

\subsection{VALIDIT) OF THE BASIC EQUATIONS TO CONDITIONS IN ENA}

Equation 5-1 ahove was developed using data from California. Where instrumental carth. quate records are abundant. There are, however. a number of arguments why the relationship) 
Table 5-1

\section{RELATIONSHIPS BETWEEN \\ INSTRUMENTAL AMPLITUDE \\ AND SITE INTENSITY \\ (derived from California data)}

Sources: $(\underline{1}),(\underline{5}$, Table IV.2.3)

$\ln A=a+b I_{S}$

\begin{tabular}{|c|c|c|}
\hline A† & $a$ & $b$ \\
\hline $\operatorname{PSV}(1 \mathrm{~Hz})$ & -3.50 & 0.86 \\
\hline $\operatorname{PSV}(2 \mathrm{~Hz})$ & -3.37 & 0.84 \\
\hline $\operatorname{PSV}(5 \mathrm{~Hz})$ & -2.49 & 0.66 \\
\hline $\operatorname{PSV}(10 \mathrm{~Hz})$ & -2.29 & 0.54 \\
\hline $\operatorname{PSV}(25 \mathrm{~Hz})$ & -3.08 & 0.48 \\
\hline Accel. & -0.19 & 0.67 \\
\hline $\begin{array}{l}\text { Spectral v } \\
\text { units of } \\
\text { celeration } \\
\mathrm{cm} / \mathrm{sec}^{2} .\end{array}$ & $\begin{array}{l}\text { elocities } \\
\mathrm{cm} / \mathrm{sec} \\
\text { has unit }\end{array}$ & $\begin{array}{l}\text { have } \\
\text { ac- } \\
\text { ts of }\end{array}$ \\
\hline
\end{tabular}

Table 5-2

ATTENUATION EQUATIONS OBTAINED BY LLNL GROUND MOTION EXPERT 5

(Source: J. Savy, personal communication, 19SS)

$$
\ln [A]=a+b m_{b}+c \ln [R]+d R ; \quad R>15 \mathrm{~km}
$$

\begin{tabular}{lrrrr}
$A \dagger$ & $c_{0}$ & $c_{1}$ & $c_{2}$ & $c_{3}$ \\
\hline $\operatorname{PSV}(1 \mathrm{~Hz})$ & -3.71 & 1.70 & -0.993 & $-9.2 \times 10^{-4}$ \\
$\operatorname{PSV}(2.5 \mathrm{~Hz})$ & -3.42 & 1.61 & -0.942 & $-8.8 \times 10^{-4}$ \\
$\operatorname{PSV}(5 \mathrm{~Hz})$ & -2.73 & 1.34 & -0.753 & $-7.3 \times 10^{-4}$ \\
$\operatorname{PSV}(10 \mathrm{~Hz})$ & -2.51 & 1.06 & -0.622 & $-5.8 \times 10^{-4}$ \\
$\operatorname{PSV}(25 \mathrm{~Hz})$ & -3.22 & 0.96 & -0.562 & $-5.2 \times 10^{-4}$ \\
Accel. & 0.27 & 1.34 & -0.754 & $-7.4 \times 10^{-4}$
\end{tabular}

$\dagger$ Spectral velocities have units of $\mathrm{cm} / \mathrm{sec}$ : acceleration has units of $\mathrm{cm} / \mathrm{sec}^{2}: R$ has unts of $\mathrm{km}$. 
between intensity and instrumental ground motion may not be the same in ENA and in California. There are fundamental differences in ground-motion frequency content, duration and wave types between the two regions, especially at the large distances represented in ENA intensity data. These differences affect people's perception of ground shaking, and affect structural damage. Damage is also affected by the types of structures, construction techniques, and soil conditions. For instance, it is simply incorrect to assume that an intensity VII experienced near the epicenter of the 1971 San Fernando earthquake was caused by ground motions with sinnilar peak acceleration and spectral velocities as an intensity VII experienced $400 \mathrm{~km}$ away from the epicenter of the 1811 New Madrid earthquake. These problems are well-known; one of the first investigators to warn about these problems was Trifunac (1).

Even Equation 5-2, which was developed using data from ENA, has problems that are seldom addressed. MMI assessments of pre-instrumental earthquakes are affected by a number of biases. Newspaper accounts may tend to exaggerate reports, in order to report interesting news. The more severe effects in a given locale may be reported, rather than the average or most typical effects.

Also, these reports tend to come from cities and towns, which tend to be located along river valleys or on the shores of oceans and lakes. These locations tend to be underlaid by sediments, which tend to amplify ground motions. Thus, the MMI levels usually reported do not apply to rock conditions.

The processing of intensity data, as performed in ( $\underline{3})$ and most other studies of intensity, introduces additional problems. For each value of intensity, broad isoseismal lines are drawn. which envelop all reports of that intensity' (and also include many reports of lower intensities). An average distance to each isoseismal is then calculated from the area enclosed by the isoseismal. This procedure is biased because it focuses on the extreme reports and because performs averaging of the independent variable (i.e., distance) before performing the regression.

There are a number of other problems with intensity-attenuation data; sce (ㅌ) for an in-depth discussion.

\subsection{VALIDITY OF SLBSTITLTION PROCEDURES}

The straightforward substitution procedure described above is valid for deterministic relationships, but it leads to biased results when applied to Equations 5-1 through 5-3 hecause 
these equations were obtained by regression and Equation 5-1 does not contain terms in magnitude and distance ( $\underline{6})$.

In the absence of terms on magnitude and distance in equation 5-1, the dependence on these parameters (which, as we will argue later, is present in the data), is captured only partially: by coefficient $b$; some of the dependence on magnitude and distance is lost. As a result, the magnitude and distance terms in the final attenuation function (obtained after substitution) are too small ${ }^{1}$.

There are strong reasons why the relationship between site intensity and instrumental amplitude cannot be independent of magnitude and distance. First, the frequency content and duration of ground motions change as a function of magnitude and distance, thus changing the damage potential and perceivability of the ground motions. Second, Bayes' theorem indicates that - unless amplitude and intensity are perfectly dependent-one should expect higher amplitudes from high magnitudes and short distances, whatever the intensity happens to be ${ }^{2}$ Third, regression analyses that have used California data and relationships of the form

$$
\ln A=a+b I_{S}+c M+d \ln R
$$

find that the terms in magnitude and distance are statistically significant and have signs consistent with the Bayes argument above [e.g., $(\underline{7,8})]$.

A useful way to demonstrate the bias introduced by substituting regressions is to perform the whole exercise using data from California. The California data contains both instrumental and intensity data; i.e., California data contain the following information from each ground motion record: $A, I_{S}, M$, and $R$. Having these data, one can perform a direct regression analysis to obtain $\ln A=f(M, R)$. In order to test the substitution procedure, one can perform two regression analyses to obtain $\ln A=f_{1}\left(I_{0}\right)$ and $I_{0}=f_{2}(M, R)$. Substitution of $f_{2}$ into $f_{1}$ yields a relationship that is different from that obtained through the direct regres-

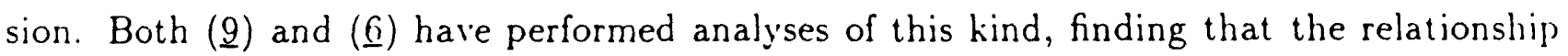
obtained by substitution underestimates dependence on magnitude and distance. Figure 5-2 summarizes the results obtained in ()ㅡ).

Expert 5's predictions for spectral velocity show obvious signs of bias. Table 5-1 shows that the intensity term $(b)$ in the relationship $\ln A=a+b I_{S}$ decreases with increasing

\footnotetext{
'The large magnitude coefficient obtained by expert 5 for peak acceleration (see Table 5-2) are likely due to the use of equation $5-3$, as we will sce in the simulation example.

In this argument. magnitude and distance act as the parameters of the prior distribution of amplitude. and intensity acts as new information about amplitude.
} 
frequency, as a consequence of source scaling and of the poor correlation between highfrequency ground motions and intensity. As a result, LLNL expert 5 obtains geometric and anelastic-attenuation terms that decrease with increasing frequency (see Figure 5-3 and Table 5-2). This form of frequency dependence cannot be explained on physical grounds; it is simply bias introduced by an invalid substitution procedure.

\subsubsection{Numerical Example}

A simple and convenient way to demonstrate the bias introduced by Expert 5's substitution procedure is by generating an artificial data set of $A, I_{S}, M$, and $R$ using Montecarlo simulation. By using simulation, we have the advantage that we know exactly what the results should be.

We want to illustrate the following three points:

1. How, by failing to include the magnitude and distance terms that should be in equation 5-1, a regression of intensity on amplitude using California data leads to an equation with coefficients similar to those obtained by (1) and used by LLNL expert 5 .

2. How substitution of this regression into the California intensity attenuation function leads to an incorrect attenuation function for California.

3. How substitution of the regression from item 1 above into the eastern US intensity attenuation relation, using the $m_{b}-I_{0}$ relationship in equation $5-3$ (as done by LLNL expert 5), leads to an incorrect attenuation function, with a magnitude coefficient that is too large and a distance coefficient that is too low.

The emphasis here is to simulate the essence of the problem; simplifying assumptions will be made for the salie of simplicity. For instance, we will ignore differences in magnitude scales between California and ENA.

We first generate an artificial database of strong motion and intensity data for California. To generate magnitudes and distances, we assume that magnitudes follow an exponential distribution with Richter's $b=0.6$ and distances follow a triangular distribution between 0 and $200 \mathrm{~km}$. The value of Richter's $b$ is somewhat low in order to represent the collection and processing bias towards higher magnitudes. The distribution of distance is that of a single station in a region where earthquates are equally litely to occur any where. Combinations of 
magnitude and distar ce that correspond to median accelerations lower than $0.05 \mathrm{~g}$ (according to our "California" attenuation equation, to be defined later) are treated as not recorded.

For each artificial event, epicentral intensity is generated from magnitude as

$$
I_{0}=-1.5+1.5 M+\epsilon_{1}
$$

which is based on $(\underline{10}) . \epsilon_{1}$ is a normal random variable with mean 0 and standard deviation 0.4 .

The site intensity at the recording location is generated as

$$
I_{S}=I_{0}+3.2-1.171 \ln R-0.011 R+\epsilon_{2} ; \quad R>15 k m \quad(5-6)
$$

in which $\epsilon_{2}$ has a standard deviation of 0.9 and the correlation coefficient of $\epsilon_{1}$ and $\epsilon_{2}$ is -1 . The above intensity-attenuation relation is based on the Gupta-Nuttli equation for the central United States (3, i.e., our Equation 5-2). We have increased the anelastic-attenuation term by a factor of 10 in order to approximate higher absorption in California. The coefficients in $\ln R$ and $R$ in the above equation are consistent with those obtained by Lee and Trifunac for California ( $\underline{5}$, Appendix A).

Finally, the peak acceleration is generated as

$$
\ln A=1.38+0.32 I_{S}+0.55 M-0.68 \ln R+\epsilon_{3} ; \quad R>15 \mathrm{~km}
$$

where $\epsilon_{3}$ has a standard deviation of $0.4 \pi$. The above equation is based on California data (I). The above relation is consistent with the our basic argument that the relationship between $A$ and $I_{S}$ is dependent on magnitude and distance. The corresponding attenuation equation for peak acceleration is obtained by substitution of equations $5-5$ and $5-6$ into equation $5-7$ 3 to obtain the following:

$$
\ln A=1.92+1.03 M-1.17 \ln R-0.0035 R ; \quad R>15 \mathrm{~km} \quad(5-8)
$$

which is a reasonable attenuation function for California. This shows that the equations used to generate our data set are reasonable equations.

We generated a large artificial "California" data set using the procedure described above. Then, we performed regressions on this data set to obtain the following relationships:

\footnotetext{
3 Sibstitution of $5-5$ and 5.6 intho $5-7$ is valid berause 5.7 contains terms $i n$. $M$ and $R$; i.e., unlite equation 5-1, no terms are missing. This is type of substitution is termed "magnitude and distance weighting" (11).
} 
- Intensity to acceleration conversion:

$$
\ln A=0.32+0.64 I_{S}
$$

which is comparable, especially in its $I_{S}$ coefficient, to the expression $\ln A=-0.19+$ $0.67 I_{S}$ obtained by $(\underline{1})$ and used by LLNL expert 5 (the difference in the leading coefficient is not critical to the results obtained here).

- Attenuation equation for acceleration:

$$
\ln A=1.89+1.04 M-1.05 \ln R-0.0041 R
$$

which agrees with the true acceleration attenuation function (equation 5-8), as expected.

The first result above shows how a reasonable data set like the one constructed above can give rise to an intensity-to-acceleration equation like that obtained by Trifunac (1), when the required magnitude and distance term are not included in the regression. The second result confirms the internal consistency of the data set.

We now apply LLNL expert 5's method to "California" (i.e., we assume that both regions 1 and 2 in Figure 5-1 correspond to California). Following the method of expert 5, we substitute equations 5-5 and 5-6 into equation 5-9, obtaining

$$
\begin{array}{rlrl}
\ln A & =0.32+0.64[(-1.5+1.5 M)+3.2-1.171 \ln R-0.011 R] & & (5-11) \\
& =1.41+0.96 M-0.75 \ln R-0.007 R ; \quad R>15 \mathrm{~km}
\end{array}
$$

which is different from the true attenuation equation (eq. 5-8), according to our "California" ground-motion model. The difference in the magnitude coefficient is not too large, but the difference in the geometric-attenuation coefficient (i.e., the term in $\ln R$ ) is significant.

We have shown that the substitution procedure used by LLNL expert 5 leads to biased results (i.e., results that are different from the results of direct regression).

Next, we apply LLNL expert 5's method to "ENA". Following expert 5, we substitute equations $5-3$ and $5-2$ into equation 5-9, obtaining

$$
\begin{array}{rlrl}
\ln A & =0.32+0.61(1-3.5+211)+3.2-1.171 \ln R-0.0011 R] & & (5-13) \\
& =0.13+1.28 .19-0.75 \ln R-0.007 R: \quad R>15 \mathrm{~km} & (5-14)
\end{array}
$$


The above equation has a magnitude coefficient of 1.28. Like the coefficient obtained by LLNL expert 5 , this coefficient is higher than the true magnitude coefficient for "California". Because we have not defined a "true" attenuation function for accelerations in "ENA", we cannot compare the above equation to another equation. In order to generate the true attenuation function for "ENA", we would need to assume that equation 5-7 is valid in "ENA".

Stepping aside from our example, we can argue that given the similarity between the $M_{L}$ and $m_{b L_{g}}$ magnitude scales used in California and in ENA, regional differences of 20 to $30 \%$ in the magnitude coefficient for peak acceleration are difficult to justify. Only very large differences in source scaling would explain these differences in coefficients, and current studies indicate little or no differences in source scaling between California and ENA [e.g., (12)].

\subsection{SUMMARY}

We have discussed a number of physical and statistical problems associated with the substitution procedure selected by LLNL expert 5 for the development of attenuation functions for ENA. The physical problems relate to the subjective nature of intensity assessments and with the difficulty in establishing that the instrumental amplitudes associated with a certain intensity level are the same for ENA and for California.

We have explained the nature of the bias introduced by substitution of incomplete regressions. We have used two examples to demonstrate this bias, which occurs even when all regressions come from the same region (i.e., California). One obvious symptom of bias is the contained in the geometric-and anelastic-attenuation terms. According to LLNL expert 5, these terms decrease in absolute value with increasing frequency. This trend is not supported by the data and is inconsistent with our physical understanding of wave propagation.

Another limitation in the method used by LLNL expert 5 is that it does not account for well understood differences in the frequency content of ground motions from ENA and from California. These differences have been confirmed by numerous recordings from earthquakes in ENA. The only frequency-dependent element in the procedure by expert 5 is the relaionship $\ln P S V=a+b I_{S}$ (see Table 2-1). which is fitted separately for each frequency. Unfortunately, this fitting is performed with California data, obtaining the wrong spectral shape (see Figure 2.2). 


\subsection{REFERENCES}

1. M. D. Trifunac. "A Note on the Range of Peak Amplitudes of Recorded Accelerations, Velocities, and Displacements With Respect to the Modified Mercalli Intensity Scale". Earthquake Notes, 47:9-24, 1976.

2. M. Trifunac and V. W. Lee. Frequency-Dependent Attenuation of Strong Earthquake Ground Motion. Technical Report 86-02, University of Southern California, Department of Civil Engineering, 1986.

3. I. N. Gupta and O. W. Nuttli. "Spatial Attenuation of Intensities for Central U.S. Earthquakes". Bulletin of the Seismological Society of America, 743-751, June 1976. Number 66-3.

4. O. Nuttli and R. Herrmann. Credible Earthquakes for the Central United States. Misc. Paper S-73-1, U.S. Army Corps of Engineers, Waterway's Experiment Station, Report No. 12, 1978.

5. V. W. Lee and M. D. Trifunac. Selection of Earthquake Resistant Design Criteria for Nuclear Power Plants - Methodology and Technical Cases. Technical Report NUREG/CR-4903, U. S. Nuclear Regulatory Commission, 1987.

6. D. Veneziano. "The Use of Intensity Data in Ground Motion Estimation". In Proceedings: Workshop on Estimation of Ground Motion in the Eastern United States, 1987. Rept. NP-5875, EPRI.

7. J. R. Murphy and L. J. O'Brien. "The Correlation of Peak Ground Acceleration Amplitude with Seicmic Jatensity and Other Physical Parameters". Bulletin of the Seismological Society of America, 67-3:877-915, June 1977.

8. R. K. McGuire. "Ground Motion Estimation in Regions with Few Data". In Proceedings: Eighth World Conference on Earthquake Engineering, San Francisco, CA, 1984. Vol. II, p. 327-334.

9. C. A. Cornell. H. Banon, and A. F. Shakal. "Seismic Motion and Response Prediction Alternatives". Earthquake Engineering and Structural Dynamics, T:295-315, 1979.

10. B. Gutenberg and C. F. Richter. "Earthquake Magnitude, Intensity, Energy, and Acceleration". Bulletin of the Seismological Society of America, 46:105-145, 1956.

11. D. L. Bernreuter, J. B. Savy, R. W. Mensing, J. C. Chen, and B. C. Davis. Stismic Hazard Charactcrization of the Eastern United States. Technical Report LL:L UCID-20421, Volumes 1 and 2, Lawrence Livermore National Laboratory, Livermore. Ca., 1985.

12. P. G. Somerville, J. P. McLaren, L. V. LeFevre, R. W. Burger, and D. V. Helmberger. "Comparison of Source Scaling Relations of Eastern and Mestern North American Earthquakes". Bulletin of the Seismological Society of America, 7T(2):322-346. 1957. 


\section{REGION 1}

(typically California)

Abundant accelerograph and seismograph data and intensity reports

\section{REGION 2}

(typically ENA)

Intensity Reports from Historical Earthquakes
Seismograph Recordings and Intensity Reports from Recent Earthquakes

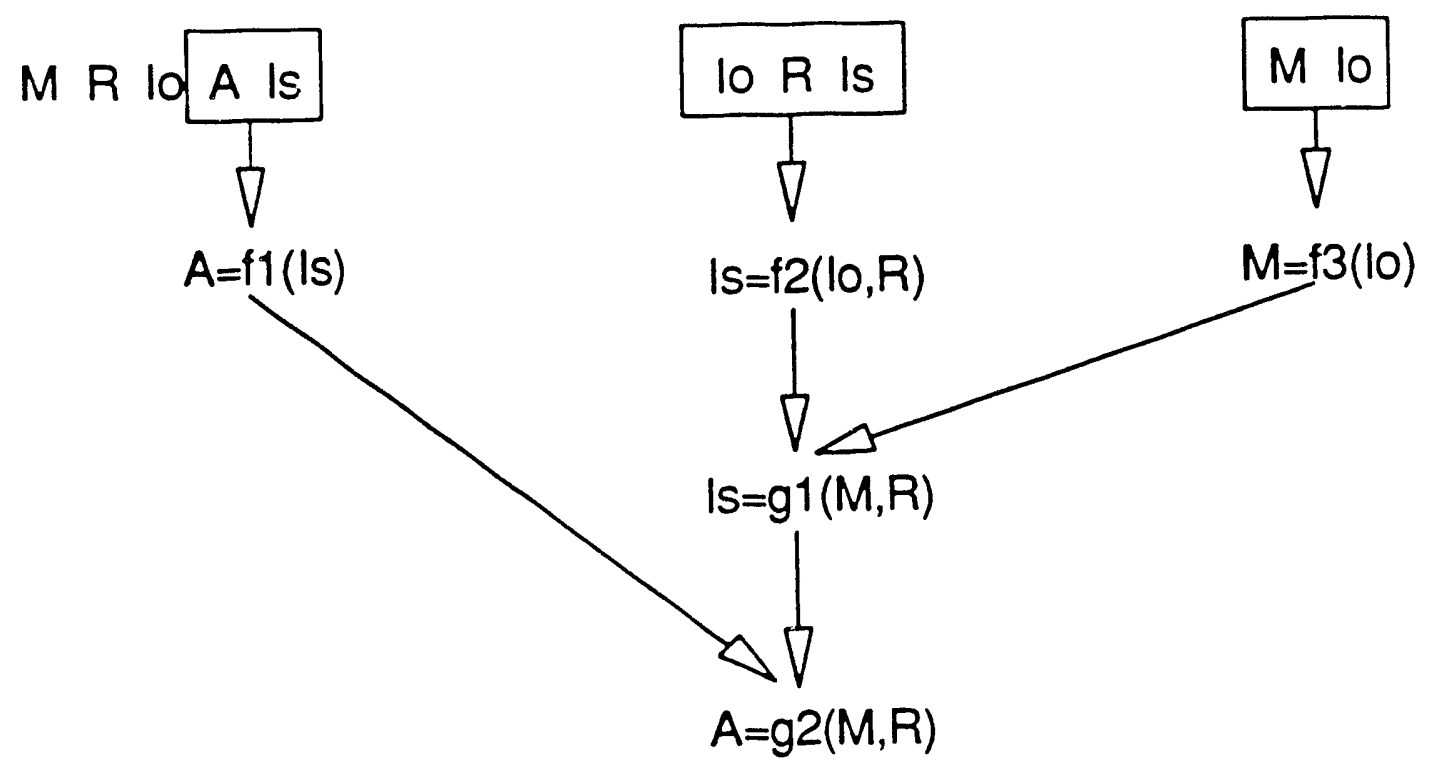

Figure 5-1. Schematic representation of the data and methods used by LLNL expert 5 to develop attenuation functions for ENA. 


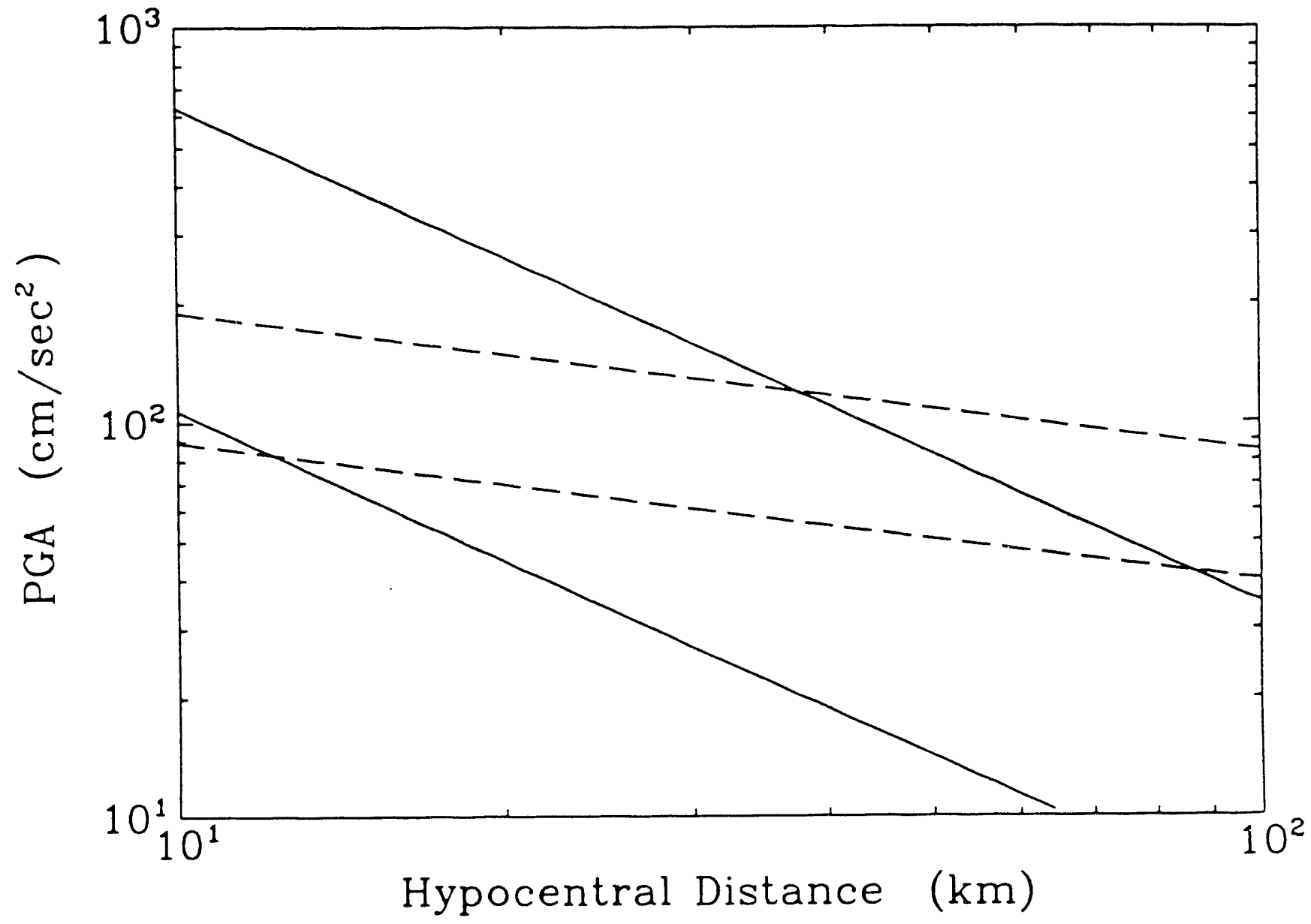

Figure 5-2. Comparison of attenuation functions obtained using direct regression (solid line: correct method) and using a two-step substitution procedure (dashed line; obtain $A=f_{1}\left(I_{s}\right)$ and $I_{S}=f_{2}(M, R)$, then substitute $f_{2}$ in $\left.f_{1}\right)$, from a single data set from California. Results shown as predictions for magnitudes 5 and 7 . After ( $\underline{6})$ 


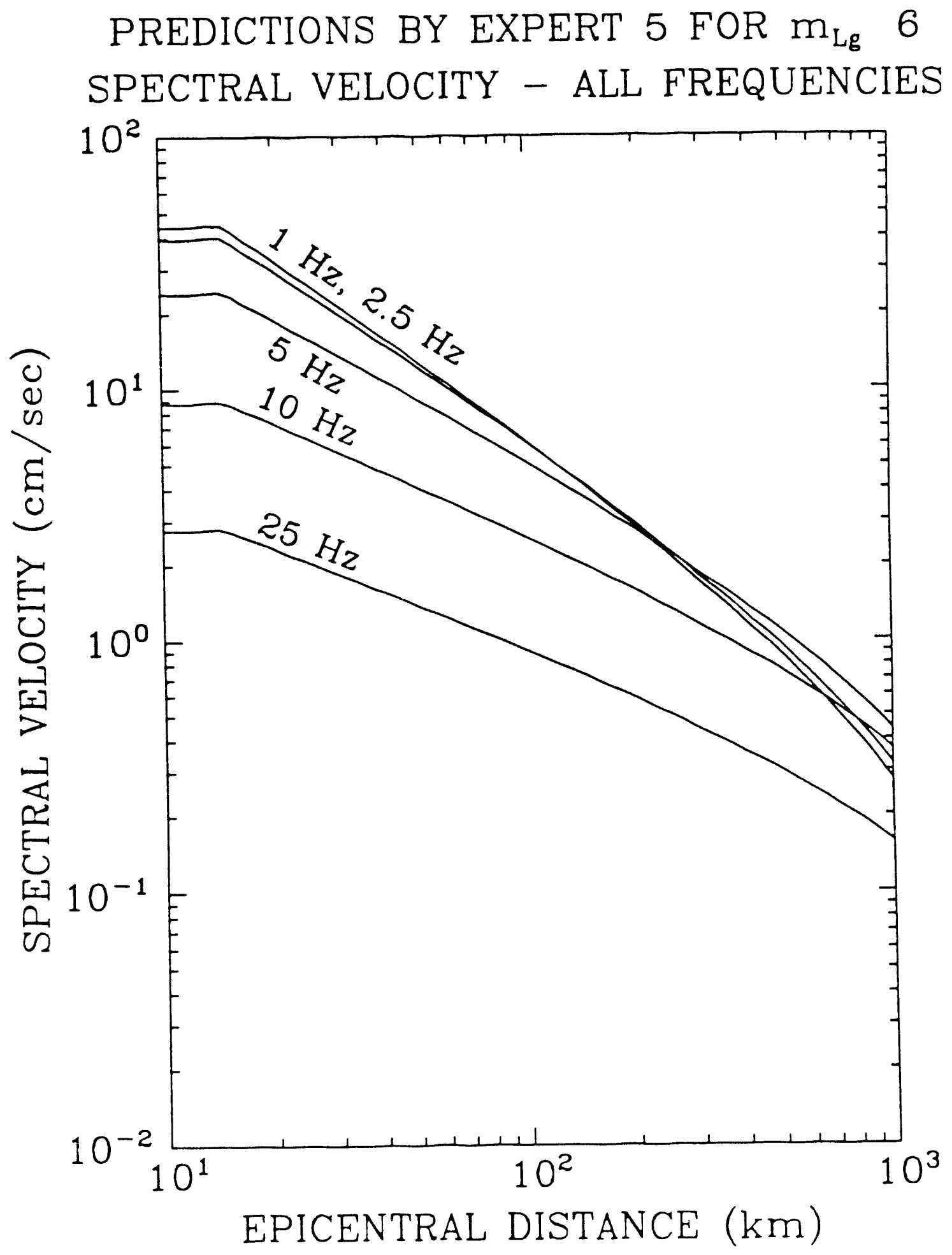

Figure 5-3. Spectral velocities predicted by LLNL Expert is for $m_{b L_{g}} 6$. 
Section 6

SUMMARY AND CONCLUSIONS

The comparisons of ground motions from Saguenay and predictions by the EPRI and LLNL attenuation functions indicate the following:

- The attenuation functions by LLNL expert 5 are generally inconsistent with the observed ground motions from the Saguenay earthquake. For most distance ranges and frequencies, these attenuation functions greatly overpredict observations. Differences are somewhat smaller at longer distances, because ground motions show little decay with distance within $150 \mathrm{~km}$ of the epicenter, due to the large depth of this earthquake.

- No individual attenuation function, from either the EPRI or LLNL sets, fits the Saguenay observations over the entire 40-200 km distance range. Both the EPRI set and the LLNL set without expert 5 , when considered as a whole, are consistent with all observed ground motions from the Saguenay earthquake.

The comparisons using other intraplate data indicate that the attenuation functions by LLNL expert 5 do not predict the proper dependence on distance for spectral velocities at frequencies above $2 \mathrm{~Hz}$.

A review of seismological studies about the Saguenay earthquake indicates the following:

- The analysis of regional and teleseismic recordings (i.e., records with energ! at frequencies of $1 \mathrm{~Hz}$ and lower) indicate that the Saguenay earthquake had a stress drop value that is typical of other earthquakes in eastern North America.

- Examination of energy release at higher frequencies indicates deviations from the simple Brune spectrum. These deviations have a modest effect on ground-motion predictions, as long as earthquake size is characterized by $m_{6 L_{3}}$.

- The Saguenay earthquake had an unusual hypocentral depth. This depth canses ground motions to remain almost constant within $150 \mathrm{~km}$ of the site. 
The latter characteristic of the Saguenay earthquake causes the observed amplitudes at large distances to fall somewhat near expert 5's predictions. On the other hand, expert 5 predicts much higher amplitudes at shorter distances, and these predictions are inconsistent with observations and with results from the seismological studies.

An examination of the method used by LLNL ground motion expert 5 to derive attenuation equations for eastern North America indicates that this method has many significant drawbacks:

- It is based on the assumption that intensities are equivalent in California and eastern North America (i.e., that the same intensity is accompanied by the same instrumental ground-motion amplitudes).

- It uses intensity reports from historic earthquakes in eastern North America. These reports are biased and do not represent average conditions. Furthermore, these reports are used improperly in the development of the intensity attenuation function.

- The substitution procedure used by LLNL expert 5 leads to biased results. We have explained the causes for this bias and have shown two examples of this bias.

- The method used by LLNL expert 5 does not account for known differences in spectral shape between ground motions in California and in the eastern United States.

We conclude, therefore, that the attenuation functions proposed by LLNL ground-motion expert 5 should not be used for seismic hazard calculations in eastern North America. These attenuation functions are inconsistent with all instrumental ground motion data from eastern North America, are based on assumptions about intensity that are incorrect, and were obtained using a substitution procedure that is invalid.

By studying ground-motion records obtained in eastern North America during the last decade, seismologists and engineers have gained considerable understanding about the similarities and differences between ground motions in California and in eastern North America. and have developed physically based mathematical models to predict these ground motions. Significant uncertainties remain, but there is sufficient confidence in these models that they. alone should be used for seismic hazard studies in eastern North America, to the exclusion of methods based on M.MII with known theoretical and physical flaws. 


\section{INTERNAL DISTRIBUTION}

\author{
1. J. E. Beavers \\ 2. W. K. Brown \\ 3. S. E. Burnette \\ 4. D. H. Cook \\ 5. G. F. Flanagan \\ 6. H. A. Glovier \\ 7. R. J. Hunt \\ 8. S. S. Hurt \\ 9. L. King \\ 10-14. M. A. Linn
}

15. L. D. Proctor

16. D. G. Renfro

17. J. B. Richard

18. R. L. Stover

19-20. Central Research Library

21-22. Laboratory Records

23. Laboratory Records - RC

24. ORNL Patent Office

25-34. RRD-DCC

35. Y-12 Technical Library

\section{EXTERNAL DISTRIBUTION}

36. Office of Assistant Manager for Energy Research and Development, Department of Energy, Oak Ridge Operations Office, P.O. Box E, Oak Ridge, TN 37831

37-48. OSTI, P. O. Box 62, Oak Ridge, TN 37830 

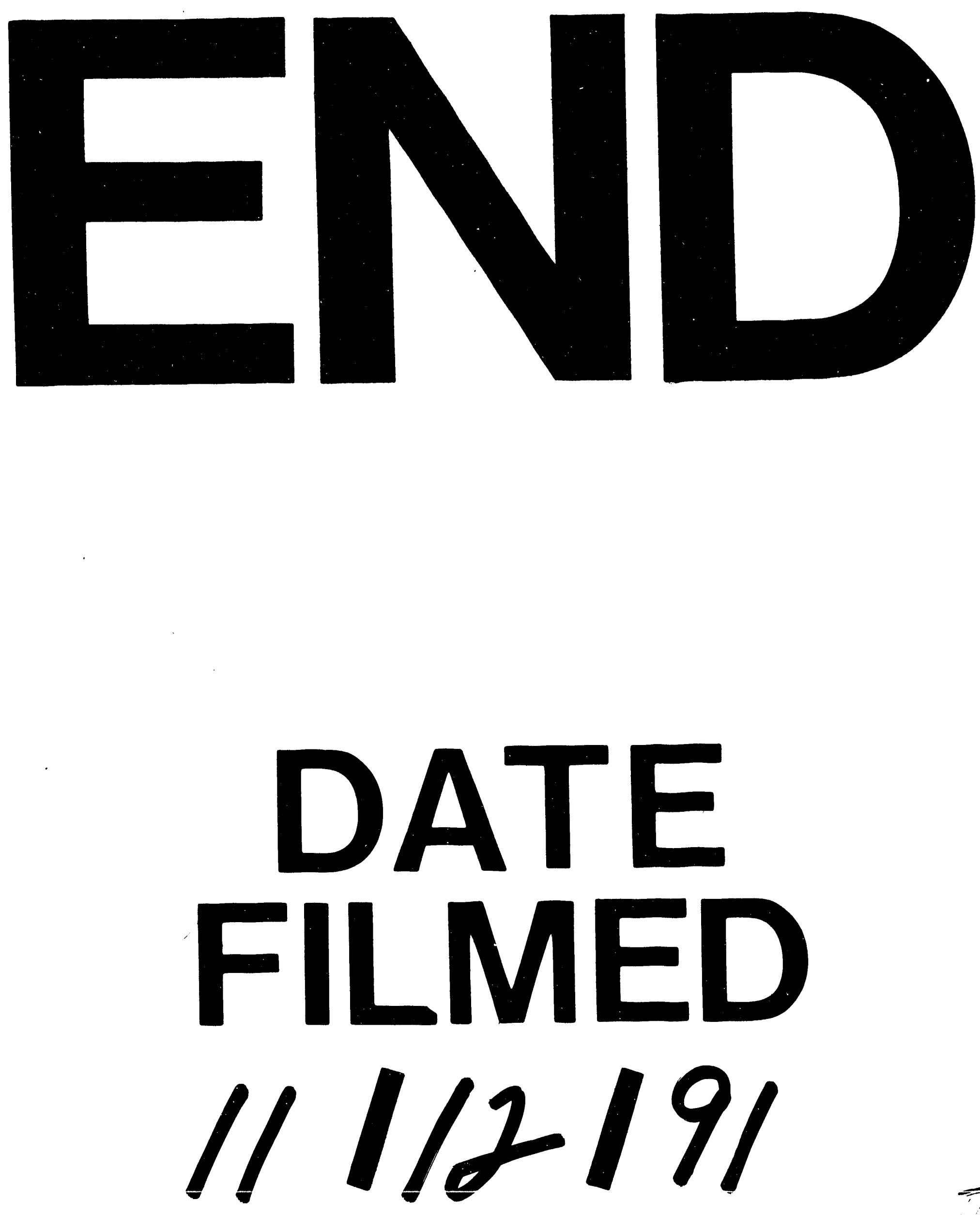


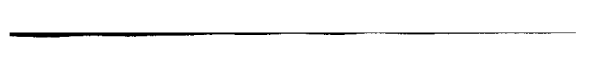

